NBER WORKING PAPER SERIES

\title{
CHARACTERISTICS OF MUTUAL FUND PORTFOLIOS: WHERE ARE THE VALUE FUNDS?
}

\author{
Martin Lettau \\ Sydney C. Ludvigson \\ Paulo Manoel \\ Working Paper 25381 \\ http://www.nber.org/papers/w25381 \\ NATIONAL BUREAU OF ECONOMIC RESEARCH \\ 1050 Massachusetts Avenue \\ Cambridge, MA 02138 \\ December 2018, Revised February 2021
}

We thank Ian Dew-Becker, Kent Daniel, Ken French, Ananth Madhaven, Michael Weber, and seminar participants at BlackRock, NYU-Stern, UC Berkeley, UC Irvine, the Joint BerkeleyStanford Seminar, and the 2018 FMA conference for helpful comments. The views expressed herein are those of the authors and do not necessarily reflect the views of the National Bureau of Economic Research.

At least one co-author has disclosed additional relationships of potential relevance for this research. Further information is available online at http://www.nber.org/papers/w25381.ack

NBER working papers are circulated for discussion and comment purposes. They have not been peer-reviewed or been subject to the review by the NBER Board of Directors that accompanies official NBER publications.

(C) 2018 by Martin Lettau, Sydney C. Ludvigson, and Paulo Manoel. All rights reserved. Short sections of text, not to exceed two paragraphs, may be quoted without explicit permission provided that full credit, including $\odot$ notice, is given to the source. 
Characteristics of Mutual Fund Portfolios: Where Are the Value Funds?

Martin Lettau, Sydney C. Ludvigson, and Paulo Manoel

NBER Working Paper No. 25381

December 2018, Revised February 2021

JEL No. G11,G12,G2

\begin{abstract}
This paper provides a comprehensive analysis of portfolios of active mutual funds and ETFs through the lens of risk (anomaly) factors. We show that these funds do not systematically tilt their portfolios towards profitable factors, such as high book-to-market (BM) ratios, high momentum, small size, high profitability, and low investment growth. Strikingly, there are almost no high-BM funds in our sample while there are many low-BM "growth" funds. Portfolios of "growth" funds are concentrated in low BM-stocks but "value" funds hold stocks across the entire BM spectrum. In fact, most "value" funds hold a higher proportion of their portfolios in low-BM ("growth") stocks than in high-BM ("value") stocks. While there are some micro/small/ mid-cap funds, the vast majority of mutual funds hold very large stocks. But the distributions of mutual fund momentum, profitability, and investment growth are concentrated around market average with little variation across funds. The characteristics distributions of ETFs and hedge funds do not differ significantly from those of mutual funds. We conclude that the characteristics of mutual fund portfolios raise a number of questions about why funds do not exploit well-known return premia and how their portfolio choices affect asset prices in equilibrium.

Martin Lettau

Haas School of Business

University of California, Berkeley

545 Student Services Bldg. \#1900

Berkeley, CA 94720-1900

and CEPR

and also NBER

lettau@haas.berkeley.edu

Sydney C. Ludvigson

Department of Economics

New York University

19 W. 4th Street, 6th Floor

New York, NY 10002

and NBER

sydney.ludvigson@nyu.edu

Paulo Manoel

University of California at Berkeley

545 S Student Services Building, \#1900

Berkeley, CA 94720

paulombfm@berkeley.edu
\end{abstract}




\section{Introduction}

Since the seminal study by Jensen (1968), most of the research on active mutual funds has been about their performance and the related issue whether fund managers have skill or not. Some recent examples include Fama and French (2010), Berk and van Binsbergen (2015), Cremers and Petajisto (2009), Kacperczyk, Nieuwerburgh, and Veldkamp (2014), Pástor, Stambaugh, and Taylor (2015), and many more. The composition and characteristics of mutual fund portfolios have received far less attention. ${ }^{1}$ The goal of this paper is to fill this gap in the literature and provide a comprehensive analysis of the cross-sectional distribution of portfolio holdings of active domestic equity mutual funds and ETFs through the lens of characteristics that are associated with return premia, such as the three "classic" size, value, and momentum anomalies. ${ }^{2}$

Studying the composition and characteristics of mutual fund and ETF portfolios is interesting for several reasons. First, we ask to what extent characteristics that are associated with return premia are reflected in portfolios of mutual funds and ETF. To what extent do active fund managers exploit these factor premia? If there are limits to arbitrage, do active funds contribute to the existence of these anomalies or do they overweight underpriced stocks?

Second, notions, such as "growth" and "value", are to some degree vague and have no precise, universally accepted definitions. How are these terms as used in the mutual fund industry related to the corresponding definitions in academic research? For example, the evidence of the value premium in the academic literature is based on portfolio sorts of price-multiples, in particular the book-tomarket ratio. Do "value" and "growth" funds hold predominantly stocks with high and low bookto-market ratios, respectively? If not, what are the key characteristics of portfolios of "value" and "growth" funds and how are they related to returns?

Finally, what set of strategies is available to retail investors via active funds? The literature on mutual funds typically takes the universe of funds as given. However, the set of funds in existence is an endogenous object subject to demand and supply. What are the market forces that determine the set of funds that are available to investors? ${ }^{3}$ This paper takes a first step in answering these questions by establishing a comprehensive set of stylized facts about the characteristics of portfolios of mutual funds, ETFs and, to a limited degree, hedge funds.

We find that (most) mutual funds do not systematically exploit return premia of well-known risk/ anomaly factors. In fact, for most factors, mutual funds target the low-return leg of long/short factor portfolios rather than the high-return leg. This bias is present in most price-multiples and is especially strong for the book-to-market (BM) ratio. The "value" premium defined as the return spread of stocks with high and low book-to-market ratios is one of the most well-known and robust stylized facts in the asset pricing literature. Yet, BM ratios of mutual funds, ETFs, and hedge funds are tilted towards

\footnotetext{
${ }^{1}$ One recent exception is Pástor, Stambaugh, and Taylor (2020) who study the relationship between liquidity and fund characteristics, in particular the optimal choice of stocks of different size.

${ }^{2}$ There is an ongoing debate whether factor premia are due to risk or behavioral biases. We remain agnostic about the underlying source of factor premia.

${ }^{3}$ Berk and Green (2004) study how demand and supply affect flows performance across funds but they take the set of funds that are available to investors as given.
} 
low BM values rather than high BM ratios.

This result is illustrated in Figure 1, which shows histograms ${ }^{4}$ of the distribution of book-tomarket ratios of mutual funds. The plot is based on the following methodology, described in more detail below. In each quarter, we assign stocks a BM score based on quintile sorts, so that stocks in the lowest/highest quintile have scores of 1 and 5, respectively. Then we compute BM scores of mutual funds as the portfolio-weighted average of the BM scores of stocks that are held by the fund. Hence, a funds that only invests in stocks in the lowest/highest BM quintiles have BM scores of 1 and 5 , respectively, while a score of " 3 " corresponds to a fund holding stocks that are on average in the middle BM quintile.

The book-to-market distribution of all 2,993 active equity mutual funds in our sample is plotted in Figure 1 (in bold red). The share of mutual funds with BM scores between 1 and 2, 2 and 3, etc. are indicated at the bottom of the figure. The vertical lines represent the BM scores of the CRSP-VW index, and the two components of HML, i.e. the high BM portfolio $\mathrm{H}$ and the low BM portfolio $\mathrm{L}$ as benchmarks. The figure shows that the distribution of mutual funds is heavily tilted towards low BM values. 33\% of all mutual funds have a BM score between 1 and 2 and a further 54\% between 2 and 3. On the other hand, $13 \%$ of funds have a moderately high BM score between 3 and 4, but only 7 of almost 3,000 funds have a BM score above 4. There are only 20 funds with BM scores as low as that of the L portfolio (with a BM score of 1.3), there are 131 funds with BM scores below 1.5 and 983 funds below 2. In contrast, there are essentially no mutual funds with a book-to-market ratio close to that of the H portfolio. In this sense, high BM "value" funds are missing from the US equity market. To put this differently, an investor can easily find "growth" mutual funds that are similar to the L portfolio, but it is virtually impossible to use mutual funds to mimic the "value" portfolio H.

\section{Figure 1: Distribution of Book-to-Market Ratios of Mutual Funds}

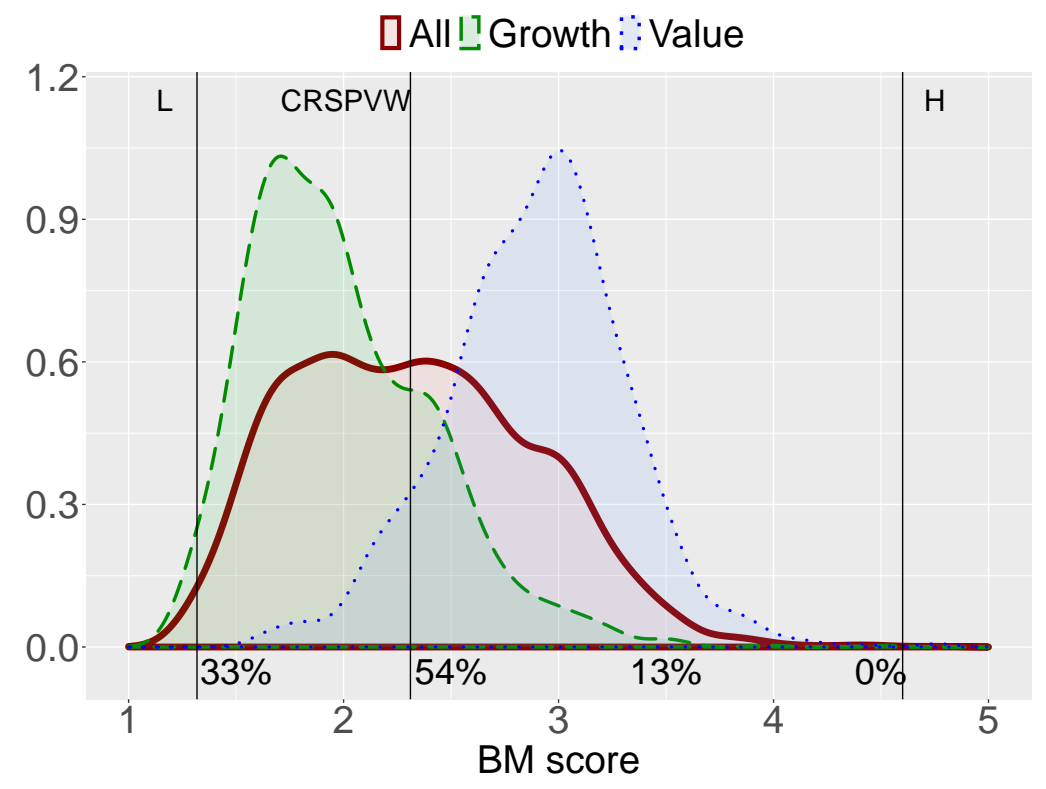

Notes: See Figure 3.

\footnotetext{
${ }^{4}$ Strictly speaking, we are plotting estimated kernel densities of histograms.
} 
Next, we study portfolio compositions in more detail and compute the portfolio weights by quintiles for each mutual fund. The average domestic active equity fund holds $39 \%$ of its equity holdings in stocks with BM scores between 1 and 2 and only 10\% in stocks in the highest BM quintile. Not surprisingly, the portfolios of "growth" funds are even more tilted towards low BM stocks. For example, 95\% of all "growth" funds hold over a quarter of their portfolios in low-BM stock. But we find that "value" funds hold a larger portion of their portfolio in stocks in the lowest BM quintile (20\%) than in stocks in the highest BM quintile (16\%). More than half of all "value" funds hold a larger share of lowBM stocks than high-BM stocks, and only $7 \%$ hold more than $25 \%$ of their portfolio in high-BM stocks. Evidently, "value" funds do not hold "value" stocks if "value" is defined by a high book-to-market ratio.

We compute a large array of robustness checks and find that the bias towards low book-to-market values is a consistent feature of the data. We consider other price-multiples, such as the earningsto-price, dividend-to-price, cash flow-to-price, and sales-to-price ratios and confirm the bias towards low valuation ratios of mutual fund portfolios. We also construct the Morningstar "value"/"growth" index that is used in their style box that classifies stocks and mutual funds according to size and "value"/"growth" factors. The Morningstar index is based on a combination of five price-multiples and five growth rates of fundamentals. In addition, we examine different methods of measuring characteristics of mutual fund portfolios, different samples, and different weighting schemes. We also find that the characteristic distribution of mutual funds has been stable over time since the beginning of the sample in 1980 .

ETF portfolios exhibit the same tilt towards low BM values as very few of the over 1,500 ETFs in our sample have consistently high BM-ratios. Since index providers publish the methodology of indices that are tracked by ETFs, we are able to trace the reasons why "value" ETFs do not hold highBM portfolios. We find that "value" and "growth" indices are based not only on price-multiples but also on growth rates of fundamentals, such as as earnings, cash flow, and sales growth. Since price multiples and fundamental growth rates have a low cross-sectional correlation, ETF portfolios hold few stocks with either very low or very high price multiples. Moreover, we find that portfolio sorts based on fundamental growth rates do not create a significant return spread, so that the "value" ETFs that are based on such indices earn a much smaller return premium relative the "growth" ETFs than the value premium based on the book-to-market ratio and other price-multiples. The distribution price-multiples of our limited sample of hedge funds is close to those of mutual funds and ETFs. We therefore conclude that the universe of active mutual funds and ETFs, with some exceptions, does not include high-BM investments.

We also finds that the majority of mutual funds hold predominantly very large stocks. The fundlevel distributions of other factor characteristics that are associated with return premia, such as momentum, profitability and investment growth are centered around the CRSP-VW index and exhibit little variation across funds. This suggests that funds do not systematically target these characteristics. The body of the paper focuses on the presentation of empirical findings. We return to the implications of the results in the conclusion. 
Our analysis focus primarily on holdings of mutual funds instead of factor exposures estimated from regressions of fund returns on factor portfolios. While estimating factor loadings is appropriate for analyzing funds returns, there are several reasons why holdings give a more accurate description of mutual fund strategies than factor loadings. First, factor loadings are estimated and thus subject to estimation error while holdings are directly observable. Second, loadings might vary over time and estimates with historical data might not reflect high-frequency changes in fund portfolios. Third, regression loadings are more difficult to interpret than characteristics computed from portfolio holdings, as we will show below. We estimate loadings of characteristic factor and find that the average HML beta if mutual funds is close to zero and more than half of all mutual funds have a positive HML beta. At first glance, it might appear that the distribution of HML loadings of mutual funds is inconsistent with their distribution of book-to-market ratios but we argue that magnitudes of regression loadings cannot be interpreted in isolation. ${ }^{5}$ When using the appropriate benchmarks, we find that the distribution of HML loadings confirm the bias towards low book-to-market ratios derived from fund holdings.

Finally, we study how mutual fund characteristics relate to their returns. When we compute the average return of stocks by characteristic quintiles, the familiar pattern emerges: Small stocks and stocks with high BM ratios and momentum have higher returns than large stocks and stocks with low BM ratios and momentum. Sorts on other price multiples, such as the earnings, cash flow, and sales-toprice ratios, yield similar return premia as BM sorts confirming the notion of a "value" premium when "value" vs. "growth" is defined as high vs. low valuation ratios. In contrast, portfolios sorted according to fundamental growth rates, such as earnings, cash flows, and sales growth, exhibit no consistent return patterns across characteristic values. Since the Morningstar index is based on valuation ratios as well as growth rates, it is not surprising that there is no "value" premium between stocks with high vs. low Morningstar indices. ${ }^{6}$ We also consider Fama-MacBeth regressions and find similar patterns between returns and characteristics. Our results are also consistent with those in Becker, Ferson, Myers, and Schill (1999), who show that returns of "value" funds are similar to returns of "growth" funds.

The rest of the paper proceeds as follows. Section 2 describes the sample and data construction. Results about the characteristics distributions of mutual funds, ETFs and hedge funds are presented in sections 3 and 4 . Section 5 compares the characteristics distributions derived regression factor loading to those of portfolio holdings. Results about the link between mutual fund characteristics and returns are reported in section 6 . Section 7 concludes.

\section{Data Construction}

The mutual fund and ETF holdings data are from Thompson-Reuters and CRSP. The quarterly sample starts in 1980Q1 and ends in 2018Q4. Our benchmark sample includes active mutual funds

\footnotetext{
${ }^{5}$ For example, over $60 \%$ of mutual funds have positive SMB betas even though most funds hold large stocks.

${ }^{6}$ Another reason for the small return premium is that the valuation ratio with the largest weight in the Morningstar index is the ratio of expected earnings-to-price, which is the only price-ratio with a negative return premium.
} 
that hold mostly domestic equities and are not index or sector funds. We use standard screens to exclude funds that hold on average fewer than 10 stocks, have an AUM of less than $\$ 10 \mathrm{M}$, and funds with less than 16 quarterly observation in the sample. ${ }^{7}$ ETFs are analyzed separately. We merge the portfolio holdings data with stock-level data from CRSP and Compustat to compute characteristics on the fund level.

Unlike mutual funds, hedge funds are not required to report holdings of individual funds to the SEC. However, every institutional investment manager, including hedge funds, with at least $\$ 100$ million in equity assets under management has to disclose their aggregate equity holdings to the SEC using form 13F. Since only aggregate holdings are reported, it is not possible to obtain holdings data for individual funds for the majority of hedge funds. Instead, we manually identify 13F filings of 79 hedge funds with only a single fund under management. ${ }^{8}$ For this subset of hedge funds, the $13 \mathrm{~F}$ filings of portfolio holdings correspond to individual funds and are thus comparable to the holdings data of individual mutual funds. Given that we can only identify portfolio holdings of hedge funds with only a single individual fund, our sample of hedge funds is very limited and not representative.

The CRSP/Thompson-Reuters database includes multiple objective codes that classify mutual funds into different "styles". However, these classifications are often unreliable, inconsistent across providers, and can change over the life of a fund. For example, 173 mutual funds that include the term "value" in their names are classified as "growth" funds (CRSP Objective Code EDYG). Manual checks of these cases confirm that the provided classification codes are less reliable than a classification based on fund names. Therefore, our primary style classification identifies "value" and "growth" funds as those funds that include these terms in their fund names. We use CRSP, Lipper, Wiesenberger, and Strategic Insight objective codes only for funds that cannot be identified by their names. Details of the classification scheme are in Appendix B. The main difference is that our classification identifies a larger number of funds as "value" funds compared to an identification scheme based on the provided objective codes. Only 177 of the 2,993 mutual funds in our sample are identified by at least one of the provided objective codes as "value" funds, wheres 624 funds include the term "value" in their fund names. The effect on the classification of "growth" funds is smaller since more funds have "growth" objective codes. However, our results do not depend on which classification is scheme is used to identify mutual fund objectives.

In addition to "value" and "growth", we use three additional categories: "balanced", "cap-based", and "sector". The benchmark sample excludes sector funds but our results hold if sector funds are included. For ease of presentation, we group all funds that are not designated as "value" of "growth" in a catch-all group "other". The benchmark mutual fund sample does not include ETFs, which we study separately. It is well know that the MFLINKS module that connects Thompson-Reuters holdings data and CRSP does not capture all ETFs, so that the ETF sample does not have the same coverage as the mutual funds sample. ${ }^{9}$

\footnotetext{
${ }^{7}$ See Appendix A for details.

${ }^{8}$ To identify hedge funds in the 13F filings we follow Agarwal, Jiang, Tang, and Yang (2013) and Agarwal, Fos, and Jiang (2013). We thank Vikas Agarwal for sharing his data.

${ }^{9}$ Recent updates of MFLINKS have improved the ETF coverage significantly.
} 
Table 1 reports descriptive statistics of the sample. The overall sample before applying any screens includes 8,892 mutual funds and 1,640 ETFs. After applying screens, our benchmark sample includes 2,993 active domestic equity mutual funds, 575 ETFs, and 79 hedge funds. The number of active mutual funds has grown from 200 in 1980Q1 to 1,552 in 2018Q4 with a peak of 1,988 in 2011Q1. The number of "growth" ("value") funds has risen from 91 (14) in 1980Q1 to 596 (385) in 2018Q4, respectively. The ETF sample starts in 2010Q3 with 149 ETFs and includes 461 active ETFs in 2018Q4. Our limited sample of hedge funds includes 2 funds in 2018Q1, 28 funds in 2018Q4, with a peak of 44 in 2007Q2. The median number of quarterly observations for mutual funds is 46,13 for ETFs, and 36 for ETFs. The median mutual fund holds 74 stocks in its portfolio, however, there is a significant amount of variation across funds. 44 mutual funds hold over 1,000 stocks while 73 hold less than 25. The distribution of the number of stocks is similar across mutual fund categories but ETFs hold on average more stocks than mutual funds while the hedge funds in our sample hold fewer stocks.

The total "total net asset value" (TNA) of active mutual funds has risen from \$25B in 1980Q1 to a maximum of $\$ 4.5 \mathrm{~T}$ in 2018Q3 (before declining to $\$ 3.8$ in $2018 \mathrm{Q} 4^{10}$ ). "Growth" funds account for the largest share of the total TNA, followed by "other" and "value" funds. The total TNA of the ETFs in our sample is \$1.3T in 2018Q4 and the total equity values of our limited sample of hedge funds is $\$ 91 \mathrm{M}$. The median fund TNA over the entire sample period is $\$ 222 \mathrm{M}$, while the medians for "values" is slightly higher than than that of "growth" funds. The TNA distribution across funds is right skewed as indicated by the fact that the TNA mean is about four times higher than the median. The size distribution of ETFs is not directly comparable to that of mutual funds since the ETF sample starts in 2010 instead of 1980, however it is more right-skewed than the mutual funds distribution as indicated by the larger difference in the median and the mean. Finally, even though our sample of hedge funds includes only 79 funds, its size distribution is very similar to the distribution of mutual funds.

The bottom three rows of Table 1 summarize the performance of funds. The median betas for all fund categories are all close to one but "growth" funds have a slightly larger beta on average (1.04) than "value" funds (0.95). Note that the reported numbers are medians of fund averages and betas, so that the returns by fund are computed over different time spans and thus not directly comparable. We therefore report median fund returns in excess of the returns of the S\&P 500 index, as well as the median 4-factor alphas. Consistent with the extensive literature on mutual fund performance, we find that funds returns are on average lower than S\&P 500 returns, even though the average fund beta is close to one. While this is true for all fund categories we study, the median for "growth" funds is less negative than the median for other categories. In addition, median 4 -factor alphas are negative as well, however, median alphas of ETFs and "value" funds are larger than medians for growth and "other" funds. The average excess returns (net of S\&P 500 returns) of $63 \%$ of mutual funds and of $72 \%$ of ETFs are negative, as are two-thirds of mutual and ETF alphas.

\footnotetext{
${ }^{10}$ The CRSP-VW return was $-14.5 \%$ in the fourth quarter of 2018.
} 


\section{Mutual fund characteristics}

Next, we construct characteristics of mutual funds, ETFs and hedge funds. The paper includes results for size (market equity, ME), the book-to-market ratio (BM), momentum (MOM) characteristics as well as the Morningstar value/growth index (MS, defined later in this section). Results for other characteristics, including other price multiples, ROE and asset growth, are reported in the online appendix.

We consider two different methods for computing fund-level characteristics. The benchmark case follows Daniel, Grinblatt, Titman, and Wermers (1997): In each quarter $t$, we sort all stocks into five quintiles based on characteristic $C$ using NYSE breakpoints. Stock $i$ in quintile $j$ is assigned a characteristic score of $C_{i, t}=j, j \in\{1,2, \ldots, 5\}$. The characteristic score of fund $m$ in quarter $t, C_{m, t}$, is computed as the portfolio-weighted average of the characteristic scores of the stocks in the fund's portfolio:

$$
C_{m, t}=\sum_{i \in I_{t}} w_{m, i, t} C_{i, t},
$$

where $I_{t}$ is the set of stocks listed in quarter $t$ and $w_{m, i, t}$ is the fraction of stock $i$ in the total value of all stocks held by fund $m$ in quarter $t$.

This procedure has several advantages. First, it is robust to stocks with extreme values of characteristics. Second, all characteristic scores range from 1 to 5 and are comparable across characteristics. Third, characteristic scores are based on the same portfolio sorts that are used in most of the asset pricing literature. On the other hand, quintile scores depend on the choice of breakpoints and the entire distribution of characteristics across all stocks. For example, it is possible that a stock switched quintiles even if its own characteristic has not changed but its ranking in the overall distribution changed. Moreover, the total market capitalizations varies across quintiles and, therefore, the valueweighted market portfolio does not necessarily have a characteristic score equal to the midpoint of three, but will be biased towards the quintiles with higher total market capitalization. For example, the top size quintile accounts for about $73 \%$ of the total market cap while the bottom quintile accounts for only 3\%. Hence, the size quintile score of the value-weighted CRSP index will be strongly tilted towards the fifth quintile. In contrast, the low BM quintiles account for a larger share of the total market cap that the high BM quintiles. Thus the BM score of the CRSP-VW index is below the midpoint of $3 .^{11}$

As an alternative measure, we compute "market-adjusted" characteristics. For example, in each quarter we compute the "market-adjusted" BM ratio for each stock $i$ as

$$
\mathrm{BM}_{i, t}^{\mathrm{adj}}=\mathrm{BM}_{i, t}-\mathrm{BM}_{\mathrm{MKT}, t}
$$

Subtracting the market BM ratio serves two purposes. First, it removes changes in the market-wide $\mathrm{BM}$ ratio, so that the distribution of the adjusted book-to-market ratio is comparable across time. Second, since the adjusted book-to-market ratio $\mathrm{BM}_{t}^{\text {adj }}$ for the market portfolio itself is equal to zero

\footnotetext{
${ }^{11}$ We also consider the case where breakpoints are chosen so that the market cap in each quintile is identical. Results are reported in the online appendix.
} 
by construction, the scale of adjusted BM of mutual funds have a natural benchmark and are easy to interpret. $^{12}$

Market-adjusted characteristics have two further advantages compared to quintile scores. First, unlike characteristic scores based on quintiles, market-adjusted characteristics do not rely on the selection of breakpoints. Second, adjusted characteristics do not depend on the characteristic of other stocks. On the other hand, adjusted characteristics of mutual funds can be sensitive to outliers since distributions of price-based ratios are typically severely right-skewed. Another drawback is that the units differ across characteristics making a comparison difficult. Most of the results reported in the paper are based on characteristics scores but the online appendix includes results for adjusted characteristics and quintile score based on different breakpoints. Our main results are not affected by the methodology of how mutual funds characteristics are constructed. We follow the same procedure to compute scores and market-adjusted characteristics for size (market equity, ME), the book-to-market ratio (BM), momentum (MOM), as well as a variety of other characteristics.

While the book-to-market ratio has become the standard metric for value/growth in academic research, there are many alternative measures, such as the earnings-to-price ratio (EP) and the cash flow-to-price ratio (CFP). We report mostly results for the book-to-market ratio and consider results for other multiples as a robustness check. The online appendix includes complete results for EP, as well as other price-ratios.

Another popular measure is the Morningstar value/growth index that is used in Morningstar's "style box". ${ }^{13}$ The Morningstar value/growth index (MS) is defined as the difference of a multiples index (MULT) and a growth index (GR). The MULT index is defined as average of price multiples while the GR index is a average of growth rates of fundamentals:

$$
\begin{aligned}
\mathrm{MULT} & =\frac{1}{2} \widehat{\mathrm{EP}}+\frac{1}{2} \operatorname{avg}(\mathrm{BM}, \mathrm{SP}, \mathrm{CFP}, \mathrm{DP}), \\
\mathrm{GR} & =\frac{1}{2} \mathrm{GRLTE}+\frac{1}{2} \operatorname{avg}(\mathrm{GRE}, \mathrm{GRCF}, \mathrm{GRS}, \mathrm{GRB}),
\end{aligned}
$$

where $\widehat{E P}, \mathrm{SP}, \mathrm{CFP}$, DP are price-ratios for expected earnings, sales, cash flows, and dividends, respectively, and GRLTE, GRE, GRCF, GRS, GRB are growth rates of expected long-term earnings ${ }^{14}$, current earnings, cash flows, sales, and the book value, respectively. ${ }^{15}$ Note that the forward-looking measures $\widehat{E P}$ and GRLTE have larger weights than the other multiples and growth rates.

Each individual characteristics are measured as percentile rank and range from 0 to 100 . While the respective components of MULT and GR are positively correlated, there is a considerable amount of orthogonal information in the variables. For example, the pairwise correlations of the five price multiples across individual stocks in our sample is on average 0.41 and ranges from 0.18 to 0.76 . The average correlation across the five growth rates is 0.33 . On the other hand, price multiples and growth

\footnotetext{
${ }^{12}$ An alternative adjustment is to take ratios, e.g. $\mathrm{BM}_{i, t} / \mathrm{BM}_{\mathrm{MKT}, t}$. We choose the adjustment using differences as default but use the ratio if its distribution is more stable and closer to normal than the distribution of the ratios.

${ }^{13}$ http://news.morningstar.com/pdfs/FactSheet_StyleBox_Final.pdf

${ }^{14}$ Mornigstar uses analyst's estimates of three- to five-year EPS growth.

${ }^{15}$ Detailed descriptions of the variables are in Appendix A.
} 
rates are only weakly correlated. The pairwise correlation of multiples and growth rates ranges from -0.44 to 0.26 and is -0.03 on average, so that the correlation of the MULT and GR indices is only -0.17 .

The Morningstar value/growth index, MS, is defined as the difference between the index of multiples and the index of growth rates

$$
\text { MS }=\text { MULT }- \text { GR }
$$

and ranges from -100 to 100. We normalize the index so that high MS scores correspond to "value" and low MS scores correspond to "growth" in line with the BM ratio. ${ }^{16}$ We construct the MS index for each stock in each quarter, form quintiles and compute the MS score for mutual funds as the portfolioweighted average of MS scores of the stocks in the fund's portfolio. Adjusted MS is computed as the difference between MS of a stock and that of the market.

\section{Benchmarks}

It will be useful to compare the distributions of mutual fund characteristics to benchmarks. We consider a variety of alternatives. First, we compute the characteristics of the CRSP-VW portfolio as a proxy for the market portfolio. We also consider the S\&P 500 and the CRSP-EW portfolio as a benchmarks for large and smaller stocks, respectively. Second, given the widespread use of the Fama-French factors, the portfolios that underlie these factors are natural choices as characteristic benchmarks. We compute the characteristics of the component portfolios of SMB, HML, and MOM and treat them as if they were mutual funds. For example, SMB and HML are based on the four corner portfolios of the intersection of two size and three BM-sorted portfolios (value-weighted with NYSE breakpoints). Let SL denote the small/low-BM portfolio, BL the big/low-BM portfolio, etc.. The longshort portfolios $\mathrm{SMB}$ and $\mathrm{HML}$ are in turn defined as $\mathrm{SMB}=\mathrm{S}-\mathrm{B}$, where $\mathrm{S}=(\mathrm{SH}+\mathrm{SL}) / 2, \mathrm{~B}=(\mathrm{BL}+\mathrm{BL}) / 2$ and $\mathrm{HML}=\mathrm{H}-\mathrm{L}$, where $\mathrm{H}=(\mathrm{SH}+\mathrm{BH}) / 2, \mathrm{~L}=(\mathrm{SL}+\mathrm{BL}) / 2$. We compute characteristics of each of the four corner portfolios, SH, BH, SL, and BL, as well as S, B, H, and L, following the same methodology described above for mutual funds. These portfolios span the ME/BM spectrum and are therefore useful benchmarks for mutual fund portfolios. The construction of the momentum factor follows the same methodology using a size/momentum double-sort and we compute characteristics of the four size/momentum portfolios $\mathrm{SD}, \mathrm{BD}, \mathrm{SU}$, and $\mathrm{BU}$, as well as $\mathrm{D}=(\mathrm{SD}+\mathrm{BD}) / 2, \mathrm{U}=(\mathrm{SU}+\mathrm{BU}) / 2$. Finally, we compare the distributions of mutual fund characteristics to those of individual stocks.

Table 2 reports the quintile characteristics scores of the benchmark portfolios. Consider first the characteristic scores of the CRSP-VW index computed as time-series averages of quarterly scores over the sample period. The average size (ME) score of the CRSP-VW portfolio is 4.51. The BM score is 2.31, which is slightly lower than the average Morningstar (MS) score of 2.76. The average momentum (MOM) score is 3.44. The reason why these value-weighted averages are not equal to the midpoint of 3 is that the total market capitalizations in the quintiles are different. For example, the 5th size quintile contains on average $71 \%$ of the total market cap, while the 1 st size quintile contains only $3 \%$. Therefore, the average ME score of the value-weighted CRSP index is closer to the maximum of

\footnotetext{
${ }^{16}$ The Morningstar index used in the style box is defined as scaled GR[0,100] - scaled MULT[0,100]. We adjust the definition so that low/high MS values have the same value/growth interpretation as low/high BM scores.
} 
5 than to the midpoint of 3 . For the same reason, the BM and MS scores are below the midpoint of 3 while the MOM score is above 3. Since the S\&P 500 portfolio is composed of only large stocks, its ME score of 4.90 is close to the maximum of five, while the ME score of the CRSP-EW portfolio is 1.90. The BM, MS and MOM scores of the S\&P 500 are close to that of the CRSP-VW portfolio. On the other hand, CRSP-EW scores can differ significantly from CRSP-VW scores as the equally-weighted index is dominated by small stocks that have on average higher BM scores but lower MS and MOM scores.

The remaining columns of the top panel report characteristics of the six portfolios that are used to construct SMB, HML, and MOM: S, B, H, L, U, and D. Recall that S and B are value-weighted portfolios based on bivariate sorts rather than on quintile sorts, hence $S(B)$ contains stocks from lower (higher) ME quintiles. The corresponding ME scores of S and B are 2.31 and 4.80 . Since the return of the long-short SMB portfolio is a benchmark for the size return premium, the S and B size scores are in turn benchmarks for mutual funds with an objective to exploit the size premium. The H and L BM scores of 4.61 and 1.30, respectively, are in turn benchmarks for mutual funds that exploit the value premium, and the $\mathrm{U}$ and D momentum scores of 4.65 and 1.40 are momentum benchmarks.

Characteristic scores of the double-sorted SL, BL, ... portfolios are reported in the bottom panel of Table 2. The four "small" portfolios have ME scores between 2.10 and 2.44, while the "big" portfolios range between 4.70 and 4.85 . This pattern is similar for the other characteristics. Note that the BM score of the high-BM portfolio of large stocks, $\mathrm{BH}$, is 4.70 is similar to that of the high-BM portfolio of small stock SH, 4.85. The same is also true for the low BM portfolios BL and SL. This implies that the book-to-market distribution of bigger and smaller stocks are similar and that portfolios with high BM scores can be constructed not just from small and potentially illiquid stocks but also from large liquid stocks. The same pattern is true for other characteristics, MS and momentum.

\section{An Example}

As an illustration, Figure 2 plots the characteristics of the largest mutual funds in our sample, the “Growth Fund of America" (ticker AGTHX, 2018Q4 AUM \$166B). The fund is classified as a "growth" fund, holds an average of 225 stocks, and invests on average 77\% of its assets in domestic common stocks. Note that, for this fund, there are 16 quarters with missing observation over the sample. Panel A plots the quintile scores for size (ME), book-to-market ratio (BM), Morningstar index (MS), and momentum (MOM). At the beginning of the sample, ME scores are around 3.5 but increase close to the maximum of five over the rest of the sample. This pattern implies that the fund started out holding medium to large stocks but then started to hold only very large stocks: In 1980Q1, the about 70\% of the portfolio was invested in ME decile 3 and 4 stocks, while about $90 \%$ of the portfolio consists of stocks in the top size quintile while. The BM and MS scores are close to each other and appear to be stable over the course of the sample. They range from 1.4 to 2.5 with an overall mean of 2 , while the fund invested about half of its portfolio in BM and MS deciles-1 stocks over the course of the sample. In contrast to the other characteristics scores, the time series of the MOM score varies at a higher frequency and is less persistent, which is a typical patterns across the sample. On the one hand, this is not surprising since momentum is also less persistent than other characteristics on the 
stock-level, but the fact that this pattern is carried over to mutual funds suggests that mutual funds do not maintain a portfolio that minimizes variation in momentum.

Panel B show the market-adjusted characteristics. Recall that the adjusted characteristics are constructed so that a value of zero indicates a characteristic that is equal to that of the CRSP-VW index. However, the scales are not comparable since different characteristics have different "units", hence we normalize the sample standard deviation to one. Note that in contrast to the quintile scores, the adjusted BM ratio is higher than the adjusted MS index over the entire sample. The reason for this pattern is that the MS score of the CRSP-VW index is on average higher than the BM score, so that even though the BM and MS scores of the mutual fund are similar, the market-adjusted MS index is negative while the adjusted BM ratio is on average close to zero.

\section{Characteristics Mutual Fund Portfolios}

In this section we study the univariate distributions of mutual fund characteristics. The histograms of mutual funds scores of size (ME), book-to-market (BM), Morningstar (MS) and momentum (MOM) are shown in Figure 3. (Figures 4 to 6 show further results and have similar layouts.) Each panel shows the histogram of a characteristics score for all funds in our benchmark mutual fund sample (solid red) in the sample, as well as the histograms of "growth" (dashed green) and "value" (dotted blue) funds. The vertical lines show the scores of the CRSP-VW index and passive benchmark portfolios. The numbers at the bottom of each histogram represent the percentage of all funds in the sample with characteristic scores between 1 and 2, 2 and 3, etc., respectively. The means, medians, and 10th, 25th, 75th, and 90th percentiles of the distributions are reported in Table 3.

Panel A shows the histograms of ME scores. The distributions of all funds and "value" and "growth" is heavily skewed towards large quintile scores. The size score of $66 \%$ of all funds is above 4 implying that most mutual funds invest in large stocks. The histogram shows that $18 \%$ of funds have an ME score between 2 and 3, and only 3\% of funds hold on average stocks with a ME quintile between 1 and 2. The size scores of the majority of mutual funds are similar to those of the CRSP-VW and "Big" portfolios. The size score of $47 \%$ and $28 \%$ of mutual funds is larger than those of the CRSP-VW and "Big", respectively. In contrast, only $6 \%$ of funds have an ME score that is lower that that of "Small". Thus, the stocks that make up the composition of the S component of SMB are smaller than the stocks held by all but $6 \%$ of mutual funds. The figure also shows the size distribution of "growth" and "value" funds. The ME distribution is similar for "growth" and "value" funds, although "growth" funds have somewhat larger ME scores than "value" funds. One possible explanation why mutual funds tilt towards large stocks because small-stocks a more expensive to trade as argued in Pástor, Stambaugh, and Taylor (2020). In equilibrium, funds optimally choose the tradeoff of trading costs versus potentially higher returns of small stock. Large funds have higher trading costs and therefore hold large stocks.

The BM histogram in Panel B is identical to that in Figure 1. As already described in the introduction, the BM distribution is heavily skewed towards low BM scores as $89 \%$ of all funds have a BM score below 3, and virtually no funds have a BM score that exceeds 4 . The histogram also shows that many 
funds have a BM score that is close to that of the "Low" portfolio but no funds with a BM score that is similar to that of the "High" portfolio. Only 7 of the 2,657 funds in the sample are in fact high-BM funds with a score above 4, while 983 funds have a BM score below 2. While it is not surprising that the distribution of "growth" funds is more skewed towards low BM scores, it is noteworthy that the BM score of the majority of "value" funds is also below 3. The means of BM scores, shown in Panel A in Table 3, are 2.33 for all funds, 1.99 for "growth" funds and 2.90 for "value" funds. Furthermore, the BM score of $90 \%$ of mutual funds is below 3.08. This fact is not driven by the lack of large and liquid stocks in the top quintile. Recall from Table 2 that the BH portfolio is made up entirely of large stocks but has a BM score of 4.56. We will investigate the issue of liquidity in mutual fund holdings in more detail below.

One possible explanation is that the BM ratio does not capture the notion of "value" as viewed by fund managers and investors. To explore this possibility further, we study next the distribution of the Morningstar value/growth index (MS) that underlies the well-known Morningstar style box. As explained in section 2, the Morningstar index is an average of price multiples and growth rates of firm fundamentals. The histogram of MS scores in Panel C shows that the distribution is somewhat shifted to the right compared to the BM distribution but still skewed towards low MS scores. 33\% of mutual funds have an MS score below 2 while the MS score of only 22 funds is above 4 . The average MS score of "value" funds is only slightly above the midpoint of 3 and only $10 \%$ of all "value" funds have a MS score below 3.8 (Table 2, Panel C)

Finally, Panel D shows the momentum (MOM) histogram. The vast majority of mutual funds have a MOM score between 3 and 4 and are thus somewhat tilted towards higher momentum stocks. However, only $4 \%$ of funds have a MOM score above 4 indicating that few funds focus on momentum as a primary strategy. We will see below that the momentum tilt is due to the fact that most funds hold low BM stocks that on average have higher MOM scores than high BM stocks. Moreover, we will also show that there is more time variation in the momentum scores of individual funds than in the size and growth/value scores. Hence the distribution of fund averages is less informative for momentum than for the other more persistent characteristics.

Next, we take a closer look at the mutual funds with the lowest and highest BM scores. Table 4 shows the 10 funds with the highest BM score and the 10 funds with the lowest score. The scores of the $\mathrm{H}$ and $\mathrm{L}$ components of HML are included for comparison. In our sample of 2,657 funds, only seven funds have a BM score above 4, and only one fund exceeds the BM score of H. Most of the these high BM funds are small and only four of the 10 funds have an AUM above \$1B. Interestingly, the two largest fund on this list are Dimensional Fund Advisor (DFA) funds that, according to their prospectuses, specifically target stock with high price multiples but, in contrast to the Morningstar definition of "value", do not take fundamental growth into account. ${ }^{17}$ Note, however, that the BM scores of the DFA funds are significantly below that of the $\mathrm{H}$ portfolio. The bottom panel shows the 10 funds with the lowest BM scores. Note that their BM scores are all below that of the low BM

\footnotetext{
${ }^{17}$ The prospectuses of the DFA funds state: “Securities are considered value stocks primarily because a company's shares have a low price in relation to their book value." (https://us.dimensional.com/funds)
} 
benchmark portfolio.

\section{Characteristics of Stocks}

Since mutual funds hold mostly large stocks, it is instructive to compare the characteristics distribution of mutual fund portfolios to characteristics distributions of individual large and liquid stocks. We include stocks that were constituents of the S\&P 500 index for at least eight quarters during the sample period but none of our results depend on this choice of benchmark sample. ${ }^{18}$

Figure 4 plots characteristic histograms of these individual S\&P 500 stocks (dashed black) along with the histograms for mutual funds for comparison. Panel B of Table 3 reports means and percentiles of the stock characteristic distributions. The histogram of size distribution in Panel A shows that ME scores of mutual funds is skewed to the right relative to the size distribution of S\&P 500 stocks confirming the result that mutual funds hold mostly very large stocks. Panel B shows that the BM score distribution of S\&P stocks differs substantially from that of mutual funds. While most of the mass of the mutual fund distribution is to the left of the midpoint of 3 , the stock distribution is more spread out and has significantly more mass on the right side of the score range. $38 \%$ of stocks have BM scores that exceed 3 compared to $13 \%$ of mutual funds, and the BM score of 14\% of S\&P stocks is larger than 4 compared to $0.2 \%$ of 7 mutual funds ( 7 out of 2,993). The average BM score of stocks is 2.62, which is significantly higher than the mean for mutual funds of 2.23, as are the 25th, 75 th, and 90th percentiles (Table 3). Even the 75th and 90th percentiles of the BM distribution of "value" funds are significantly smaller that those for the stock distribution: 3.45 and 4.22, compared to 3.15 and 3.38. In contrast, the 10 th and 25 th percentiles of "growth" funds are similar to those of the stock distribution. The shift towards "growth" characteristics of mutual funds relative to S\&P 500 stocks is present not just in book-to-market scores but also in Morningstar MS scores (Panel C) and other price multiples (see online appendix) and is a robust finding, as we will document further below.

The momentum distributions of stocks, shown in Panel D, exhibits significantly less variation than the BM and MS distributions as the momentum score of 96\% of S\&P 500 stocks is between 2 and 4 (compared to 97\% of all mutual funds, see Panel D of Figure 3). The distribution of stocks is slightly shifted towards lower scores compared to the distribution of mutual funds and the respective means are 3.16 for stocks and 3.35 for mutual funds.

\section{ETFs and Hedge Funds}

How do portfolios of Exchange Traded Funds (ETFs) and hedge funds compare to those of mutual funds? Figure 5 shows the BM and MS distributions of 575 ETFs and our limited samples of 79 hedge funds, and Panels E and F of Table 3 reports descriptive statistics. ${ }^{19}$ The BM distribution of ETFs shown in Panel A is shifted towards low BM scores but slightly less so than the distribution of mutual funds. $19 \%$ of ETFs have a BM score above 3, compared with 13\% of mutual funds, but only 4 out

\footnotetext{
${ }^{18}$ The characteristic distributions of stocks do not vary much across stocks with size scores above 2. For example, the means BM scores across stocks with ME scores between 2 and 3 is 2.71 , between 3 and 4 is 2.67 , and between 4 and 5 is 2.61, while the BM mean of the smallest stocks with size scores between 1 and 2 is 2.97 .

${ }^{19}$ The online appendix includes results for other characteristics of ETF and hedge funds portfolios.
} 
of 575 ETFs in our sample have a BM score above 4, and no ETF approaches the BM score of the $\mathrm{H}$ portfolio. The sample includes 134 ETFs that track "value" indices and 264 "growth" ETFs. Portfolios of "value" ETFs show the same bias towards low BM book-to-market scores as "value" mutual funds. The mean BM score of "value" ETFs is 2.93 and 69, over half, of "value" ETFs have a BM score below 3.

Panel B of Figure 3 shows on the other hand that the distribution of the Morningstar value/growth measure of ETFs differs from that of mutual funds. While MS scores of mutual funds exhibit a similar bias as BM scores, the MS scores of ETFs are more centered around the midpoint of 3. The mean MS score of ETFs is 2.88 and 88\% of ETFs have MS scores between 2 and 4 . However, high-MS ETFs are largely missing from the sample as only 10 ETFs (1.7\%) have an MS score above 4, while 58 ETFs have a MS score below 2.

Since ETFs track stock market indices, their portfolio compositions depend on the constructions of indices. We will analyze the methodologies and properties of some of the major stock market indices in more detail in Section 4.

Panels C and D of Figure 5 show the BM and MS distribution of hedge funds and Panel F of Table 3 reports the corresponding means and percentiles. Recall that our sample of hedge funds consists of only 79 individual funds and is not representative. Yet, the BM histogram of hedge funds is very similar to that of mutual funds and the means and percentiles of both BM distributions are similar. Hedge funds also exhibit the same bias as mutual funds and ETFs towards low book-to-market values. $82 \%$ of hedge funds have a BM score of less than 3 compared to $87 \%$ of mutual funds and only one hedge fund in our sample has a BM score above 4, while the BM score of 17 funds is below 2. Hedge funds have on average lower Morningstar scores than mutual funds

We consider two further samples. Panel E of Figure 5 and Panel G of Table 3 shows the BM distribution of all 8,892 mutual funds in the Thompson-Reuters/CRSP database without applying any screens. This sample includes not only domestic active equity funds but also index funds, funds holding foreign assets, sector funds, etc. Comparing the quantiles to those of our benchmark sample in Panel A Table 3 shows that this broader sample has similar properties as our benchmark sample for all characteristic that we construct. In addition to the 7 funds in our main sample, 361 mutual funds in this broader sample have BM scores above 4. 205 of these are foreign equity funds (CRSP objective code EF) and 125 are non-equity funds. Of the remaining 31 domestic equity funds with BM score above 4, 13 are sector funds, 5 are index funds, and 13 funds that did not pass our other screens. We conclude that the results found for the benchmark sample are also valid in the broader sample without applying screens.

Finally, we construct characteristics of portfolios of financial institutions that file a 13F form, see Panel F of Figure 5 and Panel $\mathrm{H}$ of Table 3. Our sample includes 9,006 such institutions. The total market value of assets of the 4,571 institutions in 2018Q4 is \$21T, or about 90\% of GDP. Even though the $13 \mathrm{~F}$ portfolios represent aggregate holdings of each institution instead of portfolio holdings of individual mutual funds, the characteristic distributions are similar. The means and quantiles of $13 \mathrm{f}$ institutions (Panel $\mathrm{H}$ ) are almost identical to those for mutual funds (Panel A). 88\% of all financial institutions have a BM score less than 3 , so the the aggregate $13 \mathrm{~F}$ portfolios shows the same bias 
towards low BM scores that is present in the BM distribution of mutual funds, ETFs, and hedge funds. 236 out of 9,006 institutions, or 2.6\%, have a BM score above 4 while 3,533 institutions, or 39\%, have a BM less than 2.

\section{Robustness}

Next, we perform a number of robustness checks that are reported in Figure 6. Results for additional robustness checks are reported in the online appendix. First, we consider alternative price-ratios. Panel A plots the histograms of the scores of the earnings-to-price, cash-flow-to-price, dividends-to-price, and the sales-to-price ratios of the mutual funds in our benchmark sample. The book-to-market score distribution is included for comparison. The sales-to-price distribution is more strongly biased towards low scores than the BM distribution and has a lower mean of 2.24 compared to the mean of the BM distribution of 2.33. The earnings-to-price and cash-flow-to-price distributions are shifted further to the right compared to the BM histogram but most of their mass is below 3 (81\% and 75\% of mutual funds have EP and CFP scores below 3, respectively). However, there are virtually no mutual funds with EP, CFP, or SP scores above 4 confirming the results for BM. Our sample includes two mutual funds with an EP score above 4, four with a CFP score above 4, and a single fund with a SP score above 4.

The distribution of dividing-price ratios differs significantly from those of the other four pricemultiples and is more spread out and only very slightly biased to the left. Its mean of 2.87 is close to the midpoint of 3, 46\% of mutual funds have a DP score above 3, and 190 mutual funds (or, 6\%) with a DP ratio above 4 . Hence, the dividend-price ratio is the only "value" measure that is associated with a significant number of mutual funds in our sample. The main reason for this finding is that a number of the mutual funds in our sample are "Dividend" funds that specifically invest in stocks that pay high and stable dividends. For example, 79 mutual funds and 57 ETFs include the term "Dividend" in their name. While there might be other reasons for the higher number of high-DP funds, there is no evidence of a return premium in sorts involving the dividend-price ratio, in contrast to the well-documented return premia in BM and EP-sorted portfolios.

The results reported so far are based on averages by fund, in other words, we compute the time series mean characteristic score for each of the 2,993 fund in our sample over the quarters in which the fund is in our sample. Panel B shows instead the BM distributions of fund/quarter observations of all funds in our sample (154,418 fund/quarter observations), "value" funds (30,412 observations), and "growth" funds (63,591 observations). The BM distributions of all funds in our sample, "value" funds, and "growth" funds based on fund/quarter-level data are almost identical to those for fund-level data shown in Panel B of Figure 3.

The results reported are based on quintile characteristics scores. Panel C shows the distribution of market-adjusted book-to-market ratios, i.e. the difference between the BM-ratio of the mutual fund and the BM-ratio of the CRSP-VW index, see Section 2. Market-adjusted characteristics do not rely on quintile sorts but are more sensitive to outliers and are not directly comparable across different characteristics. The distribution of all mutual funds in our benchmark sample is centered around 
0 , and therefore close to the BM-ratio of the CRSP-VW index. To interpret the fund distribution, consider the adjusted BM-ratios of the portfolio sort that underlies HML: -0.20 for L, 0.17 for the medium portfolio $\mathrm{M}$, and 0.71 for $\mathrm{H}$. $81 \%$ of mutual funds have an adjusted BM-ratio that is between the that of the $\mathrm{L}$ and $\mathrm{M}$ portfolios, while only $18 \%$ of funds have a adjusted ratio that is between $\mathrm{M}$ and $\mathrm{H}$. The adjusted BM-ratio of 32 funds, less than 1\%, is below that of L, and only 2 funds have a adjust BM-ratio above that of $\mathrm{H}$. The overall results are consistent with those found for BM quintile scores.

Since the sizes of mutual funds varies significantly in our sample, it is useful to compute characteristic Distributions that are weighted by the AUM of funds instead of equally-weighting each fund regardless of size. However, the AUM-weighted distributions of BM scores plotted in Panel D is essentially identical to the equally-weighted histogram in Panel A in Figure 3. Weighted histograms for other characteristic are included in the online appendix and confirm that the results are similar to those based on equally-weighted distributions.

The book-to-market distributions of 296 index and 124 sector funds that pass our other screens, shown in Panel E, also show the same pattern found in the benchmark sample. Only 4 sector funds and 3 index funds have a BM score above 4 , while $82 \%$ and $74 \%$ of index and sector funds, respectively, have a BM score below 3.

Finally, we study the BM distribution across time. Panel F shows the BM histograms of mutual funds in the fourth quarters of 1990Q1, 2000Q1, 2010Q1, and 2018Q4. The book-to-market distributions in 1990Q1, 2010Q1, and 2018Q4 are similar to the distribution across all quarters but the histogram in 2000Q1 is shifted even further to left towards low BM scores. The bias towards low BM ratios and lack of mutual funds with high BM ratios is present throughout the sample. The mean of the BM distribution by quarter range from 1.74 in $2000 \mathrm{Q} 2$ to 2.60 in $2014 \mathrm{Q} 2$ and is thus below 3 across the sample. This is true for the absence of high BM funds as well. The quarter with the highest share of mutual funds with a BM score above 4 is 1984Q4 with $4.82 \%$ and less than $1 \%$ of mutual funds had BM score higher than 4 in every quarter since 1996Q1.

Panel A of Figure 7 plots the number of mutual funds with BM scores between 1 and 2, 2 and 3, 3 and 4 , and 4 and 5 over time. The total TNA of funds in each interval is plotted in Panel B. Until about 2005, the sample is dominated by funds with BM scores between 1 and 3, both in terms of number and TNA. In 2000Q3, 95\% of all mutual funds had a BM score below 3 and accounted for 99\% of the total TNA of the funds in our sample. After 2005, the number of funds with moderately hi book-to-market scores between 3 and 4 increases to around 400, or about 20\%, with about 15\% of the total net asset value at the end of the sample. In contrast, mutual funds with book-to-market scores above 4 are virtually absent throughout the sample. On average, there are 6.7 such funds in each quarter with a maximum of 18 in 2003Q4, and account for less than 2\% of the total TNA per quarter. In 1991Q3, none of the 327 funds in the sample had a BM score above 4 . We conclude that the bias towards low book-to-market scores of mutual funds portfolios is present throughout the sample. Although we report only results for the book-to-market ratio here, additional results for other prize-multiples included in the internet appendix confirm this conclusion. 


\section{Other characteristics}

Figure 8 shows heat maps of scores of additional characteristics for our samples of S\&P 500 stocks, mutual funds, "growth" funds, and values funds. We construct scores for the two components of the Morningstar MS index, MULT and GR, as well as the multiples and growth rates that make up the index (BM, EP, SP, CFP, DP, and GRLTE, GRE, GRCF, GRS, GRB), profitability (OP), investment (INV), quality (QUAL), and three liquidity measures, Pastor-Stambaugh (PSLIQ), turnover (TURN), and volume (DVOL). The appendix includes a description of the construction of all characteristics.

We analyzed the size, book-to-market ratio, Morningstar, momentum, and price ratios above. Note that the portfolio characteristics of fundamental growth rates are more concentrated across mutual funds than for price multiples. At least three quarters of mutual funds have scores between 3 and 4 for growth rates of current earnings, cash flow, sales, and the book value. There are virtually no mutual funds with growth scores below 2 and above 4 . Only the scores of expected long-term earnings growth are more dispersed. The same pattern is more true for "growth" funds, however there are very few "growth" funds that have growth scores above 4, with the exception of long-term earnings growth. Always all "value" funds have growth scores between 2 and 4.

Recent research has documented significant return premia in sorts on profitability (OP) and investment (INV). The portfolio patters for these characteristics are similar to those for fundamental growth rates. Most mutual funds have OP and INV scores between 3 and 4 and there are very few funds with INV and OP scores below 2 and above 4 . The same is the case for QUAL.

\section{Portfolio Composition by Quintiles}

So far, we have focused on average portfolio characteristics of mutual funds. Next, we analyze portfolio compositions in more detail. For each fund in each quarter, we compute the share of its portfolio that is invested in stocks in the five quintiles of a given characteristic. The results reported in this section are based on the time-series averages of shares over the lifetime of each fund.

Panel A of Table 5 shows the portfolio composition across BM quintiles for all mutual funds, "value" and "growth" funds, as well as results for ETFs and hedge funds. The average portfolio share of mutual funds in our benchmark sample is declining across BM quintiles. Mutual funds invest on average $38.53 \%$ of their portfolio in stocks that are in the lowest BM quintile and $9.75 \%$ in stocks in the highest BM quintile. The portfolios of "growth" funds are more heavily concentrated in extreme low BM stocks. The average portfolio share of stocks in quintile one is $50.1 \%$ and $22.82 \%$ in quintile two. "Growth" funds hold on average 15\% of their portfolios in high BM stocks that are in the top 2 quintiles. The portfolios of "value" funds are more evenly distributed across BM quintiles. In fact, "value" funds hold on average a higher share of their portfolios in stocks in the lowest BM quintile (20.32\%) than in stocks in the highest quintile (16.13\%). In other words, on average "value" funds hold a higher fraction of their portfolios in low BM "growth" stocks than in high BM "value" stocks. This pattern explain why the average BM score of "funds" is 2.89 and below the midpoint of 3 . The two bottom rows of Panel A report the average portfolio shares of ETFs and hedge funds and show a similar pattern as mutual fund portfolios. ETFs and hedge funds hold mostly low book-to-market 
stocks but the portfolio share of high BM stocks is relatively small.

The BM shares of the five largest "value" funds as of 2018Q4, shown in Panel B, illustrate the typical pattern of "value" fund portfolios. The portfolios of four of the five largest "value" funds are invested mostly in low BM "growth" stocks instead of high BM "value" stocks and the shares are declining from quintile 1 to 5 . One of these "value" funds holds almost 60\% BM1 and BM2 stocks and only less than 8\% and 14\% in BM5 and BM4 stocks, respectively. The notable exception is the "DFA US Large Cap Value" fund. This fund holds very small fractions of stocks in the lowest two BM quintiles and holds on average $70 \%$ in stocks in the two highest BM quintiles. In contrast, portfolios of "growth" funds are more concentrated in low BM stocks. Panel C shows the average portfolio weights for the five largest "growth" funds in our sample. These funds hold at least 62\% of their portfolios in BM1 and BM2 stocks and the portfolio shares are declining in BM.

Figure 9 shows the distribution of portfolio shares in the five BM quintiles across all mutual funds (in black), "value" funds (in red), and "growth" fund (in blue). The percentages of mutual funds with portfolio weights between $0 \%$ and $25 \%, 25 \%$ to $50 \%, 50 \%$ and $75 \%$, and $75 \%$ to $100 \%$ are at the bottom of each histogram. Panel A shows that most mutual funds hold a large share of their portfolio in stocks that are in the lowest BM quintile. $28 \%$ of funds old more than half of their portfolios in stocks in the lowest BM quantile and 73\% of funds hold at least a quarter in BM1 stocks. Panels B to E show that portfolio shares of BM quintile-2 to 5 stocks are much lower than the BM1 shares and more shifted towards low portfolio shares the higher the BM quintile. For example, the share of mutual funds that hold more than 25\% of their portfolio in BM3, BM4, BM5 stocks is $6 \%, 5 \%$, and $3 \%$, respectively, and the portfolios of $75 \%$ of all funds hold at least $96 \%$ of BM1 to BM4 stocks.

Portfolios of "growth" funds are more concentrated in low book-to-market stocks and few "growth" funds invest a significant portion of their portfolios in BM4, and BM5 stocks. On the other hand, Figure 9 confirms the finding that portfolios of "value" funds are also biased towards low BM "growth" stocks. $29 \%$ and $24 \%$ invest at least a quarter of their portfolio in stocks in BM1 and BM2 stocks, respectively, and $90 \%$ of "value" funds hold at least half of their portfolios in BM1, BM2, and BM3 stocks. There are 11 "value" funds with portfolios that consist of over 50\% in BM1 stocks but only 2 "value" funds with over 50\% in BM5 stocks.

\section{Stock Ownership by Characteristics}

The results presented so far focused on properties of mutual funds. Next, we explore how characteristics are related to the ownership structure of shares of individual stocks. For each stock we compute the fraction of the total market cap that is held by various types of mutual funds. Table 6 shows results for the ownership share of funds in our benchmark sample of active equity funds, all funds in our sample (without applying any screens, including index and sector funds), as well as value and growth funds for S\&P 500 stocks. Unless otherwise stated, results refer to those in the benchmark sample. Panel A reports summary statistics. Active equity funds hold on average $8.61 \%$ of the total market cap of S\&P 500 stocks and an average of 13.22\% is held by all mutual funds in our sample. Ownership of growth funds is about three times as high as that of value funds. The 10\% and $90 \%$ 
quantiles suggest that there is considerable variation across stocks, e.g. the ownership share of all funds ranges from $0.15 \%$ to $47.64 \%$.

Panel B shows the average ownership by book-to-market scores of stocks. Ownership shares by all funds as well as active equity fund of low BM stocks are significantly higher than those of high BM stocks. For example, mutual funds ownership of stocks with BM scores between 1 and 2 is 9.45\%, which is almost twice that of stocks with BM scores above 4. While ownership of "growth" funds also declines with BM scores, but this is not the case for ownership by "value" funds. Stocks with BM scores in the middle intervals 1-2 and 2-3 have the highest fraction of market cap held by "value" funds, while holdings of stocks in the lowest and highest BM intervals are less than $1 \%$.

Next, we run stock-level cross-sectional regressions of the ownership shares of mutual funds on MS, and MOM scores. ${ }^{20}$ The results for mutual funds in the benchmark sample are in the first column of Panel C. Since all characteristic scores are between 1 and 5, the coefficient magnitudes are comparable across characteristic. To assess the economic significance of each coefficient, we compute the predicted ownership shares of stocks with characteristic scores of 1 and 5 while holding the other variables constant at their sample means. The book-to-market coefficient of 0.21 is positive but small in magnitude and statistically insignificant. The predicted ownership share of a BM1 stock is $8.27 \%$ and $9.12 \%$ for a stock with a BM score of 5 . in contrast, the MS coefficient is negative and statistically significant. The predicted ownership shares of MS1 and MS5 stocks are 12.17\% and 3.99\%, respectively, so the impact of the MS score on ownership is economically large. The results when we include all mutual funds in our sample are similar but the BM slightly larger and marginally statistically significant. For "growth" funds, only the coefficient of the Morningstar index of -1.92 is economically and statistically significant. The $R^{2}$ is $34 \%$, hence BM and MS scores capture a significant amount of the variation in ownership by "growth" funds. The $R^{2} \mathrm{~s}$ in univariate regressions with BM and MS scores are $17 \%$ and $35 \%$, respectively, suggesting that the Morningstar index of a stock has a stronger relationship to ownership by "growth" funds than the book-to-market ratio.

The results for the regression for "value" funds are different from the other three specifications. The BM and MS coefficients are both positive and marginally statistically significance but their magnitudes are small, so that neither variable has a sizable economically effect on ownership shares by "value" funds. In addition, the $R^{2}$ is only $2 \%$ and thus smaller then in the other regression specification. The $R^{2}$ increases only marginally to $3.3 \%$ if all six price-multiples are included in the regression.

In summary, we find that book-to-market ratio and Morningstar characteristic scores have economically and statistically large negative effect on the ownership share of mutual funds in the total market caps of stocks. The ownership share by mutual funds is lower the higher are the BM and MS scores. However, this pattern is not true for ownership by "value" funds and BM and MS scores have only a minor effect on ownership. We conclude that these results are consistent with those presented above about the distributions of "value" and "growth"-related characteristics of mutual funds portfolios.

\footnotetext{
${ }^{20}$ We do not include ME scores since the sample of S\&P 500 stocks includes only large stocks. However, includes ME score in the regression does not change the results significantly.
} 


\section{Liquidity}

One possible reason why mutual funds hold relatively few high-BM stocks is that such stocks might be small, illiquid, and costly to trade. To investigate whether this is indeed the case, we first study the relationship between stock sizes and book-to-market ratios. Panel A of Figure 10 shows a scatter plot of BM scores on the $x$-axis and ME scores on the $y$-axis for all 23,801 stock in our sample. The size of each circle is proportional to the market cap of the stock. The scatter plot shows that there is no strong relationship between the book-to-market ratios and market caps across stocks. The correlation is -0.10 and slightly negative. Of the 1,100 stocks are in the largest size quintile, 185 have BM scores above 4 and 246 have a BM score between 3 and 4. An additional 276 and 326, stocks in the second largest size quintile have BM scores above 4 and between 2 and 4, respectively. In total, there are 1,033 large stock with high book-to-market ratios that are in the top two quintiles.

The scatter plot also displays the BM and ME scores of Fama-French portfolios. Since the SL, BL, SH, and $\mathrm{BH}$ portfolios are based on ME/BM sorts, they are located towards the four corners of the plot. The size and book-to-market scores of the big/low-BM BL portfolio are 4.85 and 1.27, respectively, so it is positioned very close to the top left corner of the figure. The big/high-BM portfolio $\mathrm{BH}$ is slighter further from the top right corner and its ME and BM scores are 4.70 and 4.55, respectively. The ME scores of small-stock portfolios are above 2 because they are value-weighted, so that the smallest stocks with a ME score below 2 are dominated by the slightly larger stocks in the small-stock portfolios. The S, B, H, and L portfolios are averages of the double-sorted portfolios and are therefore between the two portfolios from which they are constructed.

The BM scores of the three high-BM portfolios, $\mathrm{BH}, \mathrm{SH}$, and $\mathrm{H}$ are 4.55, 4.65, and 4.61, respectively, are almost identical. Since the big/high-BM portfolio consists only of large stocks, it is therefore possible to form high-BM portfolios using only liquid stocks without having to rely on smaller and potentially illiquid stocks.

The scatter plot for mutual funds is in Panel B. "Growth" funds are in black, "value" funds in blue, and "other" funds are in orange. The size of the circles are proportional to the TNA of funds. The joint distribution of size and BM scores of mutual funds is different from the joint distribution of stocks as $61 \%$ of funds invest in very large and low book-to-market stocks (727 funds, or $24 \%$, are in ME5-BM1 and 1,099, 37\%, in ME5-BM2 quintiles). Even though there are many stocks in the top $\mathrm{ME} / \mathrm{BM}$ quintile, there is only a single mutual fund with ME and BM scores above 4 . In fact, there is a significant mass in the joint distribution of stocks with BM scores above 4 in each size quintile but virtually no mutual funds.

Next, we construct characteristics that are designed to measure liquidity on the stock level directly; the Pástor, Stambaugh, and Taylor (2015) measure (PSLIQ) and the bid-ask spread (SPREAD). Additional results for trading volume and turnover in the internet appendix. We group stocks and mutual funds with ME and BM scores between 1 and 2, 2 and 3, 3 and 4, and 4 and 5 and compute average liquidity characteristics for each of the 16 combinations. The four panels of Table 7 show results for PSLIQ in the sample of stocks (Panel A) and mutual funds (Panel B), and bid-ask-spreads in Panels C and D. Recall that there are only seven mutual funds with book-to-market scores above 
4. Of these seven funds, two are in each of the first, second and third ME groups, and only one fund has a size score above 4 . Therefore, the results in the BM[4,5] column are based on no more than 2 observations and are indicated with $\mathrm{a}^{\dagger}$ superscript.

There is little variation in the average Pástor-Stambaugh liquidity measure PSLIQ across size and book-to-market scores of stocks (Panel A) and mutual funds (Panel B). The PSLIQ means for stock quintiles range from 2.96 to 3.11 and 2.91 to 3.15 for mutual funds and thus close to the midpoint of 3. Even though the means are similar, the variation of PSLIQ is much larger for small stocks than for large stocks. The cross-sectional standard deviation of stocks in the bottom size quintile is 0.61 compared to 0.25 for stock in the top quintile. In contrast, the PSLIQ means and variation across BM quintiles are similar, implying that the Pástor-Stambaugh liquidity measure is not closely related to book-to-market ratios.

The PSLIQ score shows little variation across mutual funds and is also not related to ME and BM scores of funds. The PSLIQ score of $90 \%$ of all mutual is between 2.8 and 3.2 and the minimum and maximum scores in the sample are 2.68 and 3.31. Average scores of bid-ask spreads of stocks and mutual funds, shown in Panels C and D, are, not surprisingly, negatively correlated with size scores but are only weakly related to BM scores. Conditional on the ME score, high BM stocks and mutual funds have slightly higher bid-ask spreads than low BM stocks and funds but the spread is much smaller than that across size.

Based on the evidence presented above, it seems unlikely that the lack of high-BM funds can be explained by liquidity. First, the number of large stocks with high book-to-market ratio is sufficient to create well-diversified portfolios consisting of liquid stocks. Second, controlling for size, liquidity of individual stocks is only weakly correlated with the book-to-market ratio. Third, the liquidity of stocks in mutual fund portfolios varies little across funds and is not related to book-market-ratios

\section{Stock Market Indices}

Our sample, before applying screens, contains 1,214 domestic equity index mutual funds and ETFs, of which 164 are "value" and 317 are "growth" funds. Next, we analyze the properties of the underlying indices focussing on "value" and "growth" indices. We first match ETFs and index mutual funds to the indices that are tracked by the funds, then aggregate funds by index, and analyze the portfolio compositions of the funds that are associated with an index. Results for the five value and five growth indices with the largest net asset values are in Table 8. Panels A shows the sum of asset values of all funds that track the index and book-to-market, Morningstar, earnings-to-price, and sales-to-price scores and Panel B reports the portfolio shares across BM quintile scores.

While all indices in Panel A are "value" indices, their portfolio properties are heterogeneous. The BM scores range from 2.89, which is below the midpoint of 3, to 3.75, while all MS scores are somewhat higher and between 3 and 4. EP scores are between 2.64 and 3.30 but all SP scores are well below 3. All valuation scores in the panel are below 4 indicating that none of the indices is a "true" value index in the sense of high price-based ratios. In contrast, the "growth" indices in Panel B are indeed true 
"growth" indices with low valuation ratios. The BM score of all "growth" indices are all well-below 2 and scores of other price-ratios are only slightly higher and between 1 and 2 (with some exceptions).

The portfolio weights across the five BM quintiles reported in Panels C and D show the differences between "value" and "growth" indices in more detail. With the exception of the small-cap Russell 2000 Value index, about 70\% of the portfolios of "value" indices is concentrated in the middle BM2, BM3, and BM4 quintiles, and share of high-BM5 stocks of all indices is less than 25\%. Instead, the portfolios of all "growth" indices are without exception strongly tilted towards stocks with low book-to-market ratios.

Next, we download the index methodology documentation of the major index providers (S\&P, FTSE Russell, and CRSP) and compile a list of characteristics that are used in the construction of "value" and "growth" indices, see Panel C. While the details of the methodology vary, all indices are based on the same principle, which is similar to that used in the Morningstar index. All "value" and "growth" indices are a combination of two separate components: The first component is based on an average of several price-multiples. In addition, all indices also include a second component that is computed using (mostly) growth rates of fundamentals. The two components are then combined to form a single "value"/"growth" index for each stock that is then applied to a subset of stocks based on size. For example, the Russell 1000 Value/Growth indices include only the 1,000 largest stocks while the Russell 2000 Value/Growth include only small-cap stocks.

Each index provider uses a different set of characteristics. CRSP and Morningstar combine five price-multiples to form their valuation index while Russell uses only the book-to-market ratio. The construction of the indices of growth characteristics varies even more. While Russell and Morningstar indices use only growth rates of fundamentals (e.g. current and expected long-term earnings, sales, cash flow, book value), the other providers incorporate characteristics that are not directly linked to growth rates. For example, the S\&P "growth" index uses 12-month momentum, and CRSP includes the investment-to-assets ratio and the ROA. MSCI's index includes the current internal growth rate (which is a function of the ROA and the payout ratio) as well as long-term trends of earnings and sales growth.

The academic literature on the value premium has focused almost exclusively on price-multiples, in particular on the book-to-market ratio, as measures of "value" vs. "growth". In contrast, indices that are tracked by "value" and "growth" index funds and ETFs also incorporate information in other firm fundamentals, some of which are not directly linked to multiples of fundamental growth rates. Therefore, the properties of mutual fund and ETF portfolios that are created based on these indices are different from those of characteristic sorts and portfolios that underlie the extensive body of research about the value premium. One consequence is that very few, if any, index funds and ETFs are true "value" investments if "value" is defined in the academic sense as stocks with high price-multiples. Nor do any "value" and "growth" ETFs or index funds resemble long-short "value"/"growth" portfolios typically studied in academic research. It is an open question if and how these different notions of "value" vs. "growth" are related to returns and performance of mutual funds and ETFs. We will return to this issue in Section 6. 


\section{Loadings vs. Holdings}

In the literature on mutual fund performance, the magnitudes of regression factor loadings (i.e., betas) are less relevant since the factors serve only as controls for diversifiable risk. For our purposes, the question is whether loadings estimated from time series regressions of fund returns on factors such as SMB, HML, and MOM are informative indicators of fund strategies. Next, we argue that while factor loadings are appropriate as a measure of exposure to diversifiable risk, they are not necessarily reliable indicators of the underlying investment strategy of an active mutual fund.

First, risk exposures are estimated using historical data and are thus subject to estimation error. Historical data might also not reflect the current portfolio of an active fund. This is especially true for firm characteristics that change over time, such as momentum. Unless a fund deliberately hedges momentum, the momentum of a fund's portfolio changes as momentum of the stocks in its portfolio change over time. In contrast, measuring fund characteristics directly from portfolio holdings yields an accurate assessment of the fund's portfolio at each point in time.

Second, the interpretation of the magnitudes of estimated loadings in factor regressions are not straightforward and can easily be misinterpreted. Consider the following simple example. Let P and Q be two portfolios that are based on sorts on some characteristic and let $\mathrm{P}_{t}-\mathrm{Q}_{t}$ be the corresponding long/short portfolio. It is easy to see that the coefficients of regressions of $\mathrm{P}$ and $\mathrm{Q}$ on P-Q satisfy $\beta_{\mathrm{P}, \mathrm{P}-\mathrm{Q}}-\beta_{\mathrm{Q}, \mathrm{P}-\mathrm{Q}}=1$. Moreover, their magnitudes depend on the relative volatilities of $\mathrm{P}$ and $\mathrm{Q}:\left|\beta_{\mathrm{P}, \mathrm{P}-\mathrm{Q}}\right|>$ $\left|\beta_{\mathrm{Q}, \mathrm{P}-\mathrm{Q}}\right| \Leftrightarrow \sigma_{\mathrm{P}}>\sigma_{\mathrm{Q}}$. Hence, betas are not necessarily symmetric around 0 and the more volatile portfolio has a larger (in absolute value) beta with respect to the long/short portfolio. For example, the beta of the "neutral" portfolio $\left(\mathrm{P}_{t}+\mathrm{Q}_{t}\right) / 2$ is positive if $\sigma_{\mathrm{P}}>\sigma_{\mathrm{Q}}$ and negative otherwise. In other words, the magnitudes of betas are more informative about the volatility of the portfolios that make up the long/short portfolios than as a measure of how tilted a portfolio is towards the underlying characteristic. $^{21}$

The dependence of regression loadings on the volatility of the long/short portfolios is borne out in the data. In our sample, univariate HML betas are not centered around zero since $\sigma_{\mathrm{L}}>\sigma_{\mathrm{H}}$ and thus $\left|\beta_{\mathrm{L}, \mathrm{HML}}\right|>\left|\beta_{\mathrm{H}, \mathrm{HML}}\right|$. The estimated univariate betas are $\beta_{\mathrm{L}, \mathrm{HML}}=-0.75, \beta_{\mathrm{H}, \mathrm{HML}}=0.25$. The HML beta of the "BM-neutral portfolio" $(\mathrm{H}+\mathrm{L}) / 2$ is -0.25 . In contrast, the HML beta of a "growth-tilted" portfolio of $0.75 \mathrm{H}+0.25 \mathrm{~L}$ is 0 . Hence, a comparison of HML loadings of two portfolios based only on the magnitudes of their HML betas is misleading. Say, the HML betas of two portfolios are -0.2 and 0.2 , respectively. The portfolio with an HML beta of 0.2 is much closer to $H$ than the portfolio with an HML beta of -0.2 is to $\mathrm{L}$.

This pattern is even more pronounced for the SMB $\beta$ 's of $S$ and $\mathrm{B}: \beta_{\mathrm{S}, \mathrm{SMB}}=1.60, \beta_{\mathrm{B}, \mathrm{SMB}}=0.60$. The positive sign of $\beta_{\mathrm{B}, \mathrm{SMB}}$ is counterintuitive since $\mathrm{SMB}=\mathrm{S}-\mathrm{B}$ but is due to the fact that $\mathrm{S}$ is much more volatile than $B$ and $\operatorname{Cov}(B, S)>\operatorname{Var}(B)$. Hence, the SMB beta of any linear combination of $S$ and B with non-negative weights is strictly positive. Thus univariate SMB betas of large stocks, or

\footnotetext{
${ }^{21}$ The beta of the excess market return is an extreme example. The volatility of the risk-free rate is negligible relative to that of the market return, so that $\beta_{\mathrm{M}, \mathrm{M}-\mathrm{RF}} \approx 1$ and $\beta_{\mathrm{RF}, \mathrm{M}-\mathrm{RF}} \approx 0$.
} 
mutual funds that hold large stocks, are positive. By themselves, beta coefficients in regressions on long/short factors are generally not informative. Instead, betas need to be interpreted relative to the range spanned by the betas of the components of the long/short factors.

In multivariate regression, betas depend on the joint variance-covariance structure of the left- and right-hand side variables and the relative magnitudes and signs of betas can take any value. The betas of the six component portfolios of SMB, HML and MOM in 4-factor regressions are in shown Table D.4. The SMB loading of S is 0.90 , while the loading for B is -0.10 and thus much smaller in absolute value. The same pattern is true for the HML loadings of $\mathrm{H}$ and $\mathrm{L}: \beta_{\mathrm{H}, \mathrm{HML}}=0.72$ and $\beta_{\mathrm{L}, \mathrm{HML}}=-0.28$, while $\beta_{\mathrm{U}, \mathrm{MOM}}=0.34$ and $\beta_{\mathrm{D}, \mathrm{MOM}}=-0.66$. While the signs of the betas are intuitive in the sense that betas of "long" portfolios S, H and U are positive and betas of "short" portfolios B, L and D are negative, the betas are not symmetric around zero.

The asymmetry of loadings is present in the estimation of multifactor models in standard data sets. Panels B and C of Table 9 shows SMB and HML loadings of 25 ME-BM sorted portfolios in a factor model with the market, SMB, HML, and MOM. SMB betas of all portfolios constructed from size quintiles 1 to 4 are positive and only the five portfolios with the smallest stocks have a negative SMB beta. The magnitudes of the SMB betas are only interpretable in comparison to the $\mathrm{S}$ and $\mathrm{B}$ betas of 0.9 and -0.10 (Panel A). The SMB loadings of ME1 and ME2 portfolios are between 0.70 and 1.33 and thus comparable to the loading of S, while SMB loadings of ME5 portfolios are similar to the $\mathrm{H}$ loading. ${ }^{22}$ The pattern of HML betas is similar. Only the portfolios with the lowest BM quintile have negative HML betas. As in the case of SMB betas, HML betas need to be interpreted in conjunction with $\mathrm{H}$ and $\mathrm{L}$ betas, which are 0.72 and -0.28 , respectively. HML loadings of BM1 portfolios are similar to the loading of H and BM5 betas are similar to that of L. The SMB and HML loadings of the "neutral" ME/BM portfolio formed from stocks in the third ME and BM quintiles are 0.35 and 0.55 and positive, suggesting, incorrectly, that this portfolio is tilted towards large, high BM stocks.

Clearly, estimated loadings of models with long/short factors cannot be interpreted without a proper scale. We suggest to use the estimated loadings of the long and short components of the factors as natural benchmarks for high and low exposure of any test asset to a factor. The exposure of a factor-"neutral" midpoint is given by the average of the betas of the long and short components of the factor. For example, the low, neutral, and high SMB benchmarks are -0.10, 0.40, and 0.90, and those of HML are -0.28, 0.22, and 0.72 (see Table 9, Panel A).

Proper framing is important when interpreting factor loadings of mutual funds. Consider two mutual funds with $\beta_{1, \mathrm{HML}}=0.25$ and $\beta_{2, \mathrm{HML}}=-0.25$, respectively. Since the HML betas are equal in absolute value, it might seem that both funds are comparable in terms of their respective value and growth strategies. However, the HML beta of fund 2 is close to the HML beta of L of -0.28 while the HML beta of fund 1 is much smaller than the HML beta of $\mathrm{H}$ of 0.72 . Hence, fund 1 is a "moderate" "value" fund, while fund 2 is an "extreme" growth fund.

We estimate the 4-factor model with the market, SMB, HML, and MOM for each mutual fund and

\footnotetext{
${ }^{22}$ The betas of the 25 ME-BM portfolios can be larger in absolute value than the S, B, H and L betas since the they are based on quintiles while $\mathrm{S}, \mathrm{B}, \mathrm{H}$ and $\mathrm{L}$ are constructed from two ME quantiles and BM terciles.
} 
ETF in our sample and study the distributions of the loadings. ${ }^{23}$ The histograms are plotted in Figure 11 along with the loadings of the component portfolio of the factors as vertical lines. The distributions of ETF betas in all cases is almost identical to those of mutual funds, hence we will focus on the mutual funds sample. This histogram of market betas in Panel A shows that the betas of almost all mutual funds is between 0.5 and 1.2. The mean market beta across funds is 0.96 with an inter-quartile range of $(0.89,1.05)$. SMB betas, shown in Panel B, vary significantly more across mutual funds and range from about -0.3 to 1 with an overall mean is 0.2 . We have seen in section 3 that mutual funds hold predominantly large stocks but only 39\% of all funds have a negative SMB beta. The reason for relatively small number of funds with negative SMB betas is of course that the SMB of the B portfolio of large stocks is -0.1 and thus only slightly less than zero, thus the SMB beta of the majority of mutual funds is similar to that of B. The beta of the small stock S portfolio is 0.9 , so that the size-neutral midpoint is 0.4. The overall distribution of SMB loadings is consistent with the size distribution based on portfolio holdings when it is compared to the betas of the $\mathrm{S}$ and B portfolios.

The distribution of mutual fund HML betas in Panel C is centered around 0, with a mean and median of 0.04, and close to symmetric. Most HML betas are small in magnitude as 93\% are between -0.5 and 0.5. Of course, this does not imply that most funds hold book-to-market neutral portfolios since the betas of the high and low-BM portfolios $\mathrm{H}$ and $\mathrm{L}$ are not symmetric around 0 . The HML beta of $\mathrm{H}$ is 0.72 and that of $\mathrm{L}$ is -0.28 with a midpoint of 0.22 . The fact that $75 \%$ of all mutual funds have HML betas that are smaller than 0.22 confirms the finding that funds are biased towards low book-to-market stocks. Moreover, only 18 funds have a HML beta that is larger than that of H but 383 funds with smaller betas than L.

\section{Characteristics and Returns}

The results presented above suggest that the notion of "value" vs. "growth" in the mutual fund industry is vague and involves a diverse set of characteristics. This is particularly transparent in the construction methodologies of indices that are tracked by "value" and "growth" ETFs. While the precise definition differs across providers, all indices incorporate information in price multiples, fundamental growth rates, and sometimes other variables. The popular Morningstar index is constructed in a similar fashion. The extensive academic literature has documented of return premia in sorts based on price-multiples but there is less evidence about the return patterns in growth characteristics.

We first compute average returns of stocks and mutual funds by characteristic decile. For stocks, we sort stocks according to their characteristic score in each quarter and measure the return over the following quarter. We then compute the value-weighted average return by quarter and then take the mean across quarters. Panel A of Table 10 shows the results for size, book-to-market, Morningstar, momentum, as well as the "growth" and multiples components of the MS index. Results for all individual characteristics components of the MS index are in Table 11. Consistent with the literature, the mean returns of the quintile 5 minus quintile $1 \mathrm{long} / \mathrm{short}$ portfolios of book-to-market

\footnotetext{
${ }^{23}$ We focus on the point estimates of betas but acknowledge that the standard errors are substantial and range from about 0.25 to 0.6 .
} 
and momentum are positive while the size premium is negative. In contrast, there is no evidence of a return premium associated with the Morningstar index as mean returns show no clear pattern across quintiles. The last two columns show results for MULT and GR, the two components of the MS index. Stocks in the lowest MULT quintile have a higher return than those in the highest quintile, so that there is a negative MULT premium. However, the pattern across quintiles is not monotonic. The return premium associated with the growth index, GR, is also negative. Recall the GR is an average of five fundamental growth rates, long-term expected earnings, current earnings, book values, sales, and cash flows. Panel A of Table 11 shows that return premia of all fundamental growth rate are negative, hence we conclude that stocks with low growth rates earn higher returns than stocks with high growth rates. In addition to the book-to-market ratio, long/short portfolios of high earnings-to-price, cash-flow-to-price, and sales-to-price ratios stocks minus stocks with low values of respective priceratios carry a positive return premium, while the expected-earnings-to-price and dividend-price ratios are associated with negative return premia. ${ }^{24}$ Note that the weight of the expected-earnings-to-price ratio in the Morningstar GR index is 50\%, while the other four multiples have a weight of $12.5 \%$. Since the expected-earnings-to-price ratio carries by far the lowest return premium of all price-multiples, it is not surprising that the return premium of the MULT index is negative and that of the MS index close to zero.

The results for mutual funds are in the middle panels of Tables 10 and 11. In each quarter, we sort funds according to their characteristic scores by intervals 1-2, 2-3, 3-4, and 4-5, compute their returns in the following quarter, and then report the average fund returns in each of the four intervals. Intervals that contain on average less than 10 funds per quarter are less reliable and are indicated by $\mathrm{a}^{\dagger}$ superscript. The overall patterns of funds returns sorted by characteristics is less clear-cut than those of stock returns as mean returns are not monotonic in scores for most characteristic. The only exceptions in Panel B of Table 10 is the BM ratio and its return spread of 1.04\% is larger than that for stock returns. Note, however, that there are few mutual funds with a BM score above 4 in our sample, so the mean return of the 4-5 interval is based on few observations. There is no evidence of a return spread associated with the MS and MULT indices. Returns of mutual funds with low momentum scores below 2 are on average negative, however, this result is based on a small number of funds. Returns of mutual funds based on the characteristics in Table 11 exhibit similar patterns. In most cases, the characteristics with positive (negative) return spreads for stocks also have positive (negative) return spreads for mutual funds. For example, the EP, CFP, and SP ratios carry positive returns spreads, while the ÊP and DP ratios carry a negative spread for mutual funds as well stocks. Growth rates are also associated with negative high-minus-low returns in both cases.

Next, we study the characteristics-return link more formally using Fama-MacBeth regressions. Let $\mathbf{X}_{i, t}$ be a vector of characteristics of stock or mutual fund $i$ at time $t$ and let $R_{i, t+1}-R_{f, t+1}$ be the excess return of asset $i$ in quarter $t+1$. In each quarter $t$, we estimate the cross-sectional regression

$$
R_{i, t+1}-R_{f, t+1}=a_{t}+\boldsymbol{\beta}_{t}^{\prime} \mathbf{X}_{i, t}+e_{i, t+1},
$$

\footnotetext{
${ }^{24}$ The data available on Kenneth French's website https://mba.tuck.dartmouth.edu/pages/faculty/ken.french/data_ library.html produces similar results.
} 
for all stocks or funds that are in our sample in the quarter. Sample betas of the characteristics in $\mathbf{X}_{i, t}$

are the time-series averages of $\hat{\boldsymbol{\beta}}_{t}, \hat{\boldsymbol{\beta}}=\sum_{t} \hat{\boldsymbol{\beta}}_{t} / T$. The model is estimated for individual stocks and mutual funds and the results are in Table 12. The first rows of Panels A and B show results for the model with ME, BM, and MOM scores. For stock returns, the book-to-market and momentum coefficients are positive and highly significant, while the size coefficient is negative but insignificant. These results are consistent with the literature (e.g. Lewellen (2015)) as well as with the mean returns reported in Table 8. In the regressions with mutual funds data, the size beta is negative and statistically significant but the beta of the book-to-market is negative but insignificant. Hence, ceteris paribus, high-BM mutual funds do not earn a higher return than low-BM funds, so that there is not value premium for mutual funds even though the value premium for stocks is positive and significant. The momentum beta of mutual funds is positive and of a similar magnitude as that of stocks but only marginally significant.

Next, consider regressions with with ME, MS, and MOM scores. The Morningstar beta of stocks in about half the size of the BM beta in the top row and statistically insignificant indicating that the value premium associated with the MS "value"/"growth" index is smaller than the book-to-market premium. The ME beta is smaller than in the first regression and marginally significant while the momentum beta is slightly higher. The ME and MOM loadings for mutual funds are also largely unchanged compared to the regression with BM instead of MS. However, the mutual fund Morningstar beta is negative confirming the result for the book-to-market ration that there is no "value" premium for mutual funds. In fact, none of the mutual fund betas of price-ratios in regressions with ME and MOM are significant, while the EP, CFP, and SP betas for stocks are positive and significant. The stock beta of $\widehat{E P}$ is negative and strongly significant, which is not surprising since its univariate return premium is also negative (Table 11, Panel A).

The bottom rows in Panels A and B report results for regressions with the two components of the Morningstar index, MULT and GR, in addition to size and momentum scores. The beta of the MULT index that is constructed as an average of price multiples is positive for stocks but negative for mutual funds, in line with the results for individual price multiples. The GR index of growth rates coefficients are negative for stocks as well as mutual funds. However, none of the MULT and GR betas are significant.

\section{Conclusion}

This paper provides a comprehensive analysis of characteristics of mutual fund portfolios. Some facts stand out. First, the BM distribution of mutual funds is strongly skewed towards low BM ratios. While there are many funds that have a BM ratio comparable to that of the L portfolio in HML, there very no funds with a BM ratio close to H. Moreover, the skew towards low BM values is more pronounced for mutual funds than for individual (large) stocks. Second, "growth" funds hold almost exclusively low BM stocks in their portfolios. In contrast, portfolios of "value" funds include stocks across the entire BM distribution. In fact, on average mutual funds hold a higher share of stocks with low BM ratios that stocks with high BM ratios. The BM distributions of ETFs and hedge funds are similar to that of mutual 
funds. Third, mutual funds are on average almost momentum-neutral. While momentum of "growth" funds varies over time, in contrast to momentum of "value" funds, there are very few mutual funds with consistently high momentum. Fourth, size, book-to-market and momentum return spreads are smaller for mutual funds than for individual stocks and insignificant in Fama-MacBeth regressions.

These stylized facts raise a number of questions about active mutual funds:

1. Why is the distribution of mutual fund portfolios so strongly tilted towards low book-to-market ratios and why are there virtually no high BM funds at all even though high BM stocks are associated with higher returns than low BM stocks?

2. Why do funds that label themselves as "value" funds hold more low BM stocks than high BM stocks while "growth" funds hold almost exclusively low BM stocks?

3. Why are portfolios of active mutual funds not more tilted towards characteristics that are associated with high returns, i.e. small, high BM and high momentum stocks?

4. Why don't mutual funds combine multiple strategies (e.g., high BM/high momentum) that have been shown to be more profitable than univariate strategies (Asness, Moskowitz, and Pedersen (2013))?

5. Why do mutual funds and ETFs follow strategies that emulate the Morningstar value/growth definition even though it has no return premium?

Our results have also broader implications for equity markets. Aside from the issue of delisting of funds and the implied survivorship bias, the literature takes the set of mutual funds as given and there is little research about why new funds are created. In other words, what economic forces determine the set of funds and strategies that we observe? Is the mutual fund market driven by investor's demand for certain strategies or by the supply of profitable strategies? Are there so many "growth" funds because investor's demand for "growth" stocks and the absence of high-BM funds is due to low demand? How can the stylized facts presented in this paper be reconciled with the evidence that capital flows react strongly to past performance? Since returns of high-BM stocks are on average higher than returns of low BM stocks, capital should flow from low-BM funds into highBM mutual funds over the sample and the number of high-BM funds should increase relative to the number of low-BM funds. Yet, there is no evidence support this conjecture.

Portfolios of active mutual funds account for about 13\% of total market cap (as of 2016) and their portfolio allocations are likely to have an effect on equilibrium prices. Whether factor premia are permanent or diminishing over time due to higher demand for underpriced stocks is still an open question. Our results suggest that active mutual funds do not systematically hold the stocks with characteristics associated with high returns and thus are unlikely to contribute to any shrinking of factor premia during the sample period. Our sample of mutual funds and ETFs is exhaustive but we only observe portfolio holdings of a very small subset of small hedge funds, so we cannot rule out that (larger) hedge funds tilt their portfolios towards profitable characteristics. 


\section{References}

Agarwal, Vikas, Vyacheslav Fos, and Wei Jiang, 2013, Inferring reporting-related biases in hedge fund databases from hedge fund equity holdings, Management Science.

Agarwal, Vikas, Wei Jiang, Yuehua Tang, and Baozhong Yang, 2013, Uncovering hedge fund skill from the portfolio holdings they hide, Journal of Finance.

Asness, Clifford, Tobias J. Moskowitz, and Lasse Heje Pedersen, 2013, Value and Momentum Everywhere, The Journal of Finance 68, 929-985.

Becker, Connie, Wayne Ferson, David H. Myers, and Michael J. Schill, 1999, Conditional market timing with benchmark investors, Journal of Financial Economics.

Berk, J.B., and R.C. Green, 2004, Mutual fund flows and performance in rational markets, Journal of Political Economy 112, 1269-1295.

Berk, Jonathan B., and Jules H. van Binsbergen, 2015, Measuring skill in the mutual fund industry, Journal of Financial Economics 118, 1-20.

Cremers, Martijn K.J., and Antti Petajisto, 2009, How active is your fund manager: A new measure that predicts performance, Review of Financial Studies 22, 3329-3365.

Daniel, K., M. Grinblatt, S. Titman, and R. Wermers, 1997, Measuring mutual fund performance with characteristic-based benchmarks, Journal of Finance 52, 1035-1058.

Fama, Eugene F., and Kenneth R. French, 2010, Luck versus Skill in the cross-section of mutual fund returns, Journal of Finance 65, 1915-1947.

Jensen, Michael C., 1968, The performance of mutual funds in the period 1945-1964, Journal of Finance 23, 389-416.

Kacperczyk, Marcin, Stijn V. Nieuwerburgh, and Laura Veldkamp, 2014, Time-varying fund manager skill, Journal of Finance 69, 1455-1484.

Lewellen, Jonathan, 2015, The Cross-section of Expected Stock Returns, Critical Finance Review 4, $1-44$.

Pástor, Lubos, Robert F. Stambaugh, and Lucien A. Taylor, 2015, Scale and skill in active management, Journal of Financial Economics 116, 23-45.

Pástor, Lubos, Robert F. Stambaugh, and Lucian A. Taylor, 2020, Fund tradeoffs, Journal of Financial Economics.

Wermers, Russ, 2000, Mutual fund performance: An empirical decomposition into stock-picking talent, style, transactions costs, and expenses, Journal of Finance 55, 1655-1695. 


\section{Appendix A. Data and Fund Selection}

\section{Mutual Funds}

Our sample of mutual funds builds upon several databases. Net assets (TNA), investment objective codes, realized returns, expense ratios, turnover, launch dates, and other fund characteristics are collected from the Center for Research in Security Prices (CRSP) Survivorship Bias Free Mutual Fund Database. After collecting these characteristics at the CRSP_FUNDNO ${ }^{25}$ level, we merge the resulting table to the Wharton Financial Institution Center Number identifiers (WFICN), which provides a common identifier for different share classes investing in the same portfolio. This is carried out using the MFLINKS table developed by Wermers (2000) and available on WRDS. We then collapse this database to the WFICN level by aggregating the total net assets across different share classes. Other quantitative characteristics are aggregated using the average of the characteristic across share classes, weighted by their total assets. Qualitative characteristics are aggregated using the characteristic of the oldest share available.

We collect holdings data from two different sources. First, we take data on portfolio weights from CRSP, merging it with the WFICN codes using the MFLINKS table. CRSP provides the most comprehensive data about mutual funds holdings in terms of number of portfolios, with the downside that it is available only since 2002. In order to cover the largest time spam possible, we also use data from the Thomson Reuters Mutual Fund Holdings (formerly CDA/Spectrum S12). Thomson Reuters tables contain data from funds holdings since 1980, when the U.S. Securities and Exchange Commission (SEC) made the disclosure of mutual funds portfolios mandatory. We merge the Thomson Reuters fund codes to the WFICN codes using the MFLINKS table. Finally, if a given fund have holdings available in both CRSP and Thomson Reuters, we keep only the CRSP holdings. In practice, discrepancies between the CRSP holdings and the Thomson Reuters at the WFICN level are very rare.

In the final step of our database construction, we merge the non-portfolio characteristics to the portfolio characteristics at the WFICN level. We then apply the following screens to select the funds of our benchmark sample of mutual funds:

- Discard ETFs and pure index funds

- Discard funds that, in the average, invest in less than 10 stocks in a given quarter

- Discard funds with average assets smaller than \$5M

- Discard funds with average weight in domestic equities smaller than $50 \%$

- Discard funds with less than 16 quarters of observations

- Discard funds not classified as "Domestic Equity" funds according to the CRSP classification CRSP_OBJ_CD

Table D.1 reports the number of funds remaining after each one of the screens is applied.

\section{ETFS}

The construction of the ETF database is similar to the construction of the database of mutual funds, with three basic differences. First, instead of identifying fund by their WFICN, we identify them by their CRSP_PORTNO. This choice was motivated by the fact that MFLINK does not cover all ETFs. Second, given that ETFs are reasonably recent, we use portfolio holdings data from CRSP instead of Thomson-Reuters.

\footnotetext{
${ }^{25}$ Unique identifier created by CRSP for each mutual fund.
} 


\section{Hedge Funds}

We use two different samples of hedge funds in this paper. The first sample comes from the Hedge Funds Research (HFR), with information about performance, strategy, net assets (TNA), fees and other fund characteristics. We include only US-based funds investing 50\% or more of their assets in US stocks, obtaining a sample with 973 hedge funds.

The HFR data do not include portfolios holdings. We address this limitation by building a second hand-collected sample of hedge funds from the 13F filings of institutional institutional investors managing more than $\$ 100$ million in value. After restricting this universe to institutional investors that (i) are hedge funds, and (ii) manage a single fund, we obtained quarterly holdings of 114 hedge funds. 


\section{Appendix B. Definition of Fund Types}

We classify the mutual funds and the ETFs in our sample in five investment style groups: "growth", "value", "balanced", “cap-based", and "sector":

1. First, we use key words in the name of the fund to classify funds:

(a) Funds with the term "value" in their names are classified as "value" funds

(b) Funds with the term "growth" in their names are classified as "growth" funds

(c) Funds with the terms "metal”, "natural”, "resource”, "energy”, "industrials”, "financ”, “tech”, "utilit”, “communication”, “consumer”, “cyclical”, “defensive”, “estate”, "health”, "infrastructure", or "sector" are classified as "sector" funds.

2. Funds that could not be classified only with their names are then classified using one of the following objective codes: CRSP Objective Code, the Wiesenberger Objective Code, the Lipper Objective Code, or the Strategic Insight Objective code:

(a) A fund is classified as a "value" fund if the Strategic Insight Objective is 'OPI', or if the Wiesenberger Objective Code is 'IEQ', or if the Lipper Objective Code is 'EI', or if the CRSP Objective Code is 'EDYI'.

(b) A fund is classified as a "growth" fund if the Strategic Insight Objective code is one of 'AGG','GRO', or if the Wiesenberger Objective Code is one of 'G', 'LTG', 'MCG', or if the Lipper Objective Code is one of 'CA', 'G', or if the CRSP Objective Code is 'EDYG'.

(c) A fund is classified as a "balanced" fund if the Strategic Insight Objective code is one of 'GRI', 'ING', or if the Wiesenberger Objective Code is 'GCI', or if the Lipper Objective Code is 'GI', or if the CRSP ObjectiveCode is 'EDYB'.

(d) A fund is classified as a "balanced" fund if the CRSP Objective Code is one of 'EDCL', 'EDCM', 'EDCS', 'EDCI', 'EDYG', 'EDYB', 'EDYH', 'EDYS', 'EDYI'.

(e) A fund is classified as a "sector" fund if the Strategic Insight Objective code is one of 'UTI', 'TEC', 'SEC', 'HLT', 'FIN', 'ENV', or if Wiesenberger Objective Code is one of 'UTL', 'TCH', 'HLT', 'FIN', 'ENR', or if the CRSP Objective Code is one of 'EDSH', 'EDSF', 'EDSN', 'EDST', 'EDSU', 'EDSG', 'EDSC', 'EDSS', 'EDSI', 'EDSM', 'EDSA'.

(f) If the fund could not be classified at this point, the fund is classified as "unclassified"

If the classification of a fund changes over the life of the fund, we require the classification to be consistent for at least $75 \%$ of the observations. If this is not the case, we designate the fund as "unclassified". 


\section{Appendix C. Construction of Characteristics}

- The market equity (ME) of each stock is defined as the product between the number of shares outstanding and the closing stock price.

- The momentum index (MOM) of each stock is defined as the return over the past twelve month, ignoring the immediate past month (2-12).

- The earnings-to-price ratio (EP) of each stock is defined as the total net income scaled by the total market equity.

- The earnings-to-price ratio $\hat{\mathbf{E P}}$ of each stock is the most recent share price to the IBES expected earnings per share for the current fiscal year.

- The sales-to-price ratio (SP) of each stock is defined as the total annual scaled scaled by the total market equity.

- The cashflow-to-price ratio (CFP) is defined as the income before extraordinary items plus depreciation and amortization scaled by the total market equity.

- The dividend-to-price ratio (DP) is defined as the total dividends paid in the previous 12 months, scaled by the total market equity.

- The expected long term earnings growth (ELTG) is the percentage difference between the IBES long term (three- to five-year) expected earnings per share and the current earnings per share.

- The earnings growth (EG) is the percentage growth in the total net income.

- The growth in sales (GRS) is the percentage growth in the total sales.

- The growth in book value (GRB) is the percentage growth in the total book value of the firm.

- The growth in the cashflow (GRCF) is defined as the percentage growth in the total cashflow. The total cashflow is the income before extraordinary items plus depreciation and amortization.

- The multiples index (MULT) is defined as

$$
\text { MULT }=0.5 \text { PR( } \mathrm{EP})+0.125 \mathrm{PR}(\mathrm{BM})+0.125 \mathrm{PR}(\mathrm{SP})+0.125 \mathrm{PR}(\mathrm{CFP})+0.125 \mathrm{PR}(\mathrm{DP}),
$$

where $\operatorname{PR}(\cdot)$ is the percentile rank function between 1 and 100.

- The growth index (GR) is defined as

$$
\mathrm{GR}=0.5 \mathrm{PR}(\mathrm{ELTG})+0.125 \mathrm{PR}(\mathrm{EG})+0.125 \mathrm{PR}(\mathrm{GRS})+0.125 \mathrm{PR}(\mathrm{GRCF})+0.125 \mathrm{PR}(\mathrm{GRB}),
$$

where $\operatorname{PR}(\cdot)$ is the percentile rank function between 1 and 100.

- The Morningstar index (MS) is defined as the difference between the multiples index (MULT) and the growth index (GR), so it ranges from -100 to 100.

- The MSCI quality index (QUAL) for each stock is calculated by combining Z-scores of three winsorized fundamental variables, namely Return on Equity, Debt to Equity and Earnings Variability. After standardizing each of the three variable values for each security, we calculate a composite Quality Z-score for each security. The Quality Z-scores are computed by averaging the $Z$ scores of all the three fundamental variables. The Quality score is then computed from the composite Quality Z-score as follows:

$$
\text { Quality }= \begin{cases}1+Z & \text { if } Z \geq 0 \\ (1-Z)^{-1} & \text { if } Z<0\end{cases}
$$


- The operating profitability (OP) for each stock is defined as the total revenue net of cost of goods sold and net of selling, general, and administrative expenses, scaled by the total book value.

- The investment index (INV) for each stock is defined as the change in total assets divided by the lagged total assets.

- The Pastor-Stambaugh Liquidity Index (PSLIQ) is defined for each stock as follow. We run one regression for each calendar month based on each stock's daily return, using the current daily return in the left-hand side. The right-hand side variables are the lagged daily return as well as the lagged daily return interacted with the lagged traded dollar volume. The coefficient of the interaction term is the measure of liquidity - for each stock and each month.

- The turnover (TURN) for each stock is defined the monthly traded volume scaled by the total number of shares outstanding.

- The traded volume in dollars (DVOL) is defined as the number of shares traded in a given month multiplied by the closing stock price. 


\section{Figure 2: Characteristics of "Growth Fund of America” (AGTHX)}

Panel A: Characteristics Scores

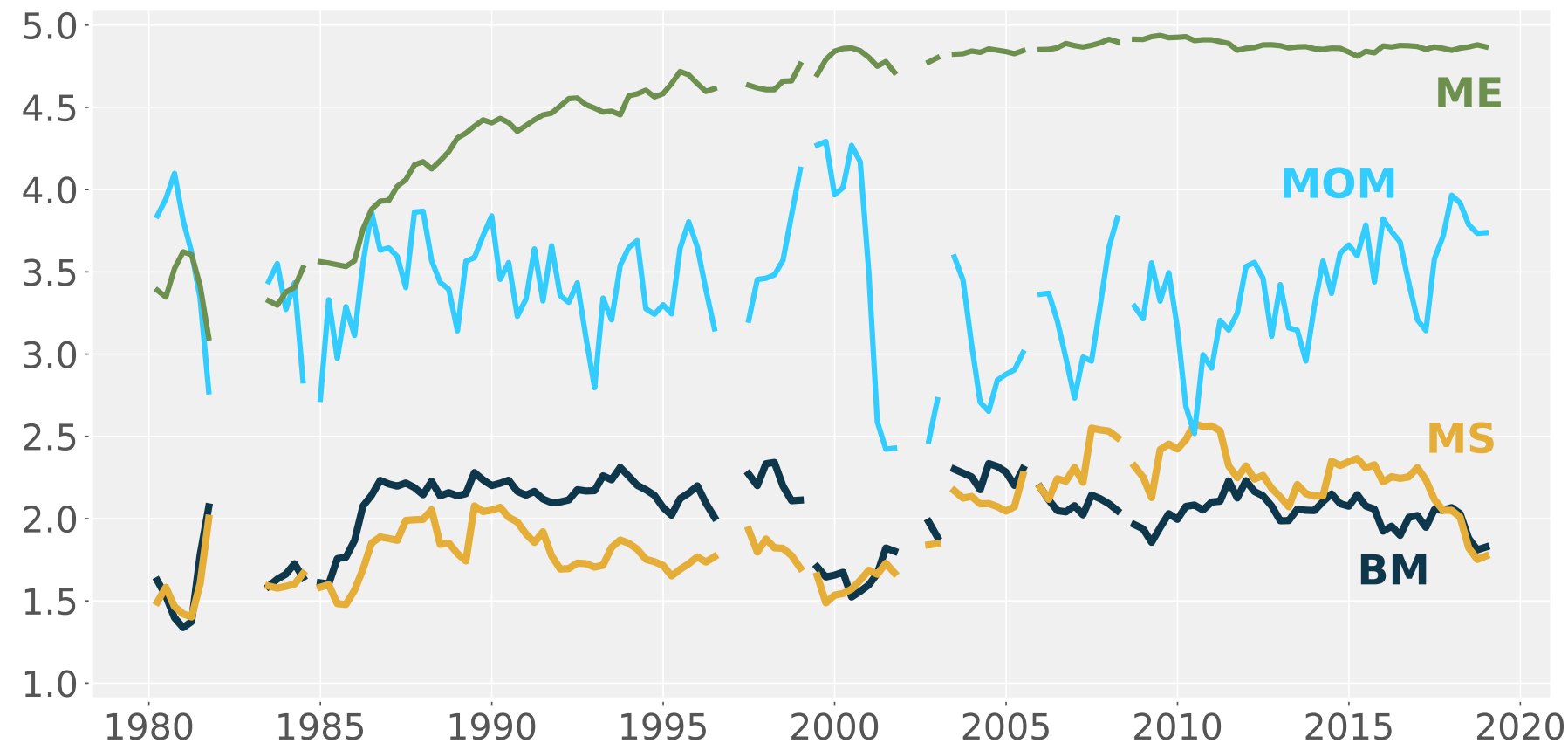

Panel B: Market-adjusted Characteristics

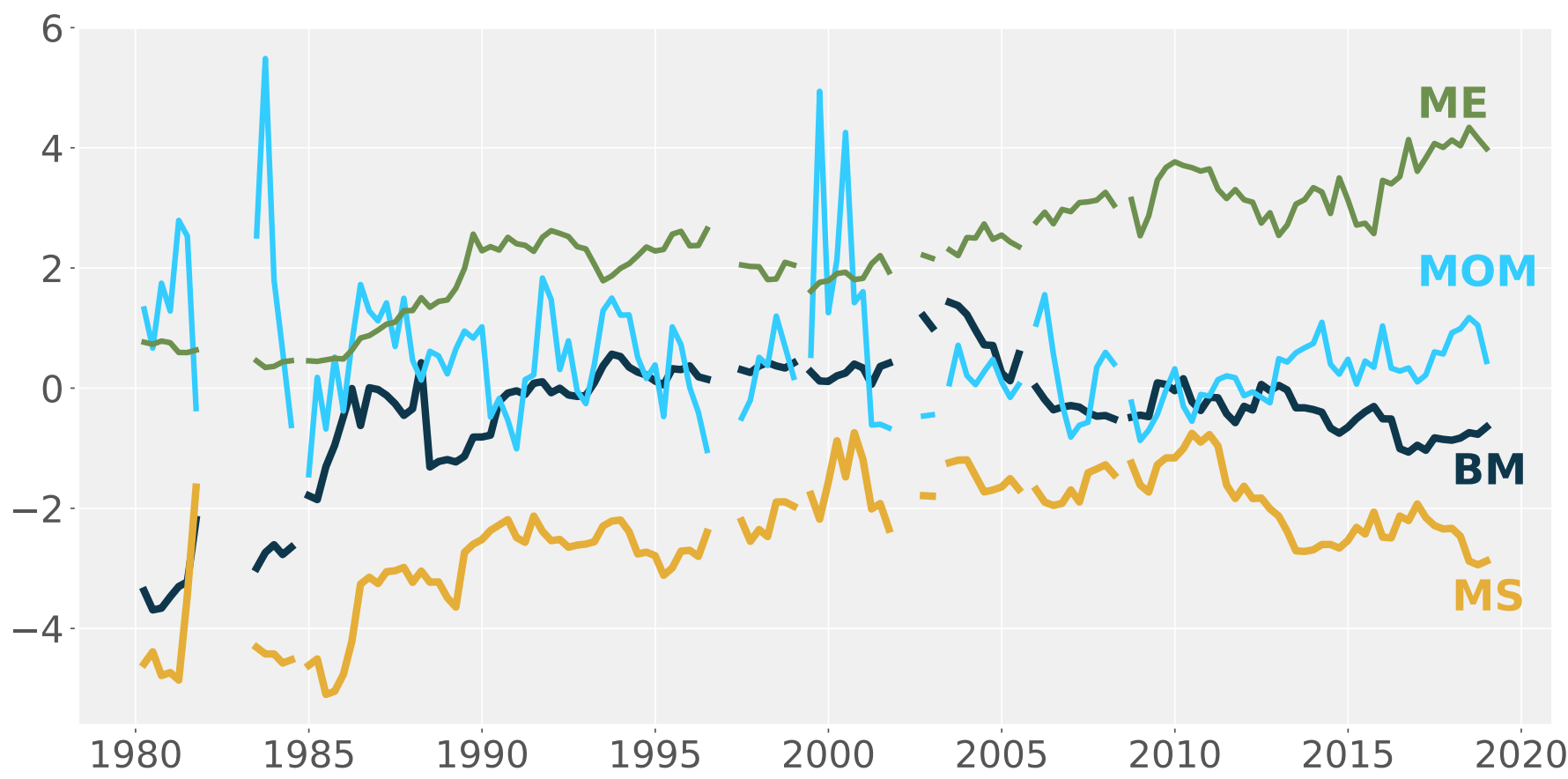

Note: This figure shows the time series of ME, BM, MS and MOM characteristics of the "Growth Fund of America"(AGTHX) mutual fund. Panel A shows the characteristic scores. The market-adjusted characteristics are normalized to a unit standard deviation and are plotted in Panel B. 
Figure 3: Characteristics of Mutual Funds

Panel A: ME

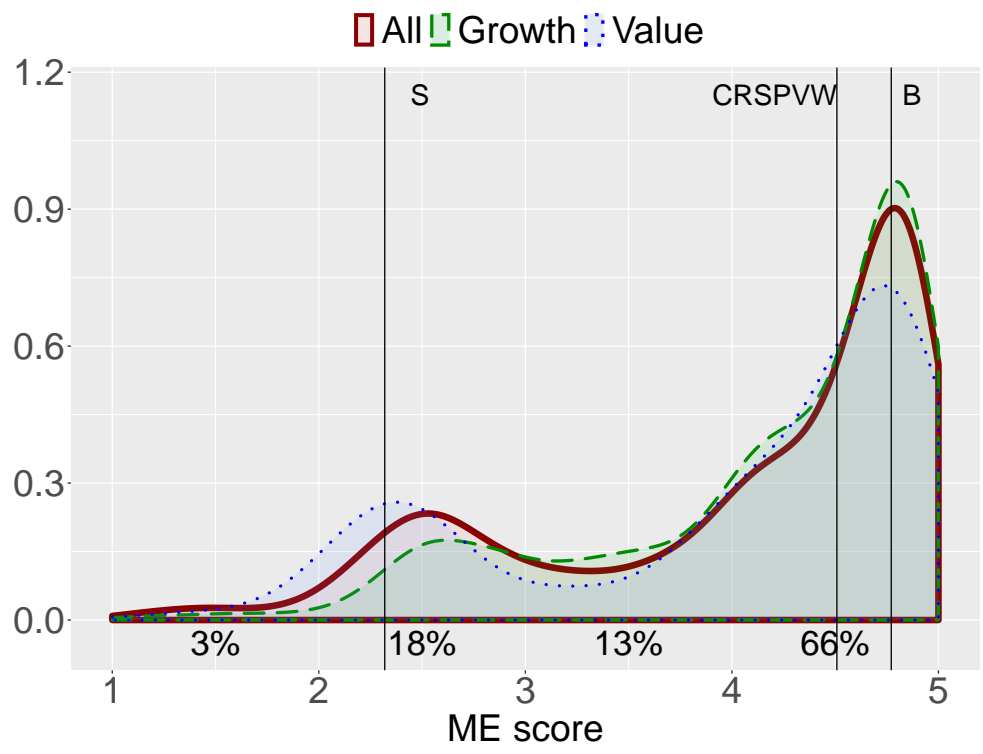

Panel C: MS

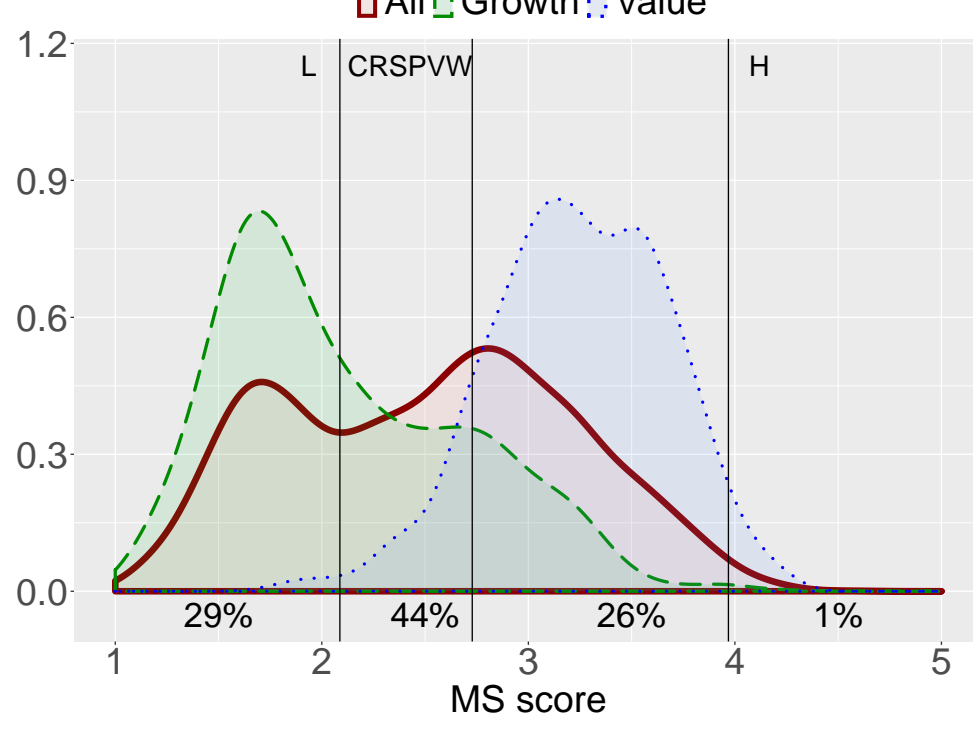

Panel B: BM

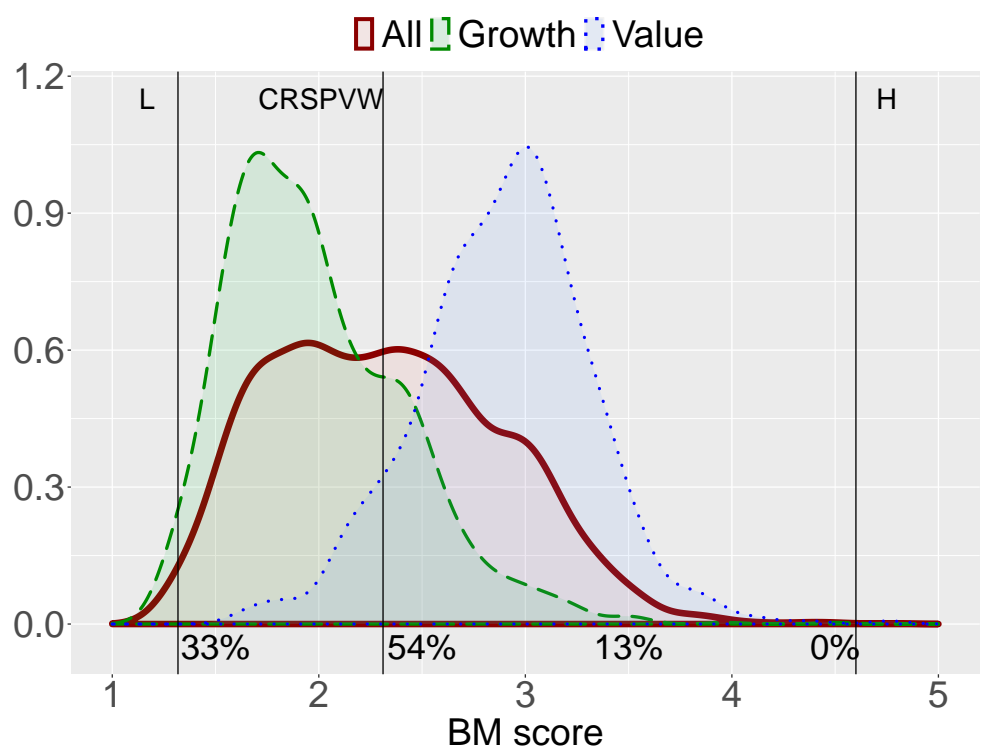

Panel D: MOM

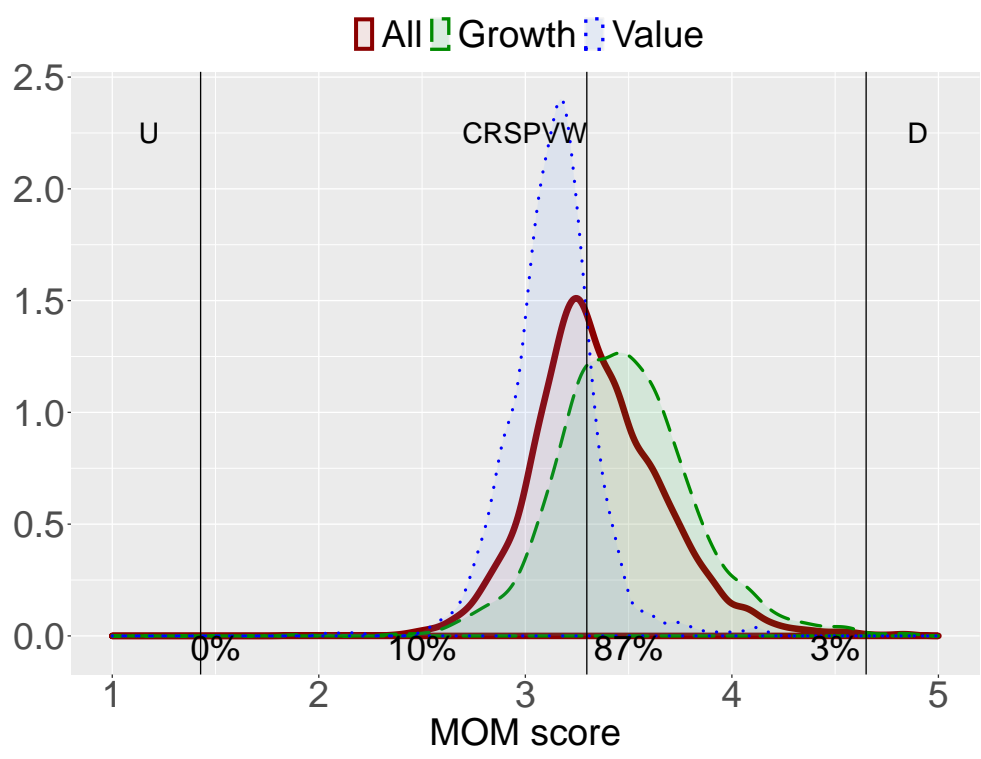

Note: This plot shows the histograms of the distribution of average size (ME), book-to-market (BM), Morningstar index (MS) and momentum (MOM) characteristics of mutual funds over the periods that the fund is in the sample. In each quarter, the fund characteristics are computed as the value-weighted averages of scores of holdings of the fund. The scores are computed using Fama-French quintile breakpoints. An index of ' 1 ' indicates firms in the lowest B/M quintile and firms with a score of ' 5 ' are in the highest $\mathrm{B} / \mathrm{M}$ quintile. The solid black line is the histogram of all mutual funds, the dashed green line is for 'growth' funds fund and the dashed blue line is for 'value' funds. The vertical lines indicate the average score of the CRSP-VW index and the corresponding "high" and "low" portfolios of Fama-French long/short portfolios. The sample is from 1980Q1 to 2018Q4. 


\section{Figure 4: Histograms - Characteristics of Mutual Funds and Stocks}

\section{Panel A: Size (ME)}

DMFs!IStocks

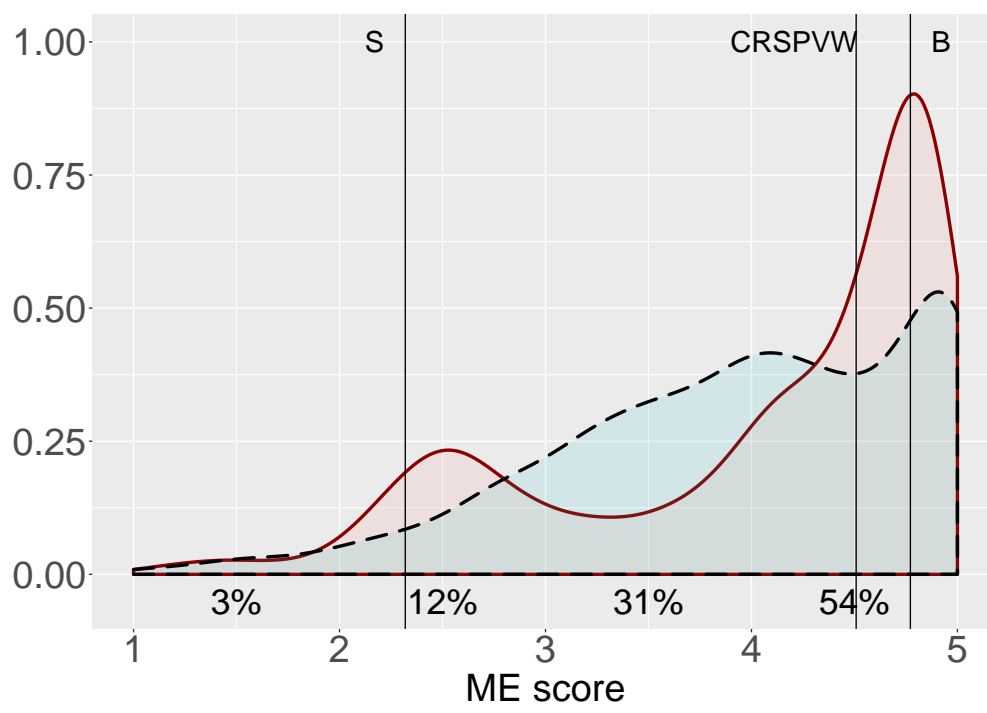

Panel C: Morningstar (MS)

DMFs I]Stocks

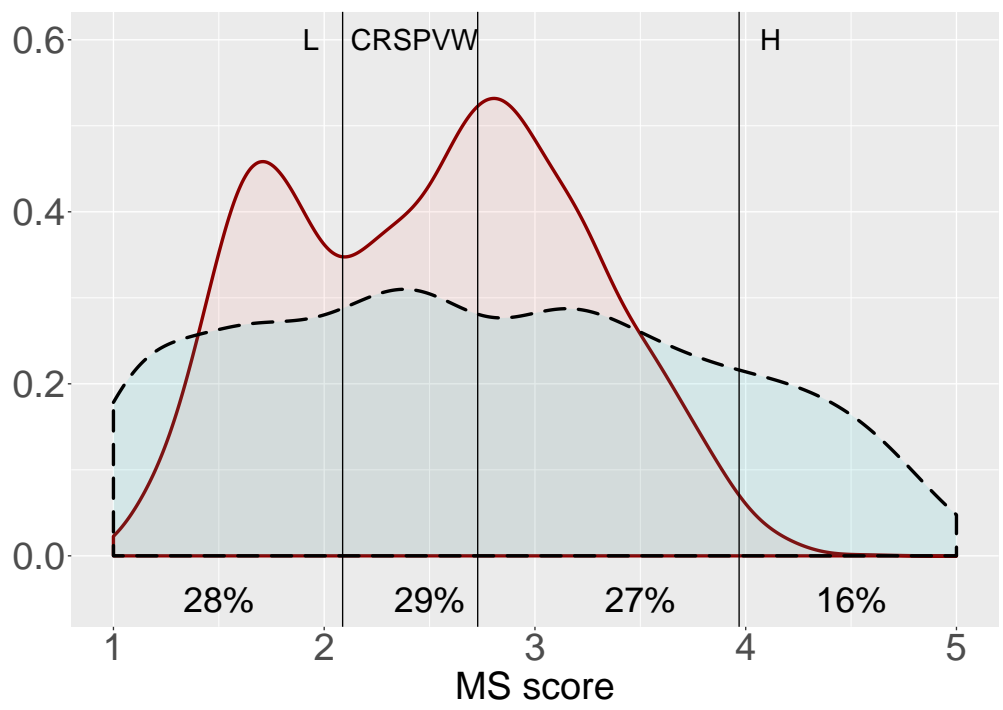

Panel B: Book-to-Market (BM)

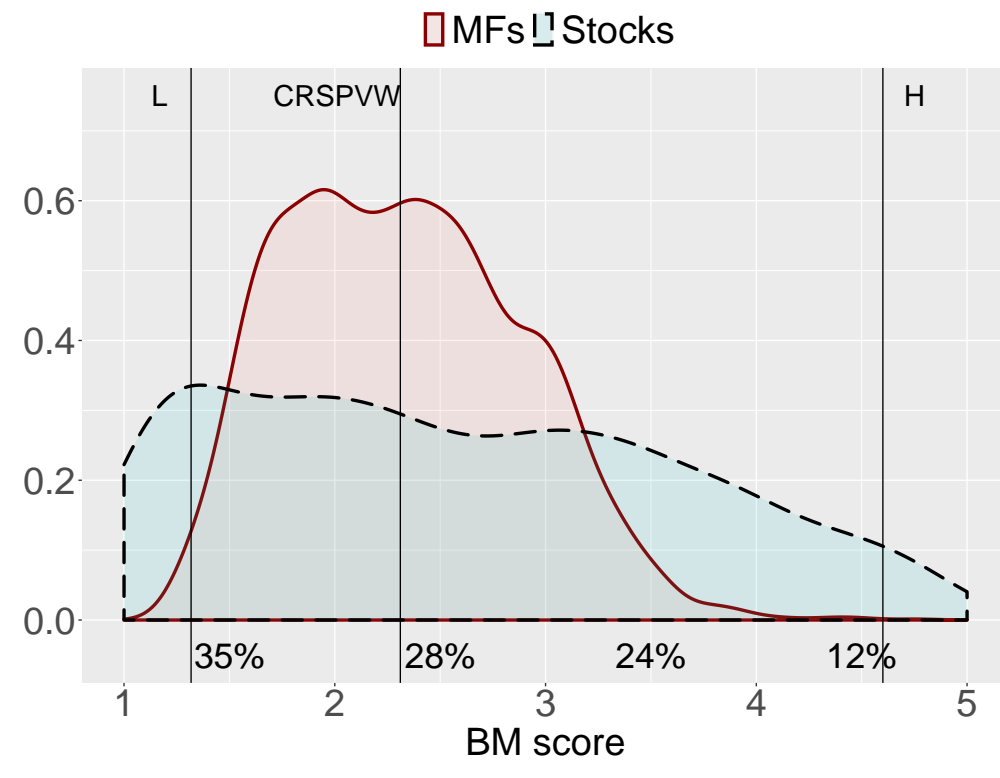

Panel D: Momentum (MOM)

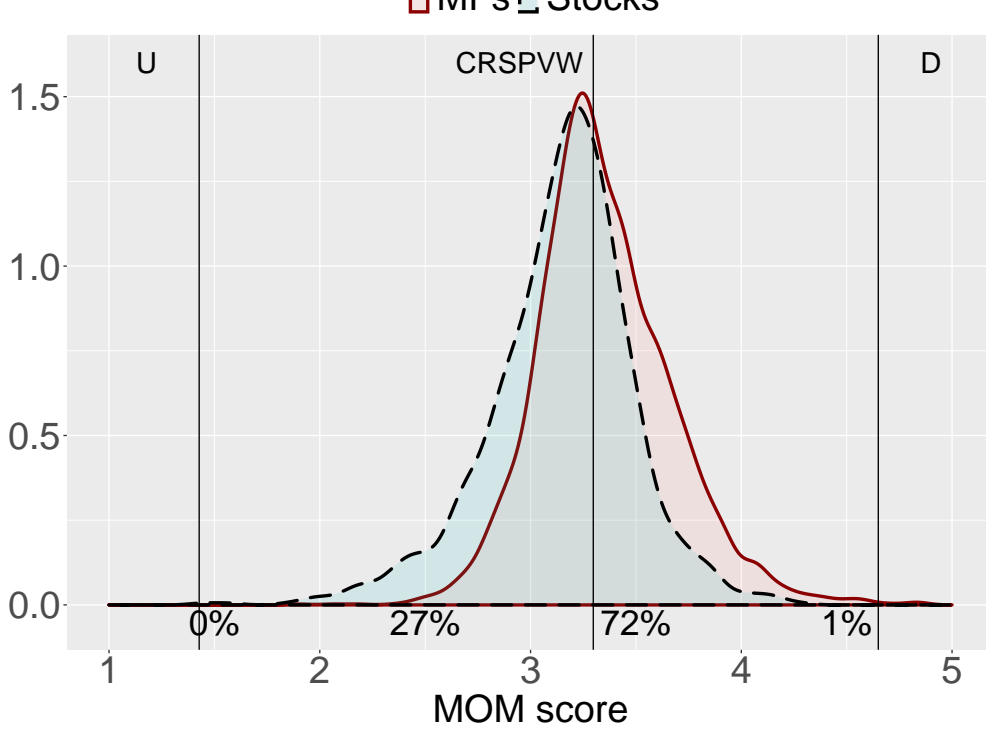

Note: This plot shows the histograms of the distribution of average size (ME), book-to-market (BM), Morningstar index (MS) and momentum (MOM) characteristics of mutual funds over the periods that the fund is in the sample as well as the histogram of average characteristics for individual S\&P500 stocks. In each quarter, the fund characteristics are computed as the value-weighted averages of scores of holdings of the fund. The scores are computed using Fama-French quintile breakpoints. An index of ' 1 ' indicates firms in the lowest B/M quintile and firms with a score of ' 5 ' are in the highest B/M quintile. The solid black line is the histogram stocks and the dashed line is for mutual funds. The vertical lines indicate the average score of the CRSP-VW index and the corresponding "high" and "low" portfolios of Fama-French long/short portfolios. The sample is from 1980Q1 to 2018Q4. 
Figure 5: Histograms - Characteristics of Hedge Funds and ETFs

\section{Panel A: ETF - BM}

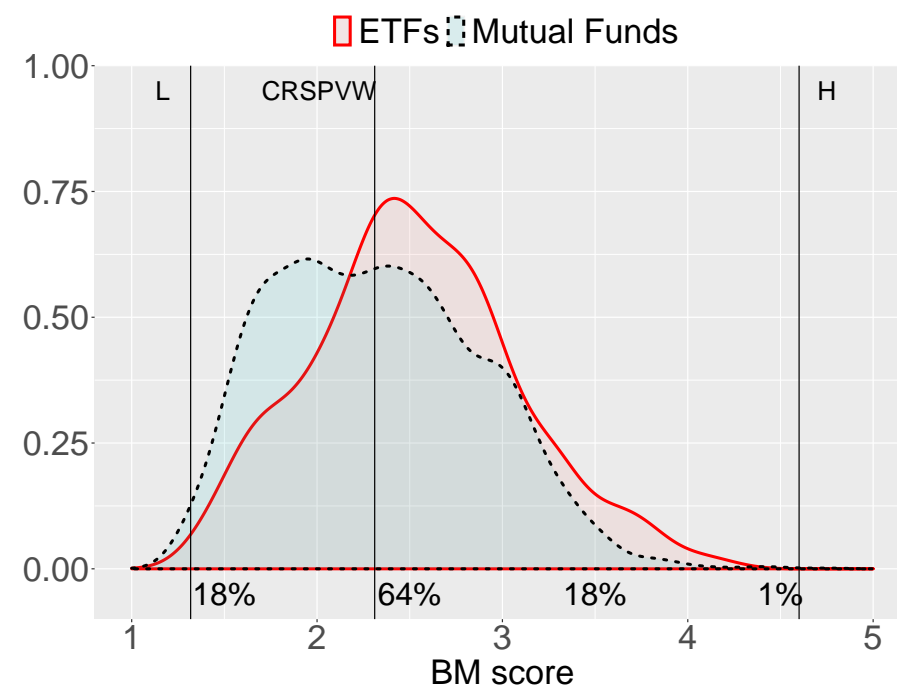

Panel C: Hedge Funds - BM

$\square$ Hedge Funds:: Mutual Funds

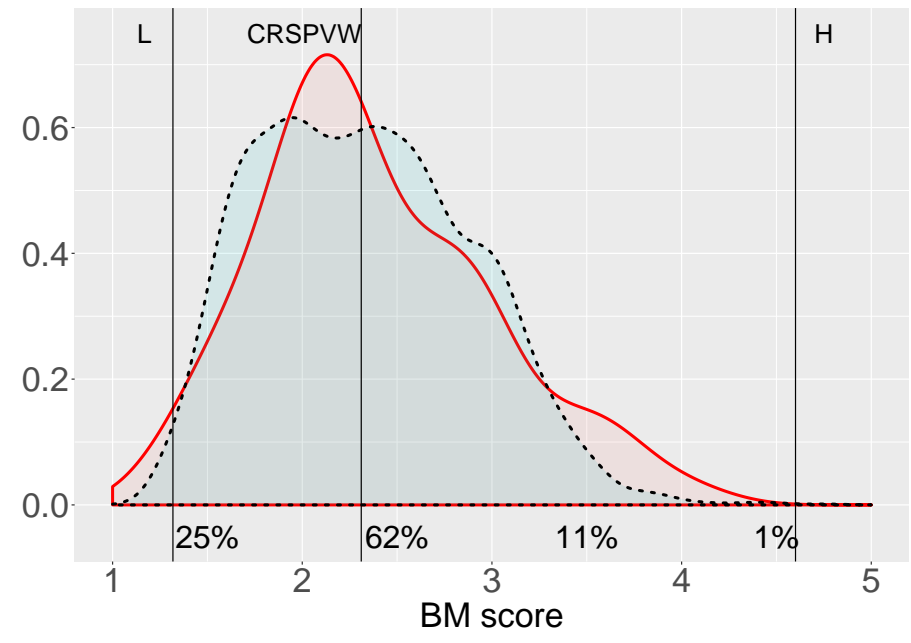

Panel E: All MF - BM

$\square$ All Mutual Funds: Mutual Funds

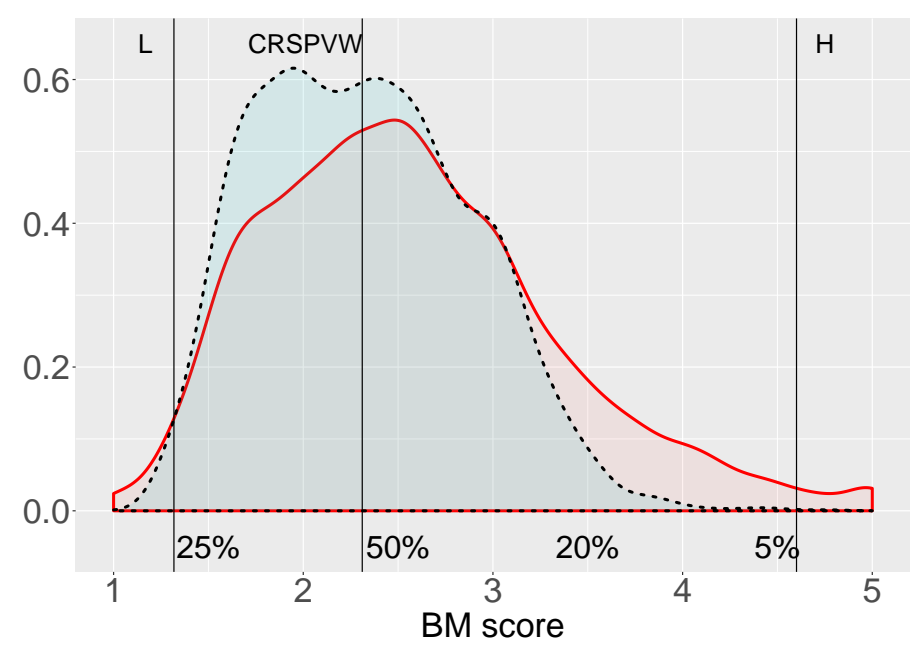

Panel B: ETF - MS

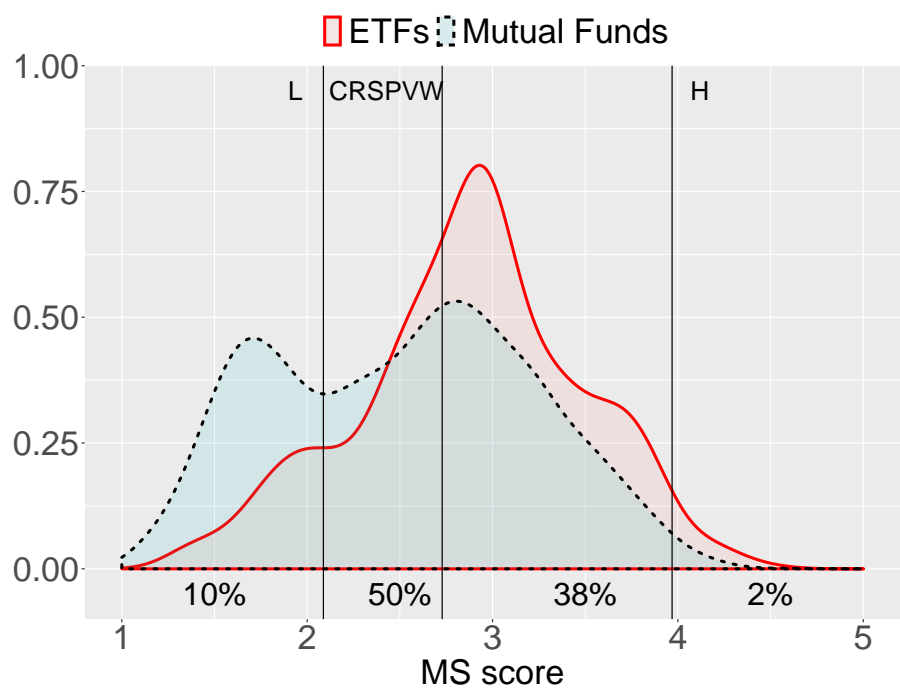

Panel D: Hedge Funds - MS

$\square$ Hedge Funds:: Mutual Funds

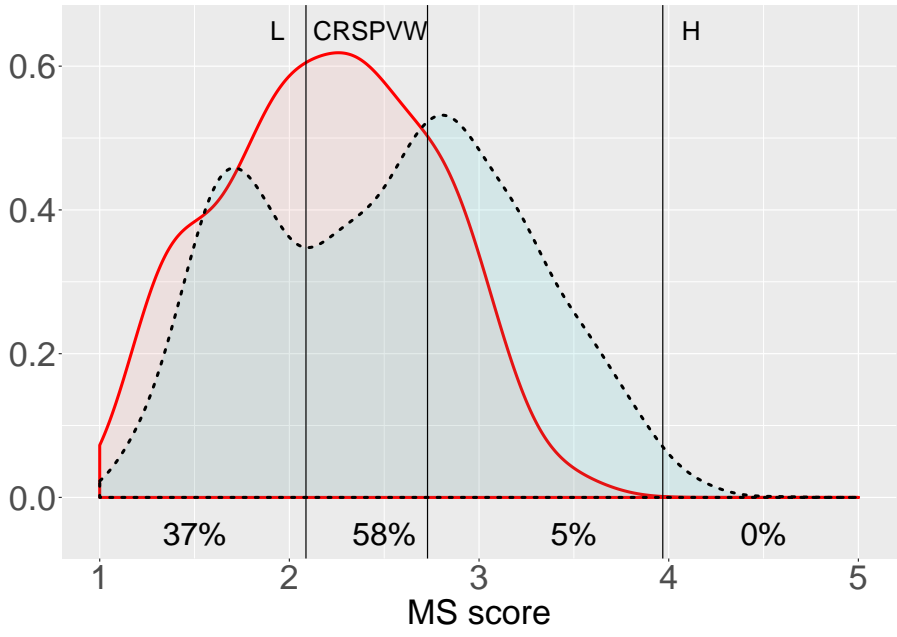

Panel F: All 13F - BM

प13F institutions : Mutual Funds

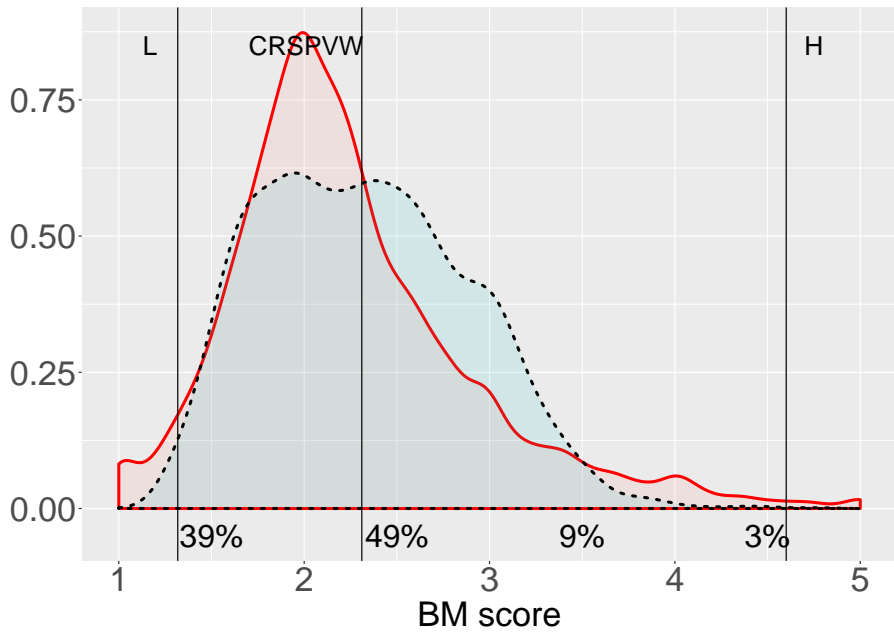


Note for Figure 5: The figure shows histograms of characteristic scores of ETFs, hedge funds, and 13F institutions. Panels A to D show the histograms of the distribution of average book-tomarket (BM) and Morningstar index (MS) characteristics of ETFs and hedge funds, respectively. Panels A and B are ETF histograms (for all, 'value' and 'growth' ETFs) and Panels C and D are HF histograms (dashed lines and solid lines for mutual funds). Panels E and F show the BM distribution of all mutual funds (i.e. without any screens) and all 13F filing institutions. The vertical lines indicate the average score of the CRSP-VW index and the corresponding "high" and "low" portfolios of Fama-French long/short portfolios. The sample is from 1980Q1 to $2018 \mathrm{Q} 4$. 
Figure 6: Characteristics of Mutual Funds - Robustness

Panel A: Other Price Ratios

varable $B M ! I E P$ ICFP $D D P$ SP

0.75

0.50

0.25

0.00

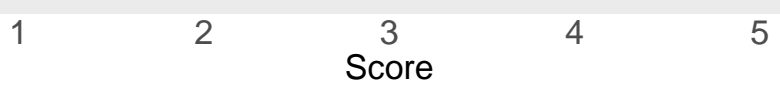

Panel C: Adjusted BM

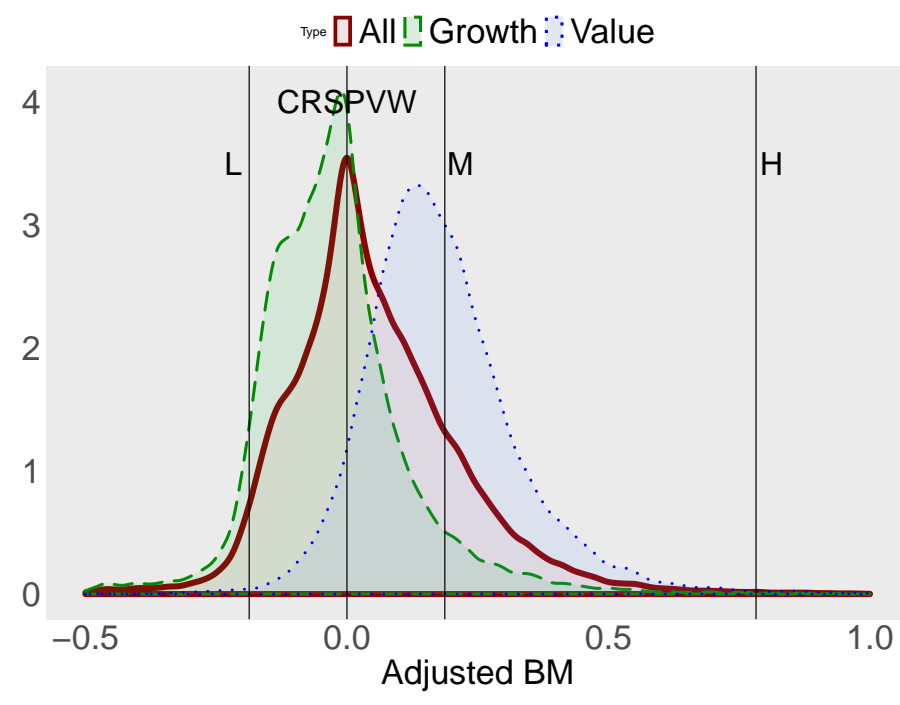

Panel E: Index \& Sector MF

DIndex Funds I] Mutual Funds Sector Funds

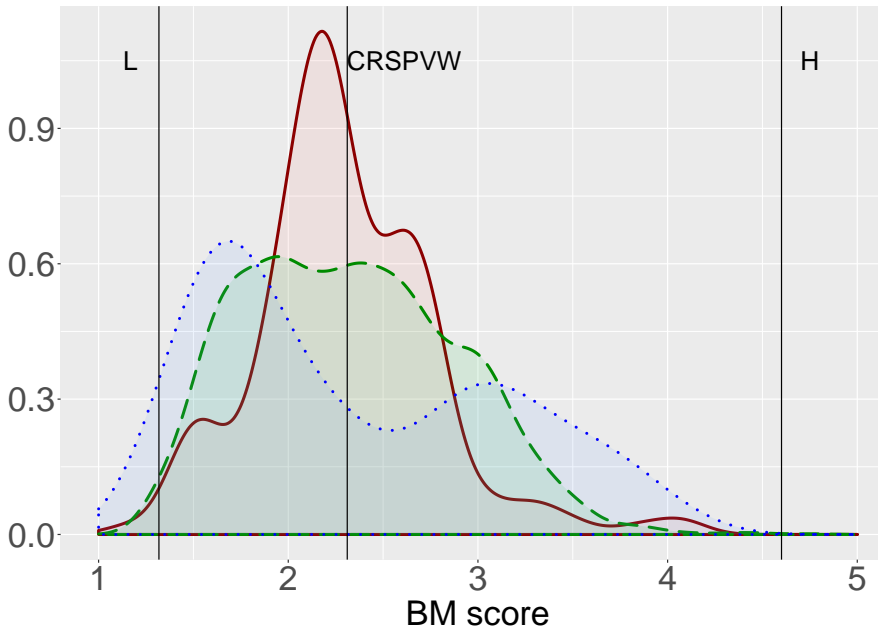

Panel B: Fund/Date obs.

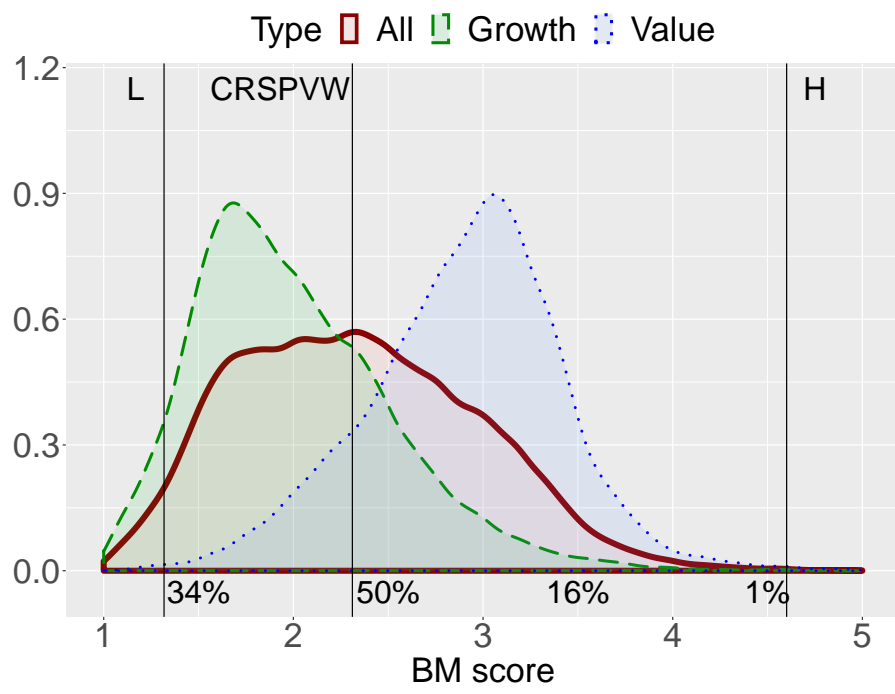

Panel D: AUM-weighted

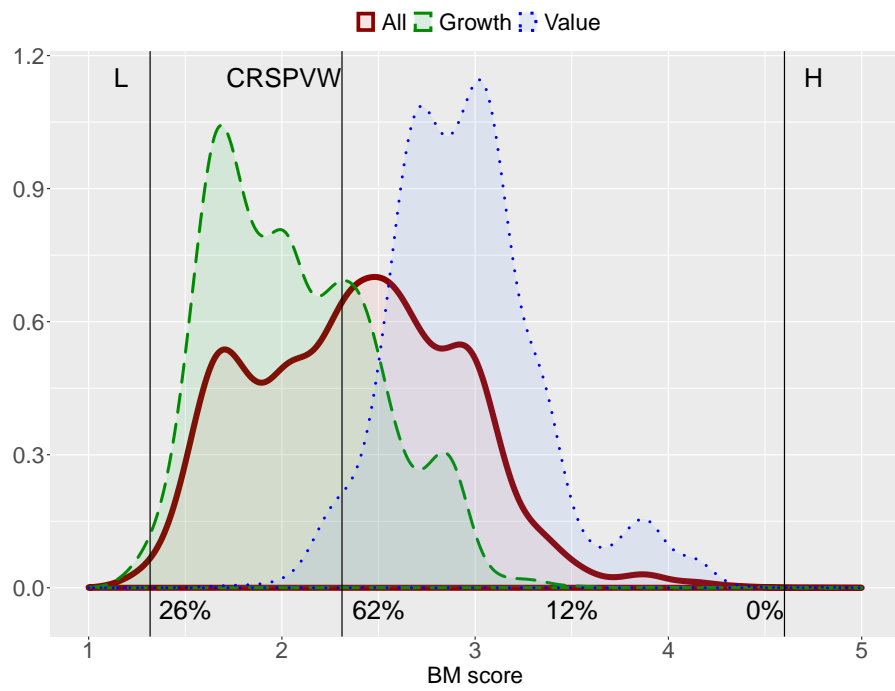

Panel F: Subsamples

प1990!|2000 $2010 \quad 2018$

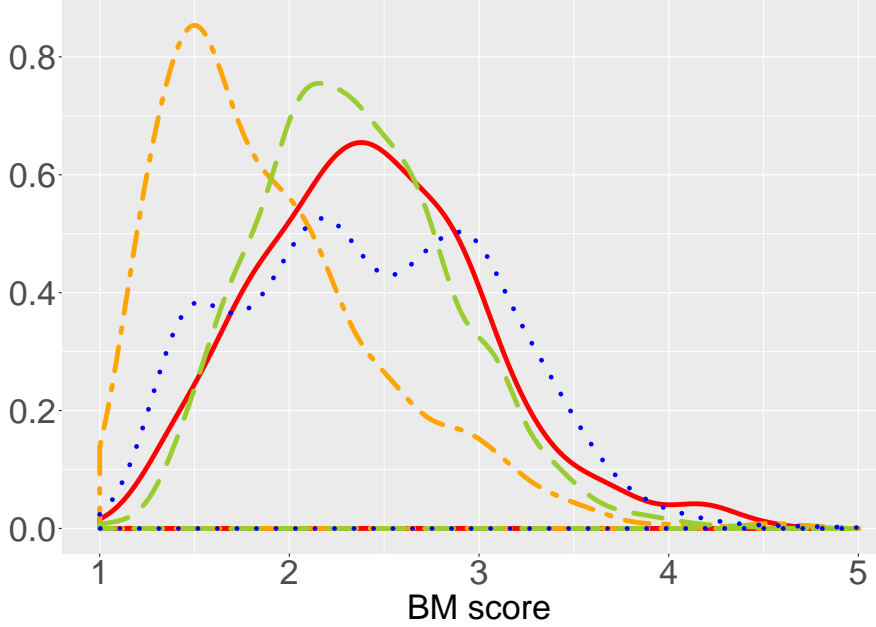

Note: This plot shows the histograms of the characteristic distributions of the earnings/price (EP) ratio, fund/date $\mathrm{BM}$, the adjusted BM ratio, AUM-weighted BM, BM for all mutual funds, including index and sector funds, and the BM in four quarters. The sample is from 1980Q1 to 2018Q4. 
Figure 7: Mutual Funds by BM Scores over Time

Panel A: Number of MFs

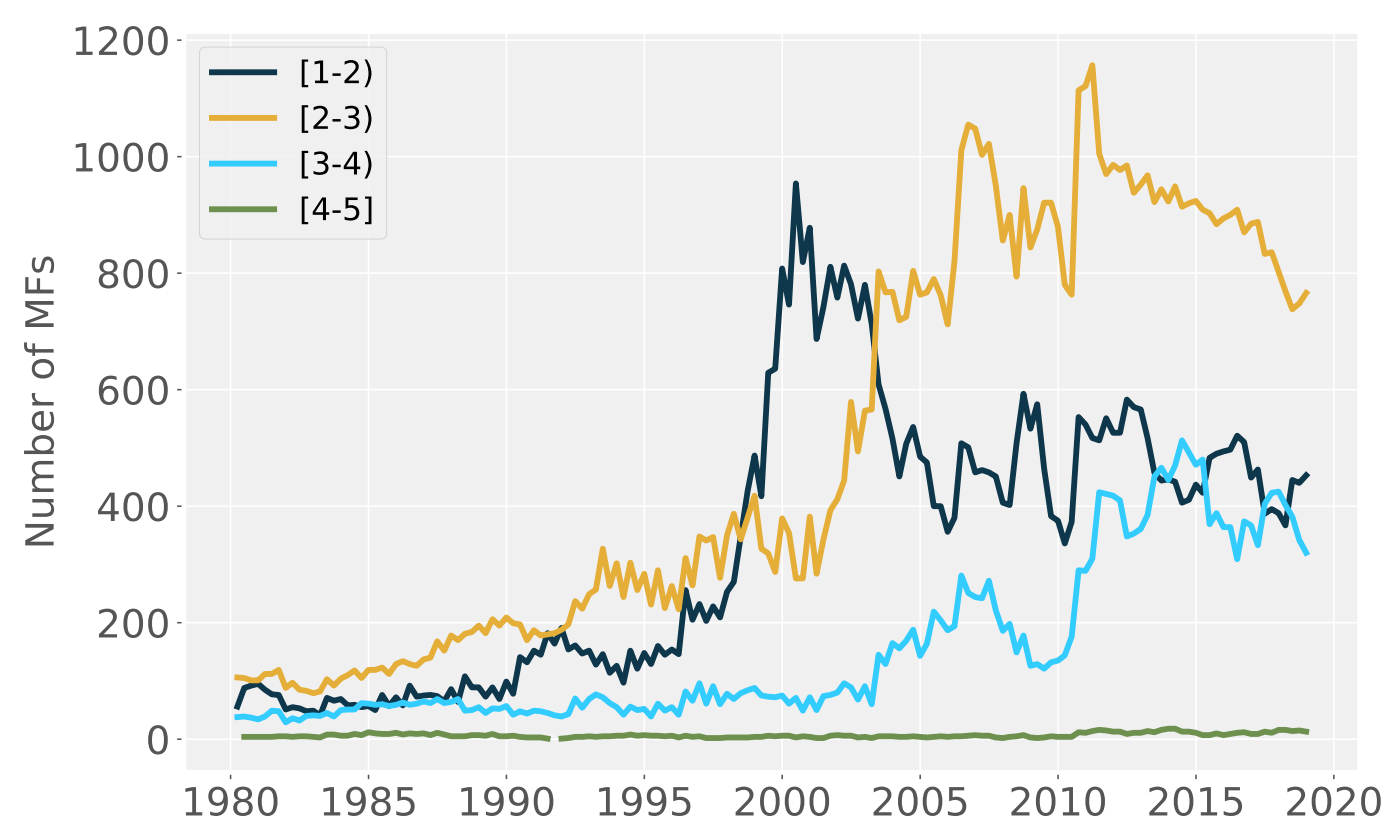

Panel B: TNA of MFs

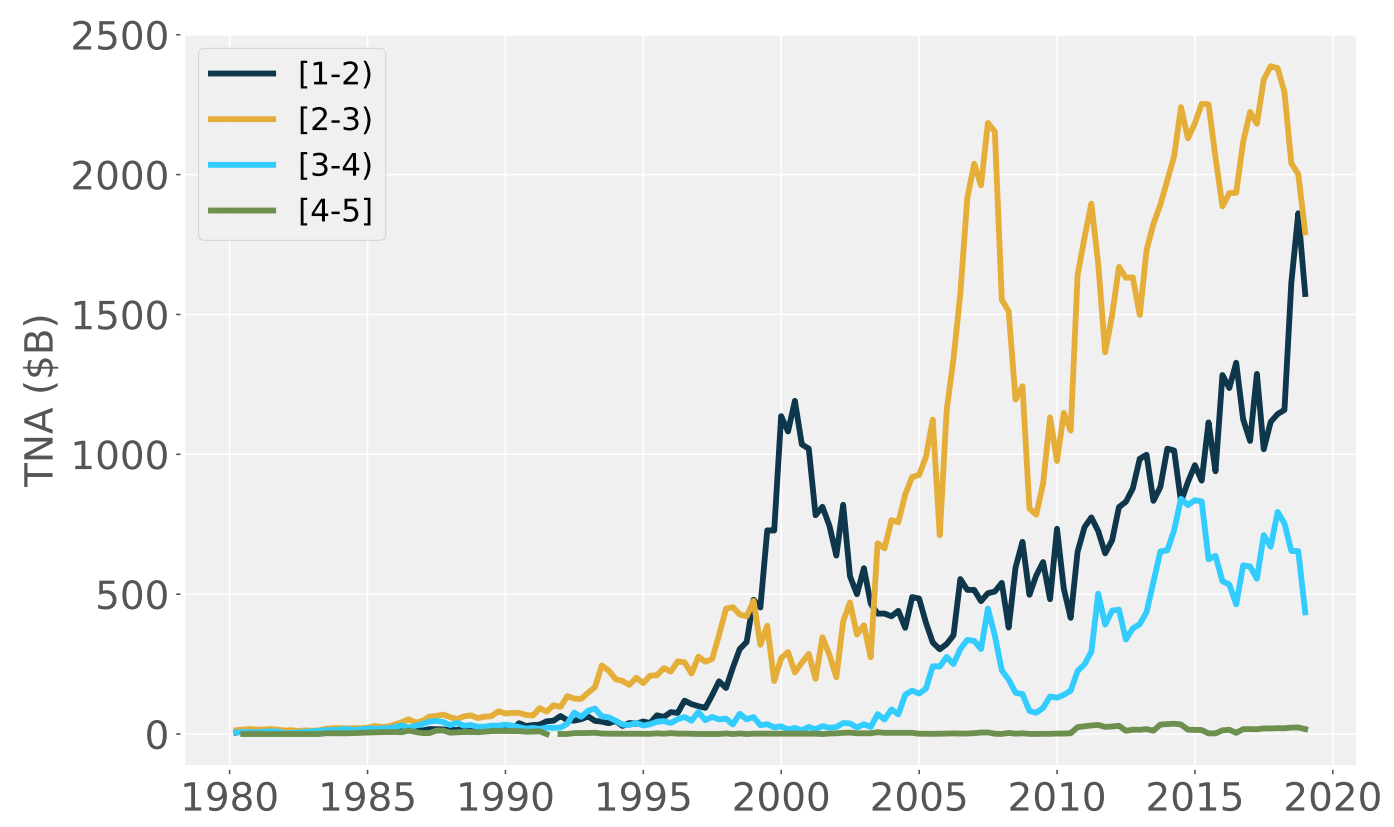

Note: The sample is from 1980Q1 to 2018Q4. 
Figure 8: Other Characteristics

\begin{tabular}{|c|c|c|c|c|c|c|c|c|c|c|c|c|c|c|c|c|}
\hline & \multicolumn{4}{|c|}{ S\&P500 Stocks } & \multicolumn{4}{|c|}{ Mutual Funds } & \multicolumn{4}{|c|}{ Growth Funds } & \multicolumn{4}{|c|}{ Value Funds } \\
\hline ME & $3 \%$ & $12 \%$ & $30 \%$ & $55 \%$ & $3 \%$ & $18 \%$ & $13 \%$ & $66 \%$ & $1 \%$ & $13 \%$ & $15 \%$ & $70 \%$ & $2 \%$ & $21 \%$ & $11 \%$ & $66 \%$ \\
\hline BM & $34 \%$ & $27 \%$ & $24 \%$ & $14 \%$ & $33 \%$ & $54 \%$ & $13 \%$ & $0 \%$ & $59 \%$ & $39 \%$ & $2 \%$ & $0 \%$ & $2 \%$ & $57 \%$ & $40 \%$ & $1 \%$ \\
\hline MS & $27 \%$ & $28 \%$ & $27 \%$ & $18 \%$ & $29 \%$ & $44 \%$ & $26 \%$ & $1 \%$ & $53 \%$ & $38 \%$ & $9 \%$ & $0 \%$ & $1 \%$ & $28 \%$ & $69 \%$ & $3 \%$ \\
\hline MOM & $1 \%$ & $27 \%$ & $69 \%$ & $3 \%$ & $0 \%$ & $10 \%$ & $87 \%$ & $3 \%$ & $0 \%$ & $5 \%$ & $88 \%$ & $6 \%$ & $0 \%$ & $21 \%$ & $78 \%$ & $0 \%$ \\
\hline MULT & $33 \%$ & $28 \%$ & $23 \%$ & $16 \%$ & $25 \%$ & $50 \%$ & $25 \%$ & $0 \%$ & $47 \%$ & $45 \%$ & $7 \%$ & $0 \%$ & $1 \%$ & $31 \%$ & $67 \%$ & $1 \%$ \\
\hline GR & $10 \%$ & $38 \%$ & $32 \%$ & $19 \%$ & $0 \%$ & $30 \%$ & $52 \%$ & $18 \%$ & $0 \%$ & $12 \%$ & $56 \%$ & $32 \%$ & $1 \%$ & $72 \%$ & $27 \%$ & $0 \%$ \\
\hline EP & $29 \%$ & $40 \%$ & $24 \%$ & $7 \%$ & $16 \%$ & $65 \%$ & $19 \%$ & $0 \%$ & $30 \%$ & $62 \%$ & $8 \%$ & $0 \%$ & $0 \%$ & $54 \%$ & $46 \%$ & $0 \%$ \\
\hline SP & $35 \%$ & $27 \%$ & $21 \%$ & $16 \%$ & $31 \%$ & $65 \%$ & $5 \%$ & $0 \%$ & $53 \%$ & $44 \%$ & $2 \%$ & $0 \%$ & $2 \%$ & $88 \%$ & $10 \%$ & $0 \%$ \\
\hline CFP & $25 \%$ & $35 \%$ & $26 \%$ & $14 \%$ & $15 \%$ & $60 \%$ & $25 \%$ & $0 \%$ & $28 \%$ & $63 \%$ & $9 \%$ & $0 \%$ & $0 \%$ & $39 \%$ & $61 \%$ & $0 \%$ \\
\hline DP & $28 \%$ & $20 \%$ & $30 \%$ & $23 \%$ & $16 \%$ & $39 \%$ & $39 \%$ & $6 \%$ & $26 \%$ & $47 \%$ & $26 \%$ & $1 \%$ & $1 \%$ & $27 \%$ & $53 \%$ & $19 \%$ \\
\hline SRLTE & $16 \%$ & $33 \%$ & $30 \%$ & $22 \%$ & $1 \%$ & $38 \%$ & $46 \%$ & $15 \%$ & $0 \%$ & $16 \%$ & $57 \%$ & $27 \%$ & $2 \%$ & $81 \%$ & $17 \%$ & $0 \%$ \\
\hline GRE & $2 \%$ & $40 \%$ & $52 \%$ & $6 \%$ & $0 \%$ & $15 \%$ & $85 \%$ & $1 \%$ & $0 \%$ & $4 \%$ & $94 \%$ & $2 \%$ & $0 \%$ & $41 \%$ & $59 \%$ & $0 \%$ \\
\hline GRCF & $3 \%$ & $40 \%$ & $52 \%$ & $5 \%$ & $0 \%$ & $13 \%$ & $87 \%$ & $0 \%$ & $0 \%$ & $3 \%$ & $96 \%$ & $1 \%$ & $0 \%$ & $34 \%$ & $66 \%$ & $0 \%$ \\
\hline GRS & $4 \%$ & $42 \%$ & $42 \%$ & $12 \%$ & $0 \%$ & $19 \%$ & $76 \%$ & $5 \%$ & $0 \%$ & $6 \%$ & $84 \%$ & $10 \%$ & $0 \%$ & $50 \%$ & $50 \%$ & $0 \%$ \\
\hline GRB & $5 \%$ & $40 \%$ & $45 \%$ & $10 \%$ & $0 \%$ & $18 \%$ & $80 \%$ & $2 \%$ & $0 \%$ & $8 \%$ & $89 \%$ & $4 \%$ & $0 \%$ & $43 \%$ & $57 \%$ & $0 \%$ \\
\hline OP & $16 \%$ & $28 \%$ & $34 \%$ & $22 \%$ & $1 \%$ & $28 \%$ & $71 \%$ & $1 \%$ & $1 \%$ & $23 \%$ & $75 \%$ & $1 \%$ & $0 \%$ & $33 \%$ & $67 \%$ & $0 \%$ \\
\hline INV & $5 \%$ & $40 \%$ & $45 \%$ & $11 \%$ & $0 \%$ & $13 \%$ & $83 \%$ & $3 \%$ & $0 \%$ & $4 \%$ & $89 \%$ & $7 \%$ & $0 \%$ & $36 \%$ & $64 \%$ & $0 \%$ \\
\hline QUAL & $16 \%$ & $27 \%$ & $33 \%$ & $23 \%$ & $0 \%$ & $13 \%$ & $85 \%$ & $1 \%$ & $0 \%$ & $4 \%$ & $94 \%$ & $2 \%$ & $0 \%$ & $38 \%$ & $62 \%$ & $0 \%$ \\
\hline PSLIQ & $0 \%$ & $23 \%$ & $76 \%$ & $0 \%$ & $0 \%$ & $17 \%$ & $83 \%$ & $0 \%$ & $0 \%$ & $11 \%$ & $89 \%$ & $0 \%$ & $0 \%$ & $21 \%$ & $79 \%$ & $0 \%$ \\
\hline TURN & $5 \%$ & $24 \%$ & $38 \%$ & $33 \%$ & $1 \%$ & $35 \%$ & $58 \%$ & $7 \%$ & $0 \%$ & $24 \%$ & $63 \%$ & $12 \%$ & $1 \%$ & $56 \%$ & $43 \%$ & $0 \%$ \\
\hline DVOL & $2 \%$ & $10 \%$ & $30 \%$ & $58 \%$ & $2 \%$ & $14 \%$ & $16 \%$ & $68 \%$ & $1 \%$ & $7 \%$ & $18 \%$ & $74 \%$ & $2 \%$ & $21 \%$ & $12 \%$ & $65 \%$ \\
\hline & {$[1-2)$} & {$[2-3)$} & [3-4) & [4-5] & {$[1-2)$} & {$[2-3)$} & [3-4) & [4-5] & {$[1-2)$} & {$[2-3)$} & [3-4) & [4-5] & {$[1-2)$} & {$[2-3)$} & [3-4) & [4-5] \\
\hline
\end{tabular}

Note: The figure shows heatmaps of the distribution of characteristics scores of S\&P 500 stocks, mutual funds, grwoth funds, and value funds. ME is market capitalization, BM is the book-to-market ratio, MS is the Mornigstar index, EP is the earnings-to-price ratio, SP is the sales-to-price ratio, CFP is the cash flow-to-price ratio, DP is the dividend-to-price ratio, MOM is momentum, OP is profitibility, INV is investment, QUAL is the MSCI quality index, PSLIQ is the Pastor-Stambaugh liquidity measure, TURN is the share turnover, and DVOL is trading volume. Each cell shows the percentage of stocks or funds with characteristic scores in the intervals [1-2), [2-3), [3-4), and [4-5]. The sample is from 1980Q1 to 2018Q4. 
Figure 9: Portfolio Shares of Mutual Funds by BM-Quintile

Panel A: BM Quintile 1

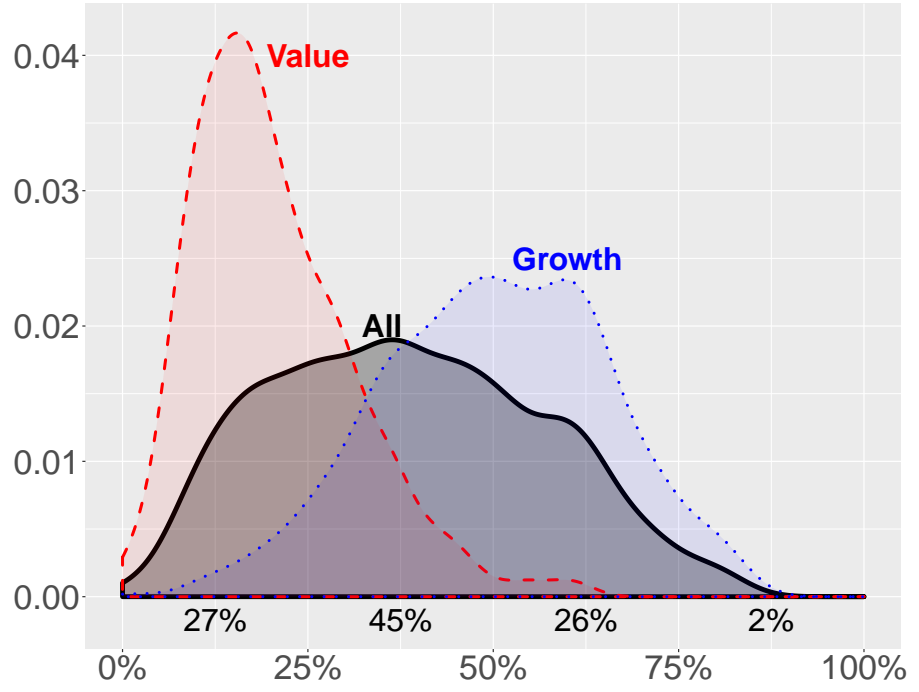

Panel C: BM Quintile 3

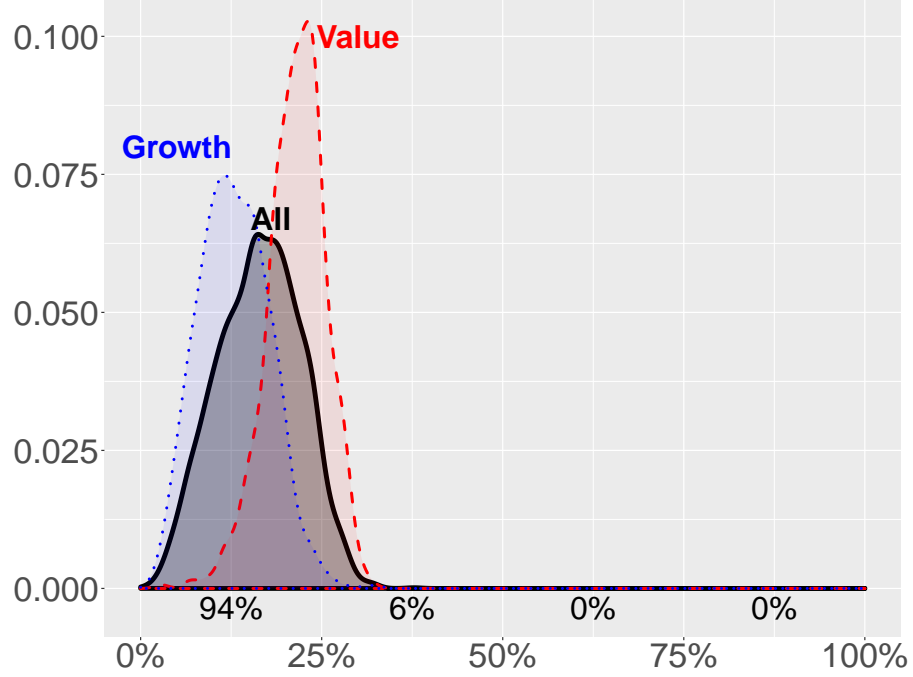

Panel B: BM Quintile 2

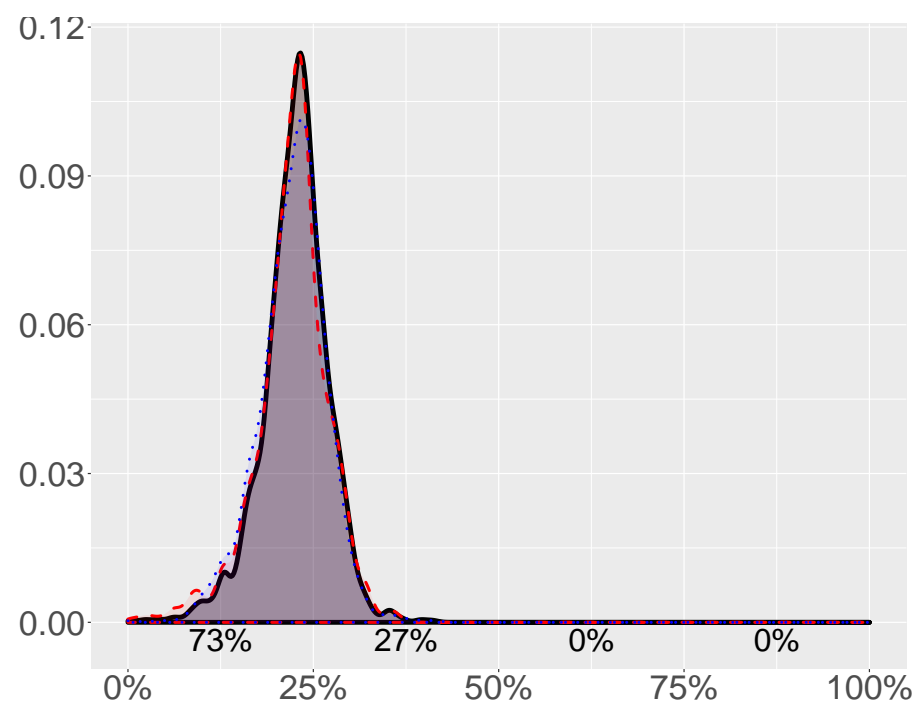

Panel D: BM Quintile 4

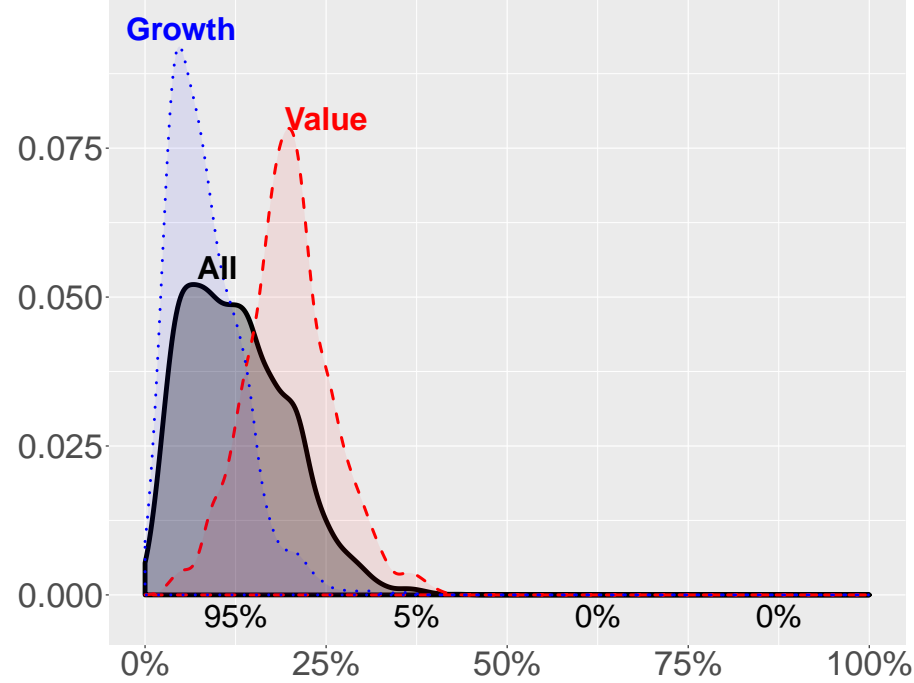

Panel E: BM Quintile 5

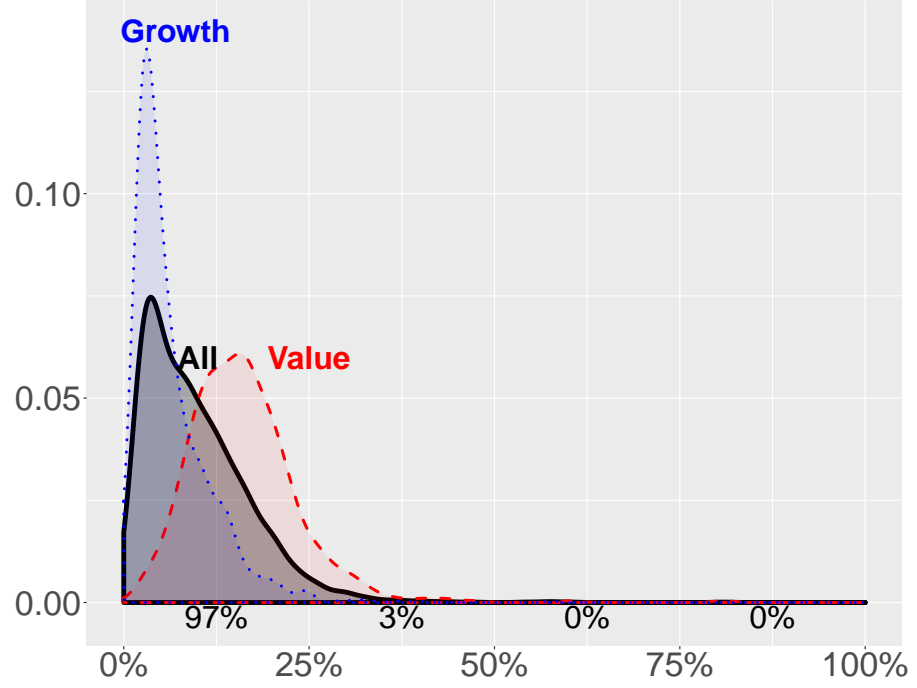

Note: The figure shows the distributions of portfolio shares in BM quintiles 1 to 5 for mutual funds, hedge funds and ETFs. 
Figure 10: Joint Characteristics Distributions - BM/ME

Panel A: Stocks

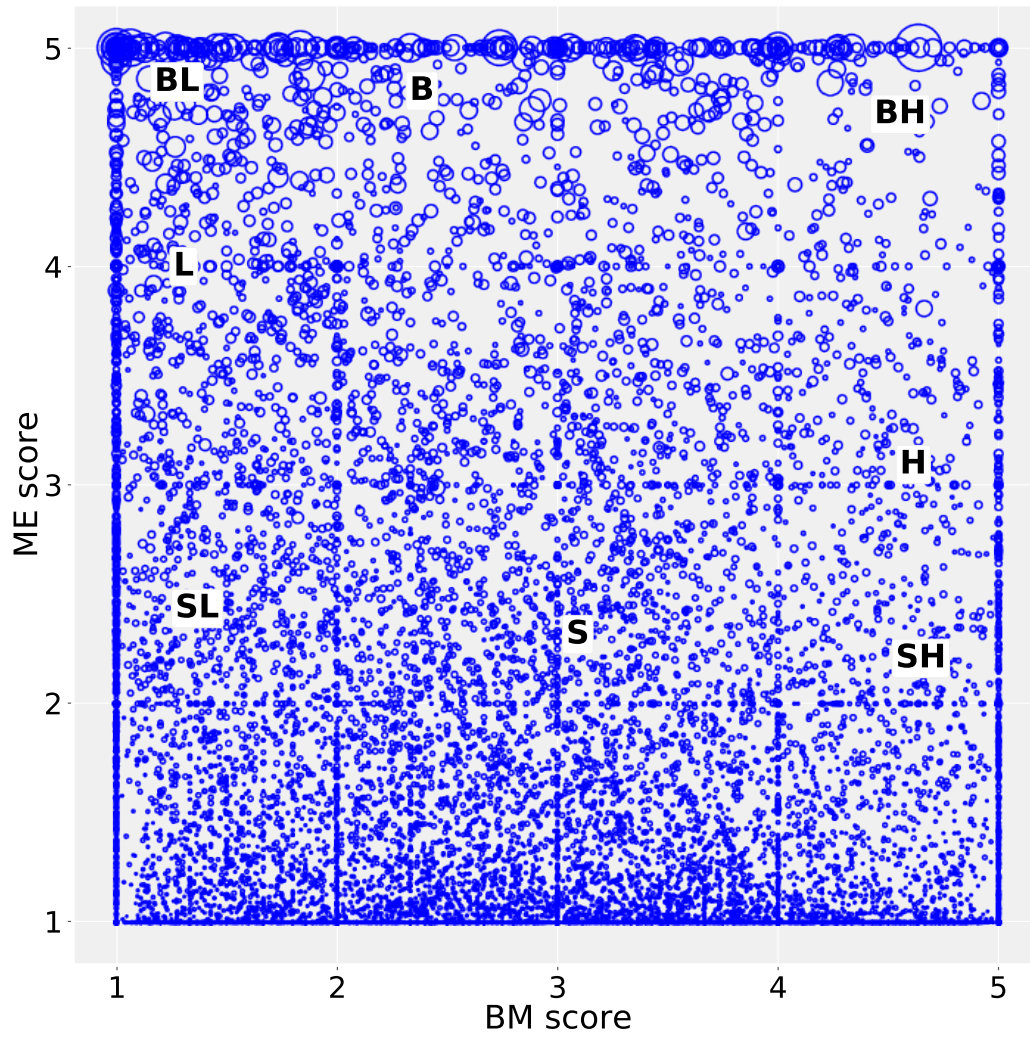

Panel B: Mutual Funds

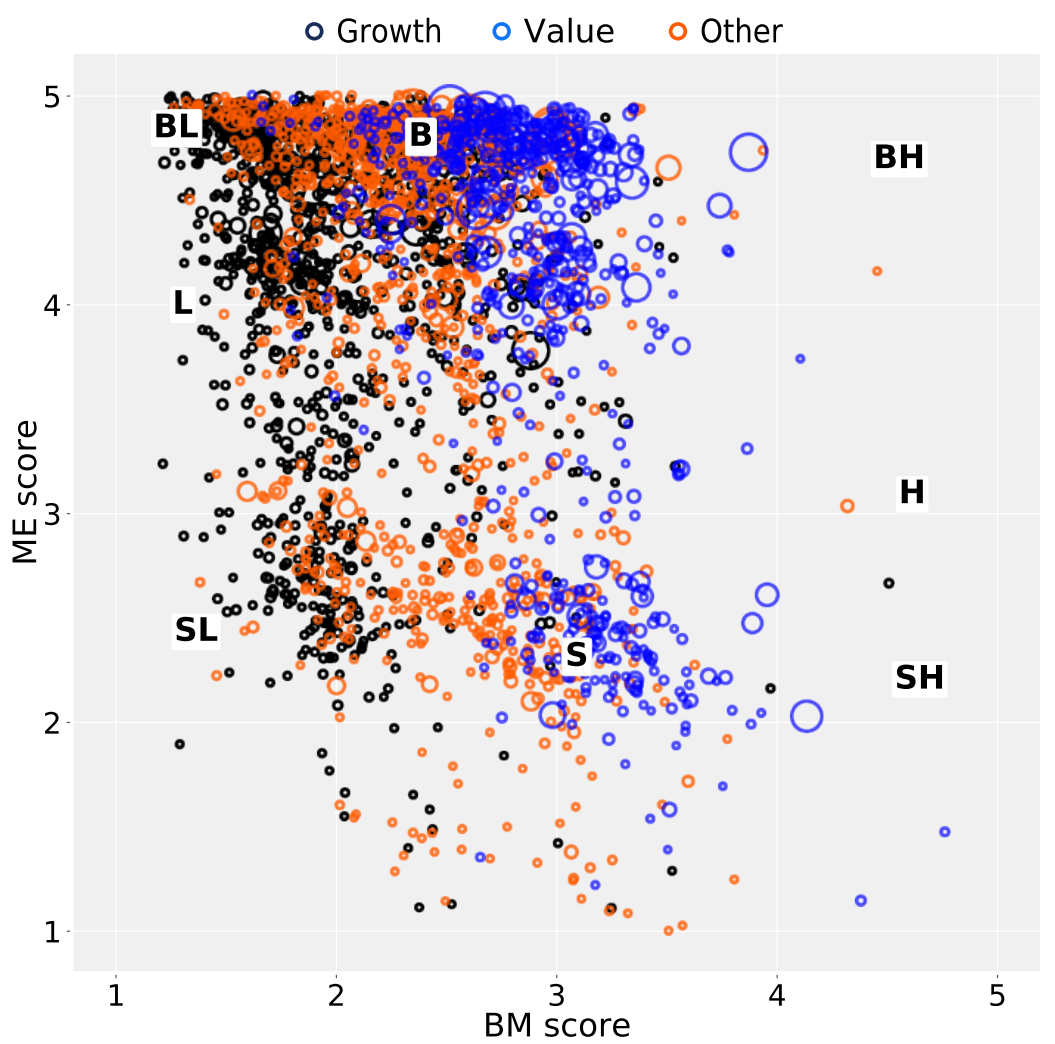

Note: This figure shows scatter plots of BM and ME characteristics of stocks (Panel A) and mutual funds (panel B). The sample is from 1980Q1 to 2018Q4. 
Figure 11: Histograms - Loadings of Mutuals Funds and ETFs

Panel A: MKT

DETFs:: Mutual Funds

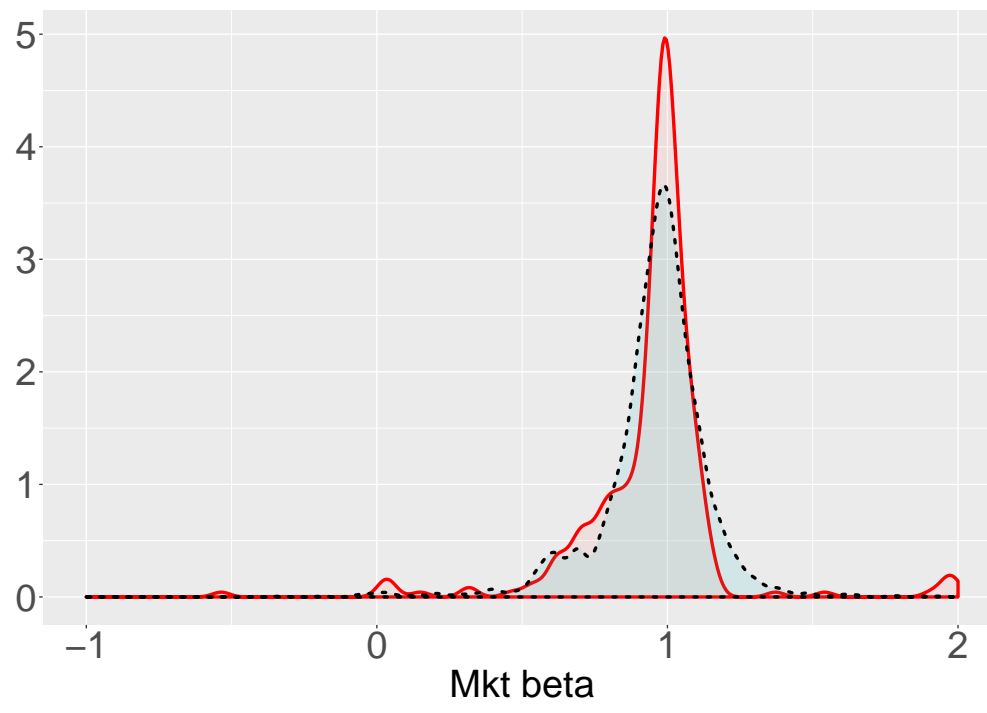

Panel C: HML

DETFs:: Mutual Funds

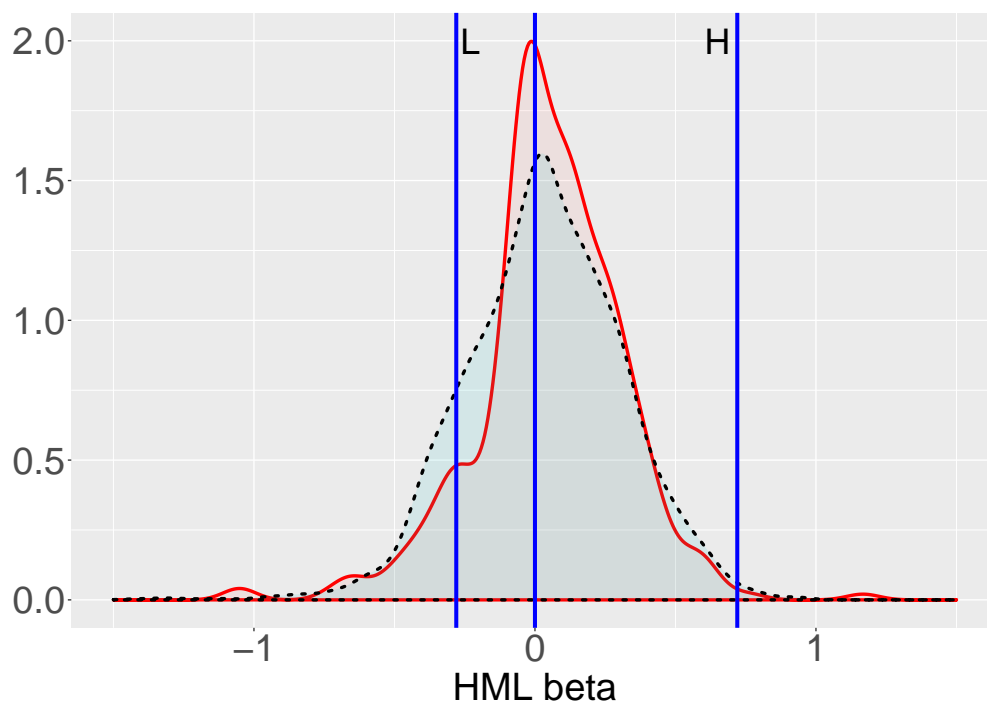

Panel B: SMB

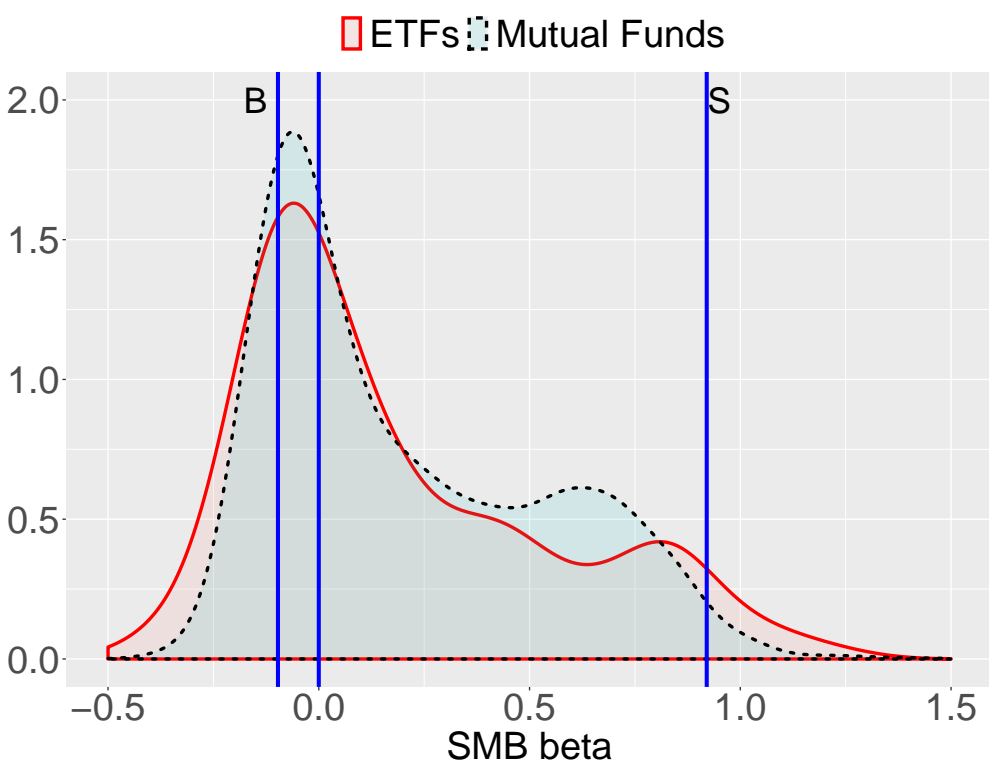

Panel D: MOM

LETFs:i Mutual Funds

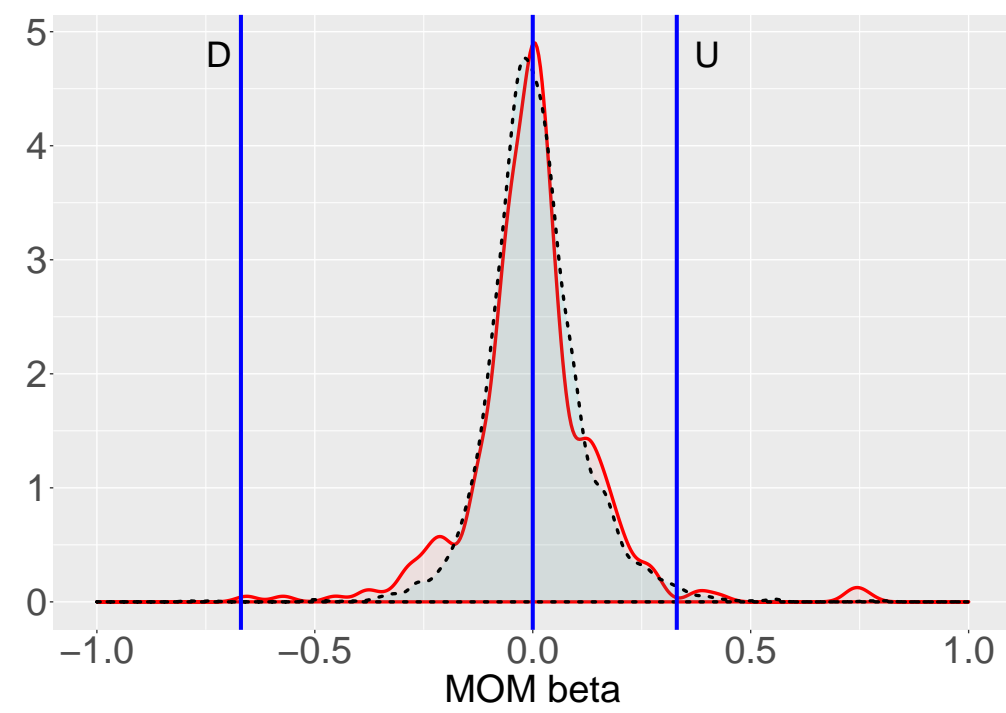

Note: This plot shows the histograms of $\beta$ 's of mutual funds and hedge funds in 4-factor regressions of fund excess returns on the market excess returns, SMB, HML, and MOM. Hedge funds returns are from Hedge Fund Research (HFR). The vertical lines indicate $\beta$ 's of the components of SMB, HML and MOM The sample is from 1980Q1 to $2018 \mathrm{Q} 4$. 
Table 1: Descriptive Statistics of Mutual Funds and Hedge Funds

\begin{tabular}{lrrrrrr}
\hline & MFs & Value & Growth & Other & ETFs & 13F HFs \\
\hline Number of funds before screens & 8892 & 1429 & 2274 & 5189 & 1640 & NA \\
Number of funds in sample & 2993 & 636 & 1257 & 1100 & 575 & 79 \\
Number of funds 1980Q1 & 200 & 14 & 91 & 95 & 0 & 0 \\
Number of funds 2018Q4 & 1552 & 385 & 596 & 571 & 461 & 28 \\
Medium number of observations & 46 & 44 & 44 & 50 & 13 & 29 \\
Medium number of stocks & 74 & 76 & 68 & 80 & 208 & 32 \\
Total TNA 1980Q1 (\$B) & 25 & 1 & 8 & 16 & 0 & 0 \\
Total TNA 2018Q4 (\$B) & 3819 & 586 & 1660 & 1572 & 1295 & 31 \\
Median TNA (\$M) & 222 & 261 & 216 & 206 & 51 & 191 \\
Mean TNA (\$M) & 939 & 866 & 993 & 919 & 1329 & 990 \\
Median return over S\&P 500 (\% p.a.) & -0.70 & -0.90 & -0.38 & -1.01 & -1.18 & NA \\
Median CAPM beta & 0.99 & 0.95 & 1.04 & 0.95 & 1.00 & NA \\
Median 4-factor alpha (\% p.a.) & -0.70 & -0.59 & -0.73 & -0.75 & -0.41 & NA \\
\hline
\end{tabular}

Note: The table resport descriptive statistics of mutual funds, ETFs and hedge funds. For each fund in our sample, we first compute averages across all observations that are the fund is in the sample. Unless otherwise stated, the statistics in the table are taken across fund averages. Since we do not have "total net asset value" (TNA) for hedge funds, we report the total market value of equities computed from 13F portfolio holdings. 
Table 2: Characteristics of Passive Benchmark Portfolios

\begin{tabular}{lccccccccc}
\hline & & \multicolumn{9}{c}{ Panel A } & \multicolumn{1}{c}{} & \\
& CRSP-VW & S\&P 500 & CRSP-EW & S & B & H & L & U & D \\
\hline ME & 4.51 & 4.90 & 1.90 & 2.31 & 4.80 & 3.09 & 4.00 & 3.68 & 3.08 \\
BM & 2.31 & 2.25 & 2.91 & 3.09 & 2.38 & 4.61 & 1.30 & 2.70 & 2.81 \\
MS & 2.74 & 2.85 & 2.46 & 2.96 & 2.97 & 3.93 & 2.13 & 2.76 & 3.04 \\
MOM & 3.30 & 3.29 & 2.85 & 3.11 & 3.27 & 3.15 & 3.23 & 4.65 & 1.40 \\
\hline & & & & Panel B & & & & & \\
& SL & BL & SH & BH & SD & BD & SU & BU \\
\hline ME & 2.43 & 4.85 & 2.20 & 4.70 & 2.10 & 4.68 & 2.44 & 4.79 \\
BM & 1.36 & 1.27 & 4.65 & 4.55 & 3.05 & 2.43 & 3.04 & 2.40 \\
MS & 1.96 & 2.22 & 3.81 & 4.14 & 3.02 & 3.09 & 2.74 & 2.78 \\
MOM & 3.12 & 3.30 & 3.10 & 3.21 & 1.34 & 1.51 & 4.72 & 4.58 \\
\hline
\end{tabular}

Note: This table shows average characteristic scores and adjusted characteristics of the CRSP-VW, CRSP-EW, and S\&P 500 indices and Fame-French portfolios. "SL" is the small/low-BM portfolio, "BL" is the big/low-BM portfolio, etc. 
Table 3: Characteristics of Mutual Funds and Hedge Funds

\begin{tabular}{|c|c|c|c|c|c|c|c|c|c|c|c|c|}
\hline & \multicolumn{6}{|c|}{ Panel A: Mutual Funds (sample) } & \multicolumn{6}{|c|}{ Panel B: S\&P 500 Stocks } \\
\hline & mean & $10 \%$ & $25 \%$ & $50 \%$ & $75 \%$ & $90 \%$ & mean & $10 \%$ & $25 \%$ & $50 \%$ & $75 \%$ & $90 \%$ \\
\hline ME score & 4.03 & 2.47 & 3.42 & 4.45 & 4.80 & 4.89 & 3.95 & 2.72 & 3.35 & 4.06 & 4.75 & 5.00 \\
\hline BM score & 2.33 & 1.62 & 1.88 & 2.30 & 2.72 & 3.08 & 2.62 & 1.20 & 1.69 & 2.50 & 3.45 & 4.22 \\
\hline MS score & 2.53 & 1.59 & 1.90 & 2.58 & 3.06 & 3.46 & 2.78 & 1.27 & 1.86 & 2.74 & 3.65 & 4.31 \\
\hline \multirow[t]{3}{*}{ MOM score } & 3.35 & 3.00 & 3.15 & 3.31 & 3.54 & 3.76 & 3.16 & 2.69 & 2.95 & 3.18 & 3.36 & 3.56 \\
\hline & \multicolumn{6}{|c|}{ Panel C: Value Funds } & \multicolumn{6}{|c|}{ Panel D: Growth Funds } \\
\hline & mean & $10 \%$ & $25 \%$ & $50 \%$ & $75 \%$ & $90 \%$ & mean & $10 \%$ & $25 \%$ & $50 \%$ & $75 \%$ & $90 \%$ \\
\hline ME score & 3.97 & 2.31 & 3.21 & 4.42 & 4.77 & 4.87 & 4.16 & 2.73 & 3.77 & 4.49 & 4.81 & 4.90 \\
\hline BM score & 2.89 & 2.35 & 2.64 & 2.92 & 3.15 & 3.38 & 1.99 & 1.51 & 1.68 & 1.92 & 2.25 & 2.55 \\
\hline MS score & 3.24 & 2.70 & 2.96 & 3.25 & 3.56 & 3.79 & 2.12 & 1.45 & 1.65 & 1.97 & 2.55 & 3.00 \\
\hline \multirow[t]{3}{*}{ MOM score } & 3.13 & 2.88 & 3.02 & 3.14 & 3.24 & 3.35 & 3.48 & 3.09 & 3.27 & 3.46 & 3.67 & 3.89 \\
\hline & \multicolumn{6}{|c|}{ Panel E: ETF } & \multicolumn{6}{|c|}{ Panel F: Hedge Funds } \\
\hline & mean & $10 \%$ & $25 \%$ & $50 \%$ & $75 \%$ & $90 \%$ & mean & $10 \%$ & $25 \%$ & $50 \%$ & $75 \%$ & $90 \%$ \\
\hline ME score & 4.04 & 2.24 & 3.51 & 4.52 & 4.80 & 4.92 & 3.68 & 2.43 & 3.22 & 3.81 & 4.34 & 4.68 \\
\hline BM score & 2.52 & 1.76 & 2.15 & 2.50 & 2.88 & 3.27 & 2.38 & 1.63 & 2.00 & 2.24 & 2.80 & 3.22 \\
\hline MS score & 2.88 & 2.00 & 2.51 & 2.92 & 3.28 & 3.69 & 2.20 & 1.41 & 1.82 & 2.26 & 2.65 & 2.92 \\
\hline \multirow[t]{3}{*}{ MOM score } & 3.32 & 2.97 & 3.14 & 3.29 & 3.48 & 3.68 & 3.31 & 2.81 & 3.02 & 3.26 & 3.59 & 3.95 \\
\hline & \multicolumn{6}{|c|}{ Panel G: All MFs } & \multicolumn{6}{|c|}{ Panel H: 13F Institutions } \\
\hline & mean & $10 \%$ & $25 \%$ & $50 \%$ & $75 \%$ & $90 \%$ & mean & $10 \%$ & $25 \%$ & $50 \%$ & $75 \%$ & $90 \%$ \\
\hline ME score & 4.00 & 2.50 & 3.52 & 4.32 & 4.74 & 4.90 & 4.13 & 2.67 & 3.78 & 4.51 & 4.81 & 4.92 \\
\hline BM score & 2.55 & 1.64 & 1.99 & 2.48 & 3.00 & 3.58 & 2.30 & 1.59 & 1.89 & 2.19 & 2.60 & 3.17 \\
\hline MS score & 2.62 & 1.59 & 2.03 & 2.64 & 3.12 & 3.60 & 2.47 & 1.54 & 2.03 & 2.48 & 2.90 & 3.30 \\
\hline MOM score & 3.28 & 2.81 & 3.07 & 3.28 & 3.51 & 3.79 & 3.30 & 2.81 & 3.11 & 3.33 & 3.53 & 3.82 \\
\hline
\end{tabular}

Note: The table reports means and 10th, 25th, 75th and 90th percentiles of the distributions of average characteristic scores for our sample of mutual funds, individual S\&P 500 stocks, value and growth funds, ETFs, hedge funds, all funds (i.e. without any screens), and all $13 \mathrm{~F}$ institutions. 
Table 4: Characteristics of highest/lowest BM Mutual Funds

\begin{tabular}{|c|c|c|c|c|c|}
\hline & BM & MS & EP & ME & TNA (\$M) \\
\hline \multicolumn{6}{|c|}{ Panel A: Highest BM Funds } \\
\hline High BM H portfolio & 4.60 & 3.98 & 3.49 & 3.45 & NA \\
\hline Aegis Value & 4.76 & 3.47 & 2.59 & 1.49 & 195 \\
\hline Mellon Capital SP SMid 60 & 4.51 & 3.90 & 3.30 & 2.67 & 449 \\
\hline Vanguard High Yield & 4.45 & 4.55 & 4.33 & 4.16 & 87 \\
\hline Franklin MicroCap Value & 4.38 & 3.20 & 3.21 & 1.15 & 337 \\
\hline Franklin Balance Sheet & 4.32 & 3.74 & 3.43 & 3.04 & 1930 \\
\hline DFA US Small Cap Value Portfolio & 4.13 & 3.36 & 3.10 & 2.03 & 7701 \\
\hline Dow Target Dividend Portfolio & 4.10 & 4.29 & 3.57 & 3.74 & 29 \\
\hline LVIP SSgA Small-Mid Cap 200 & 3.97 & 3.68 & 3.82 & 2.16 & 220 \\
\hline DFA US Targeted Value Portfolio & 3.95 & 3.37 & 3.12 & 2.61 & 3775 \\
\hline Schneider Small Cap Value & 3.94 & 3.28 & 2.39 & 2.03 & 62 \\
\hline \multicolumn{6}{|c|}{ Panel B: Lowest BM Funds } \\
\hline Low BM L portfolio & 1.32 & 2.11 & 2.60 & 3.64 & NA \\
\hline Jensen Quality Growth & 1.21 & 2.28 & 2.89 & 4.85 & 2853 \\
\hline IAI Emerging Growth & 1.21 & 1.04 & 1.73 & 3.24 & 253 \\
\hline JNL/S\&P Competitive Advantage & 1.22 & 2.42 & 3.45 & 4.68 & 1466 \\
\hline Victory Portfolios: Growth & 1.24 & 1.89 & 2.26 & 4.99 & 355 \\
\hline Touchstone Sands Capital Select Growth & 1.25 & 1.13 & 2.13 & 4.89 & 1867 \\
\hline SouthTrusts: Growth & 1.25 & 1.74 & 2.26 & 5.00 & 80 \\
\hline Excelsior Optimum Growth & 1.26 & 1.44 & 2.17 & 4.93 & 56 \\
\hline Harris Bretall Sullivan Smith Growth Equity & 1.27 & 1.49 & 2.07 & 4.97 & 15 \\
\hline Provident Investment Counsel Balanced & 1.27 & 1.24 & 1.95 & 4.94 & 26 \\
\hline Pioneer Papp Strategic Growth & 1.27 & 1.67 & 2.48 & 4.73 & 126 \\
\hline
\end{tabular}

Note: This table reports characteristics scores of the the 10 mutual funds with the highest BM scores as well as the scores of the 10 funds with the lowest BM scores. Assets-under-managment are in \$ mil. 
Table 5: Portfolio Composition by BM Quintiles

\begin{tabular}{|c|c|c|c|c|c|c|}
\hline & BM & BM1 & BM2 & BM3 & BM4 & BM5 \\
\hline \multicolumn{7}{|c|}{ Panel A: Mutual Funds } \\
\hline All & 2.33 & $38.53 \%$ & $22.58 \%$ & $16.41 \%$ & $12.73 \%$ & $9.75 \%$ \\
\hline Value & 2.89 & $20.32 \%$ & $22.12 \%$ & $21.53 \%$ & $19.90 \%$ & $16.13 \%$ \\
\hline Growth & 1.99 & $50.10 \%$ & $22.18 \%$ & $12.93 \%$ & $8.41 \%$ & $6.39 \%$ \\
\hline ETFs & 2.52 & $32.48 \%$ & $23.14 \%$ & $15.56 \%$ & $14.65 \%$ & $14.17 \%$ \\
\hline HFs & 2.38 & $37.63 \%$ & $21.09 \%$ & $16.20 \%$ & $13.28 \%$ & $11.81 \%$ \\
\hline \multicolumn{7}{|c|}{ Panel B: 5 Largest Value Funds } \\
\hline Vanguard Equity Income & 2.70 & $25.02 \%$ & $22.12 \%$ & $22.75 \%$ & $18.22 \%$ & $11.90 \%$ \\
\hline DFA US Large Cap Value & 3.87 & $1.34 \%$ & $5.85 \%$ & $26.53 \%$ & $37.11 \%$ & $29.17 \%$ \\
\hline T. Rowe Price Value & 2.83 & $23.69 \%$ & $22.68 \%$ & $19.06 \%$ & $16.55 \%$ & $18.02 \%$ \\
\hline T. Rowe Price Equity Income & 2.74 & $26.80 \%$ & $21.39 \%$ & $19.14 \%$ & $16.34 \%$ & $16.33 \%$ \\
\hline JPMorgan Equity Income & 2.36 & $36.23 \%$ & $22.62 \%$ & $18.06 \%$ & $15.44 \%$ & $7.64 \%$ \\
\hline \multicolumn{7}{|c|}{ Panel C: 5 Largest Growth Funds } \\
\hline Growth Fund of America & 2.03 & $49.71 \%$ & $21.50 \%$ & $12.37 \%$ & $9.30 \%$ & $7.12 \%$ \\
\hline Fidelity Contrafund & 2.26 & $44.07 \%$ & $18.58 \%$ & $14.78 \%$ & $12.53 \%$ & $10.03 \%$ \\
\hline Vanguard PRIMECAP & 2.16 & $41.17 \%$ & $27.56 \%$ & $13.46 \%$ & $9.74 \%$ & $8.07 \%$ \\
\hline AMCAP Fund & 1.80 & $53.46 \%$ & $25.53 \%$ & $11.16 \%$ & $6.89 \%$ & $2.97 \%$ \\
\hline T. Rowe Price Blue Chip Growth & 1.60 & $63.40 \%$ & $21.80 \%$ & $8.40 \%$ & $4.07 \%$ & $2.33 \%$ \\
\hline
\end{tabular}

Note: This table shows the average portfolio shares in the five BM quintiles. 
Table 6: S\&P 500 Stock Ownership by Mutual Funds

\begin{tabular}{|c|c|c|c|c|}
\hline & Sample MFs & All MFs & Value MFs & Growth MFs \\
\hline \multicolumn{5}{|c|}{ Panel A: Across all Stocks } \\
\hline Mean & $8.61 \%$ & $13.22 \%$ & $1.35 \%$ & $3.89 \%$ \\
\hline Std. Dev. & $5.34 \%$ & $8.56 \%$ & $1.37 \%$ & $3.46 \%$ \\
\hline $10 \%$ quantile & $2.57 \%$ & $3.43 \%$ & $0.09 \%$ & $0.62 \%$ \\
\hline 90\% quantile & $16.03 \%$ & $25.49 \%$ & $3.08 \%$ & $8.73 \%$ \\
\hline \multicolumn{5}{|c|}{ Panel B: Median by Stock-BM scores } \\
\hline $1-2$ & $9.24 \%$ & $13.93 \%$ & $0.72 \%$ & $4.65 \%$ \\
\hline $2-3$ & $7.89 \%$ & $12.95 \%$ & $1.25 \%$ & $3.02 \%$ \\
\hline $3-4$ & $6.37 \%$ & $9.97 \%$ & $1.26 \%$ & $1.77 \%$ \\
\hline $4-5$ & $5.35 \%$ & $8.09 \%$ & $0.89 \%$ & $1.22 \%$ \\
\hline \multicolumn{5}{|c|}{ Panel C: Regression on Characteristic Scores } \\
\hline const. & $\begin{array}{l}13.67^{* * *} \\
(0.40)\end{array}$ & $\begin{array}{l}20.69^{* * *} \\
(0.64)\end{array}$ & $\begin{array}{l}0.75^{* * *} \\
(0.11)\end{array}$ & $\begin{array}{l}9.07^{* * *} \\
(0.22)\end{array}$ \\
\hline $\mathrm{BM}$ & $\begin{array}{c}0.21 \\
(0.19)\end{array}$ & $\begin{array}{c}0.56^{*} \\
(0.31)\end{array}$ & $\begin{array}{l}0.11^{* *} \\
(0.05)\end{array}$ & $\begin{array}{c}0.04 \\
(0.11)\end{array}$ \\
\hline MS & $\begin{array}{c}-2.04^{* * *} \\
(0.19)\end{array}$ & $\begin{array}{c}-3.25^{* * *} \\
(0.30)\end{array}$ & $\begin{array}{c}0.11^{* *} \\
(0.05)\end{array}$ & $\begin{array}{c}-1.92^{* * *} \\
(0.11)\end{array}$ \\
\hline$R^{2}$ & 0.14 & 0.13 & 0.02 & 0.34 \\
\hline
\end{tabular}

Note: This table shows result for the share of market cap of a stock that is held by mutual funds. For each stock and quarter we compute the percentage of the total market cap that is held by different types of mutual funds. We consider all funds in our sample (without any screens), the funds in out benchmark sample, value funds, and growth funds. The table reports data for our sample of S\&P 500 stocks averaged across the qurters that the stock is in our sample. Panel A reports descriptive statistics, Panel B and C show the fund ownership by BM and MS quintile, respectively. Panel D shows the results of regressions of ownership percentages on characteristic scores across 1,390 S\&P 500 stocks. $t$-statistics are reported in parantheses. 
Table 7: Liquidity Measures by ME/BM Quintiles

\begin{tabular}{|c|c|c|c|c|}
\hline & BM 1-2 & BM 2-3 & BM 3-4 & BM 4-5 \\
\hline \multicolumn{5}{|c|}{ Panel A: Stocks PSLIQ } \\
\hline ME 1-2 & 3.03 & 3.00 & 3.00 & 2.96 \\
\hline ME 2-3 & 3.00 & 3.02 & 3.00 & 2.96 \\
\hline ME 3-4 & 3.04 & 3.00 & 3.02 & 3.01 \\
\hline ME 4-5 & 3.09 & 3.12 & 3.11 & 3.11 \\
\hline \multicolumn{5}{|c|}{ Panel B: Mutual Funds PSLIQ } \\
\hline ME 1-2 & 2.98 & 2.92 & 2.91 & $2.91^{\dagger}$ \\
\hline ME 2-3 & 3.00 & 2.99 & 2.97 & $2.96^{\dagger}$ \\
\hline ME 3-4 & 3.05 & 3.05 & 3.05 & $3.08^{\dagger}$ \\
\hline ME 4-5 & 3.15 & 3.15 & 3.14 & $3.05^{\dagger}$ \\
\hline \multicolumn{5}{|c|}{ Panel C: Stocks Bid-Ask Spread } \\
\hline ME 1-2 & 4.43 & 4.38 & 4.44 & 4.54 \\
\hline ME 2-3 & 3.28 & 3.36 & 3.45 & 3.54 \\
\hline ME 3-4 & 2.70 & 2.89 & 3.01 & 2.91 \\
\hline ME 4-5 & 2.17 & 2.28 & 2.19 & 2.38 \\
\hline \multicolumn{5}{|c|}{ Panel D: Mutual Funds Bid-Ask Spread } \\
\hline ME 1-2 & 3.94 & 3.68 & 4.08 & $4.42^{\dagger}$ \\
\hline ME 2-3 & 2.86 & 3.00 & 3.24 & $3.47^{\dagger}$ \\
\hline ME 3-4 & 2.78 & 2.75 & 2.91 & $2.86^{\dagger}$ \\
\hline ME 4-5 & 2.03 & 2.23 & 2.33 & $5.00^{\dagger}$ \\
\hline
\end{tabular}

Note: This table shows scores of three liquidity measures of stocks and mutual funds by BM quantiles: PSLIQ is the regression-based Pastor-Stambaugh liquidity measure, turnover is the ratio between shares traded and total shares outstanding and trading volume. We compute these measures for each stock/quarter observation and obtain liquidity quintile scores as described in the text. 
Table 8: Value and Growth Indices

\begin{tabular}{|c|c|c|c|c|c|}
\hline \multicolumn{6}{|c|}{ Panel A: Characteristics } \\
\hline Index & TNA (\$M) & BM & MS & EP & SP \\
\hline Russell 1000 Value & 51155 & 3.26 & 3.72 & 3.28 & 2.36 \\
\hline S\&P 500 Value & 20871 & 3.04 & 3.74 & 3.30 & 2.54 \\
\hline CRSP Large Cap Value & 16770 & 2.89 & 3.72 & 3.20 & 2.49 \\
\hline Russell 2000 Value & 15432 & 3.75 & 3.12 & 2.64 & 2.64 \\
\hline S\&P MidCap 400 Value & 2864 & 3.32 & 3.15 & 2.79 & 2.87 \\
\hline Russell 1000 Growth & 54697 & 1.44 & 2.17 & 2.52 & 1.81 \\
\hline S\&P 500 Growth & 29194 & 1.69 & 2.36 & 2.68 & 1.65 \\
\hline CRSP Large Cap Growth & 21917 & 1.46 & 1.90 & 2.19 & 1.66 \\
\hline Russell 2000 Growth & 13808 & 1.81 & 1.79 & 1.91 & 2.18 \\
\hline S\&P MidCap 400 Growth & 3209 & 2.02 & 1.91 & 2.26 & 2.02 \\
\hline \multicolumn{6}{|c|}{ Panel B: BM Quintiles } \\
\hline Index & BM1 & BM2 & BM3 & BM4 & BM5 \\
\hline Russell 1000 Value & $6.17 \%$ & $23.05 \%$ & $28.45 \%$ & $23.96 \%$ & $18.38 \%$ \\
\hline S\&P 500 Value & $16.22 \%$ & $20.71 \%$ & $23.59 \%$ & $21.77 \%$ & $17.70 \%$ \\
\hline CRSP Large Cap Value & $14.91 \%$ & $26.92 \%$ & $25.46 \%$ & $19.29 \%$ & $13.41 \%$ \\
\hline Russell 2000 Value & $2.01 \%$ & $8.40 \%$ & $26.40 \%$ & $38.50 \%$ & $24.69 \%$ \\
\hline S\&P MidCap 400 Value & $10.28 \%$ & $20.80 \%$ & $19.07 \%$ & $26.76 \%$ & $23.10 \%$ \\
\hline Russell 1000 Growth & $67.75 \%$ & $23.62 \%$ & $6.50 \%$ & $1.49 \%$ & $0.64 \%$ \\
\hline S\&P 500 Growth & $56.66 \%$ & $25.70 \%$ & $12.07 \%$ & $3.85 \%$ & $1.72 \%$ \\
\hline CRSP Large Cap Growth & $69.65 \%$ & $19.67 \%$ & $7.18 \%$ & $2.50 \%$ & $1.00 \%$ \\
\hline Russell 2000 Growth & $46.00 \%$ & $32.97 \%$ & $15.87 \%$ & $4.03 \%$ & $1.13 \%$ \\
\hline S\&P MidCap 400 Growth & $45.34 \%$ & $27.02 \%$ & $12.20 \%$ & $11.64 \%$ & $3.80 \%$ \\
\hline \multicolumn{6}{|c|}{ Panel C: Characteristics used in Value and Growth Indices } \\
\hline Index Provider & Multiples & & Growth & & \\
\hline Russell & $\mathrm{BM}$ & & GRE, GR & & \\
\hline S\&P & BM, EP, SP & & $\Delta \mathrm{EP}, \mathrm{GR}$ & $\mathrm{OM}$ & \\
\hline CRSP & BM, ÊP, EP, & & GRLTE, & GRS, INI & \\
\hline MSCI EAFE & BM, EP, DP & & GRLTE, & IGR, GRI & GRS-TR \\
\hline Morningstar & $\mathrm{BM}, \hat{\mathrm{EP}}, \mathrm{CFl}$ & SP & GRLTE, & GRS, GR & \\
\hline
\end{tabular}

Note: This table shows the average portfolio shares in the five BM quintiles. 
Table 9: Loadings in 4-Factor Regressions

\begin{tabular}{|c|c|c|c|c|c|c|}
\hline \multicolumn{7}{|c|}{ Panel A: Betas of SMB, HML, MOM Components } \\
\hline & S & B & $\mathbf{H}$ & $\mathbf{L}$ & W & L \\
\hline$\alpha$ & 0.01 & 0.01 & 0.01 & 0.01 & 0.01 & 0.01 \\
\hline MKT & 1.02 & 1.02 & 1.04 & 1.04 & 1.05 & 1.05 \\
\hline SMB & 0.90 & -0.10 & 0.41 & 0.41 & 0.50 & 0.50 \\
\hline HML & 0.26 & 0.26 & 0.72 & -0.28 & 0.05 & 0.05 \\
\hline MOM & 0.00 & 0.00 & -0.01 & -0.01 & 0.35 & -0.65 \\
\hline \multicolumn{7}{|c|}{ Panel B: SMB Betas, 25 ME/BM Portfolios } \\
\hline & BM1 & BM2 & & BM3 & BM4 & BM5 \\
\hline ME1 & 1.19 & 1.33 & & 1.04 & 1.01 & 0.91 \\
\hline ME2 & 0.93 & 0.91 & & 0.70 & 0.74 & 0.91 \\
\hline ME3 & 0.71 & 0.50 & & 0.35 & 0.43 & 0.44 \\
\hline ME4 & 0.38 & 0.16 & & 0.14 & 0.15 & 0.24 \\
\hline ME5 & -0.31 & -0.20 & & -0.21 & -0.22 & -0.36 \\
\hline \multicolumn{7}{|c|}{ Panel C: HML Betas, 25 ME/BM Portfolios } \\
\hline & BM1 & BM2 & & BM3 & BM4 & BM5 \\
\hline ME1 & -0.47 & 0.01 & & 0.27 & 0.40 & 0.61 \\
\hline ME2 & -0.37 & 0.13 & & 0.56 & 0.61 & 0.76 \\
\hline ME3 & -0.48 & 0.29 & & 0.55 & 0.70 & 0.84 \\
\hline ME4 & -0.44 & 0.21 & & 0.54 & 0.62 & 0.79 \\
\hline ME5 & -0.41 & 0.18 & & 0.37 & 0.71 & 0.71 \\
\hline
\end{tabular}

Note: The tables reports coefficients of the regression

$$
X_{t}=\alpha_{\mathrm{X}}+\beta_{\mathrm{X}, \mathrm{MKT}} \mathrm{MKT}_{t}+\beta_{\mathrm{X}, \mathrm{SMB}} \mathrm{SMB}_{t}+\beta_{\mathrm{X}, \mathrm{HML}} \mathrm{HML}_{t}+\beta_{\mathrm{X}, \mathrm{MOM}} \mathrm{MOM}_{t}+e_{\mathrm{X}, t},
$$

where $X \in\{\mathrm{S}, \mathrm{B}, \mathrm{H}, \mathrm{L}, \mathrm{W}, \mathrm{L}\}$. The sample is from 1980Q1 to $2018 \mathrm{Q} 4$. 
Table 10: Returns of Stocks and Mutual Funds

\begin{tabular}{|c|c|c|c|c|c|c|}
\hline Quintile & ME & BM & MS & MOM & MULT & GR \\
\hline \multicolumn{7}{|c|}{ Panel A: Stocks } \\
\hline 1 & $3.19 \%$ & $3.09 \%$ & $3.17 \%$ & $2.11 \%$ & $3.60 \%$ & $3.42 \%$ \\
\hline 2 & $3.37 \%$ & $3.17 \%$ & $3.22 \%$ & $2.82 \%$ & $2.78 \%$ & $3.19 \%$ \\
\hline 3 & $3.38 \%$ & $3.13 \%$ & $3.06 \%$ & $2.92 \%$ & $3.17 \%$ & $3.29 \%$ \\
\hline 4 & $3.42 \%$ & $3.23 \%$ & $3.13 \%$ & $3.17 \%$ & $2.64 \%$ & $3.08 \%$ \\
\hline 5 & $2.98 \%$ & $3.49 \%$ & $3.23 \%$ & $3.74 \%$ & $3.05 \%$ & $2.95 \%$ \\
\hline 5 minus 1 & $-0.21 \%$ & $0.41 \%$ & $0.07 \%$ & $1.62 \%$ & $-0.55 \%$ & $-0.47 \%$ \\
\hline \multicolumn{7}{|c|}{ Panel B: Mutual Funds } \\
\hline $1-2$ & $2.52 \%$ & $1.98 \%$ & $2.18 \%$ & $-1.29 \%^{\dagger}$ & $2.11 \%$ & $2.37 \%$ \\
\hline $2-3$ & $2.56 \%$ & $2.47 \%$ & $2.44 \%$ & $2.05 \%$ & $2.45 \%$ & $2.31 \%$ \\
\hline $3-4$ & $2.70 \%$ & $2.49 \%$ & $2.29 \%$ & $2.50 \%$ & $2.30 \%$ & $2.41 \%$ \\
\hline $4-5$ & $2.16 \%$ & $3.02 \%^{\dagger}$ & $2.22 \%$ & $1.99 \%$ & $2.09 \%$ & $2.10 \%$ \\
\hline 4-5 minus $1-2$ & $-0.36 \%$ & $1.04 \%$ & $0.04 \%$ & $3.28 \%$ & $-0.02 \%$ & $-0.27 \%$ \\
\hline \multicolumn{7}{|c|}{ Panel C: ETFs } \\
\hline $1-2$ & $1.72 \%$ & $3.18 \%$ & $2.97 \%$ & $0.87 \%^{\dagger}$ & $3.06 \%$ & $2.81 \%$ \\
\hline $2-3$ & $3.02 \%$ & $2.67 \%$ & $2.87 \%$ & $3.17 \%$ & $2.86 \%$ & $2.67 \%$ \\
\hline $3-4$ & $2.41 \%$ & $2.41 \%$ & $2.49 \%$ & $2.61 \%$ & $2.48 \%$ & $2.71 \%$ \\
\hline $4-5$ & $2.77 \%$ & $2.28 \%$ & $2.39 \%$ & $2.02 \%^{\dagger}$ & $1.11^{\dagger} \%$ & $3.01 \%$ \\
\hline 4-5 minus $1-2$ & $1.05 \%$ & $-0.90 \%$ & $-0.58 \%$ & $1.15 \%$ & $-1.94 \%$ & $0.20 \%$ \\
\hline
\end{tabular}

Note: The table reports the mean returns by quintile (stocks) and quintile ranges (mutual funds). 
Table 11: Returns of Stocks and Mutual Funds

\begin{tabular}{|c|c|c|c|c|c|c|c|c|c|c|}
\hline Quintile & EP & $\widehat{\mathbf{E P}}$ & CFP & DP & SP & GRLTE & GRB & GRE & GRS & GRCF \\
\hline \multicolumn{11}{|c|}{ Panel A: Stocks } \\
\hline 1 & $2.70 \%$ & $4.23 \%$ & $2.90 \%$ & $3.26 \%$ & $2.77 \%$ & $3.23 \%$ & $3.55 \%$ & $2.73 \%$ & $3.23 \%$ & $3.03 \%$ \\
\hline 2 & $3.17 \%$ & $2.82 \%$ & $3.14 \%$ & $2.22 \%$ & $3.25 \%$ & $3.07 \%$ & $3.45 \%$ & $3.56 \%$ & $3.32 \%$ & $3.50 \%$ \\
\hline 3 & $3.03 \%$ & $2.77 \%$ & $3.21 \%$ & $3.12 \%$ & $3.35 \%$ & $3.23 \%$ & $3.12 \%$ & $3.48 \%$ & $3.50 \%$ & $3.27 \%$ \\
\hline 4 & $3.50 \%$ & $2.43 \%$ & $3.27 \%$ & $3.24 \%$ & $3.47 \%$ & $3.08 \%$ & $3.33 \%$ & $3.09 \%$ & $3.06 \%$ & $3.14 \%$ \\
\hline 5 & $3.74 \%$ & $2.50 \%$ & $3.52 \%$ & $3.21 \%$ & & $3.14 \%$ & $2.64 \%$ & $2.57 \%$ & $2.74 \%$ & $2.87 \%$ \\
\hline 5 minus 1 & $1.03 \%$ & $-1.73 \%$ & $0.63 \%$ & $-0.04 \%$ & $0.98 \%$ & $-0.09 \%$ & $-0.92 \%$ & $-0.15 \%$ & $-0.50 \%$ & $-0.16 \%$ \\
\hline \multicolumn{11}{|c|}{ Panel B: Mutual Funds } \\
\hline $1-2$ & $1.79 \%$ & $2.26 \%$ & $1.35 \%$ & $2.37 \%$ & $1.94 \%$ & $2.49 \%$ & $2.76 \%^{\dagger}$ & $2.78 \%^{\dagger}$ & $1.82 \%^{\dagger}$ & $3.06 \%{ }^{\dagger}$ \\
\hline $2-3$ & $2.49 \%$ & $2.40 \%$ & $2.47 \%$ & $2.36 \%$ & $2.45 \%$ & $2.31 \%$ & $2.06 \%$ & $2.47 \%$ & $2.46 \%$ & $2.46 \%$ \\
\hline $3-4$ & $2.29 \%$ & $2.21 \%$ & $2.57 \%$ & $2.24 \%$ & $2.82 \%$ & $2.31 \%$ & $2.52 \%$ & $2.32 \%$ & $2.34 \%$ & $2.34 \%$ \\
\hline $4-5$ & $2.76 \%^{\dagger}$ & $1.96 \%$ & $3.55 \%^{\dagger}$ & $2.33 \%$ & $3.08 \%^{\dagger}$ & $2.20 \%$ & $0.88 \%$ & $1.47 \%$ & $1.84 \%$ & $0.63 \%$ \\
\hline 4-5 minus $1-2$ & $0.97 \%$ & $-0.30 \%$ & $2.20 \%$ & $-0.04 \%$ & $1.14 \%$ & $-0.29 \%$ & $-1.88 \%$ & $-1.31 \%$ & $0.01 \%$ & $-2.43 \%$ \\
\hline \multicolumn{11}{|c|}{ Panel C: ETFs } \\
\hline $1-2$ & $2.50 \%$ & $0.68 \%^{\dagger}$ & $1.55 \%^{\dagger}$ & $2.34 \%^{\dagger}$ & $3.33 \%$ & $2.98 \%$ & $1.42 \%^{\dagger}$ & $6.28 \%^{\dagger}$ & $5.33 \%^{\dagger}$ & $5.64 \%^{\dagger}$ \\
\hline $2-3$ & $2.80 \%$ & $2.92 \%$ & $2.83 \%$ & $2.80 \%$ & $2.59 \%$ & $2.48 \%$ & $2.03 \%$ & $2.45 \%$ & $2.25 \%$ & $2.24 \%$ \\
\hline $3-4$ & $2.56 \%$ & $2.56 \%$ & $2.61 \%$ & $2.72 \%$ & $2.25 \%$ & $3.03 \%$ & $3.14 \%$ & $2.81 \%$ & $2.94 \%$ & $2.88 \%$ \\
\hline $4-5$ & $2.35 \%$ & $1.80 \%$ & $1.84 \%$ & $2.55 \%$ & $1.31 \%$ & $2.57 \%^{\dagger}$ & $0.44 \%^{\dagger}$ & $1.48 \%^{\dagger}$ & $3.05 \%^{\dagger}$ & $0.18 \%^{\dagger}$ \\
\hline 4-5 minus $1-2$ & $-0.16 \%$ & $1.12 \%$ & $0.30 \%$ & $0.21 \%$ & $-2.02 \%$ & $-0.41 \%$ & $-0.98 \%$ & $-4.81 \%$ & $-2.28 \%$ & $-5.46 \%$ \\
\hline
\end{tabular}

Note: The table reports the mean returns by quintile (stocks) and quintile ranges (mutual funds). 
Table 12: Fama-MacBeth Regressions

\begin{tabular}{|c|c|c|c|c|c|}
\hline ME & BM & MS & MOM & MULT & GR \\
\hline \multicolumn{6}{|c|}{ Panel A: Stocks } \\
\hline $\begin{array}{c}-0.15 \\
(0.17)\end{array}$ & $\begin{array}{l}0.52^{* * *} \\
(0.13)\end{array}$ & & $\begin{array}{l}0.40^{* *} \\
(0.17)\end{array}$ & & \\
\hline $\begin{array}{c}-0.28^{*} \\
(0.16)\end{array}$ & & $\begin{array}{c}0.27 \\
(0.17)\end{array}$ & $\begin{array}{l}0.43^{* *} \\
(0.17)\end{array}$ & & \\
\hline $\begin{array}{c}-0.26 \\
(0.17)\end{array}$ & & & $\begin{array}{l}0.43^{* * *} \\
(0.17)\end{array}$ & $\begin{array}{c}0.13 \\
(0.13)\end{array}$ & $\begin{array}{c}-0.09 \\
(0.11)\end{array}$ \\
\hline \multicolumn{6}{|c|}{ B: Mutual Funds } \\
\hline $\begin{array}{c}-0.30^{* *} \\
(0.14)\end{array}$ & $\begin{array}{c}-0.10 \\
(0.17)\end{array}$ & & $\begin{array}{c}0.45^{*} \\
(0.25)\end{array}$ & & \\
\hline $\begin{array}{c}-0.30^{* *} \\
(0.13)\end{array}$ & & $\begin{array}{c}-0.02 \\
(0.17)\end{array}$ & $\begin{array}{c}0.43^{*} \\
(0.22)\end{array}$ & & \\
\hline $\begin{array}{c}-0.36^{* * *} \\
(0.12)\end{array}$ & & & $\begin{array}{c}0.45^{* *} \\
(0.21)\end{array}$ & $\begin{array}{c}-0.24 \\
(0.15)\end{array}$ & $\begin{array}{r}-0.23 \\
(0.17)\end{array}$ \\
\hline \multicolumn{6}{|c|}{ C: ETFs } \\
\hline $\begin{array}{c}-0.06 \\
(0.25)\end{array}$ & $\begin{array}{c}-0.73 \\
(0.37)\end{array}$ & & $\begin{array}{c}-0.74 \\
(0.51)\end{array}$ & & \\
\hline $\begin{array}{c}0.19 \\
(0.16)\end{array}$ & & $\begin{array}{c}-0.56 \\
(0.37)\end{array}$ & $\begin{array}{c}-0.73 \\
(0.49)\end{array}$ & & \\
\hline $\begin{array}{c}0.16 \\
(0.26)\end{array}$ & & & $\begin{array}{c}-0.68 \\
(0.43)\end{array}$ & $\begin{array}{r}-0.37 \\
(0.30)\end{array}$ & $\begin{array}{c}0.26 \\
(0.57)\end{array}$ \\
\hline
\end{tabular}

Note: Fama-MacBeth regressions of returns of individual stocks and mutual funds on characteristic scores. The regression coefficients are in percent per month. $t$-statistics are in brackets. 
Table D.1: Mutual Funds Remaining After Each Screen

\begin{tabular}{lr}
\hline Screen & Number of Funds \\
\hline \multicolumn{2}{c}{ Mutual Funds } \\
All mutual funds with holdings available & 8893 \\
After excluding passive funds & 7626 \\
After excluding sector funds & 6945 \\
After excluding funds holding less than 10 stocks & 5495 \\
After excluding funds with less than 5M in assets & 5116 \\
After excluding funds with less than half of assets in stocks & 4229 \\
After excluding funds with less than 4 years of data & 3073 \\
After excluding funds not classified as equity fund & 2992 \\
\hline \multicolumn{2}{c}{ ETFs } \\
All ETFs with holdings available & 1640 \\
After excluding sector funds & 948 \\
After excluding funds with less than half of assets in stocks & 621 \\
After excluding funds not classified as equity fund & 575 \\
\hline
\end{tabular}

Note: This table reports the number of mutual funds remaining after each sample screen is applied. The first line of the table is the universe of mutual funds with returns and holdings data available, while the last line is the number of funds in our sample. 
Table D.2: Distribution of Mutual Fund and Stock Characteristics

\begin{tabular}{lcccccccc}
\hline & \multicolumn{3}{c}{ Mutual Funds } & \multicolumn{5}{c}{ Stocks } \\
& {$[1-2]$} & $(2-3]$ & $(3-4]$ & $(4-5]$ & {$[1-2]$} & $(2-3]$ & $(3-4]$ & $(4-5]$ \\
\hline ME & 0.03 & 0.18 & 0.13 & 0.66 & 0.03 & 0.12 & 0.30 & 0.55 \\
BM & 0.33 & 0.54 & 0.13 & 0.00 & 0.34 & 0.27 & 0.24 & 0.14 \\
MS & 0.29 & 0.44 & 0.26 & 0.01 & 0.27 & 0.28 & 0.27 & 0.17 \\
MOM & 0.00 & 0.10 & 0.87 & 0.03 & 0.01 & 0.27 & 0.69 & 0.03 \\
MULT & 0.25 & 0.50 & 0.25 & 0.00 & 0.33 & 0.28 & 0.23 & 0.16 \\
GR & 0.00 & 0.30 & 0.52 & 0.18 & 0.10 & 0.38 & 0.32 & 0.19 \\
EP & 0.16 & 0.65 & 0.19 & 0.00 & 0.29 & 0.40 & 0.24 & 0.07 \\
SP & 0.31 & 0.65 & 0.05 & 0.00 & 0.35 & 0.27 & 0.21 & 0.16 \\
CFP & 0.15 & 0.60 & 0.25 & 0.00 & 0.25 & 0.35 & 0.26 & 0.14 \\
DP & 0.16 & 0.39 & 0.39 & 0.06 & 0.27 & 0.19 & 0.29 & 0.22 \\
GRLTE & 0.01 & 0.38 & 0.46 & 0.15 & 0.15 & 0.32 & 0.29 & 0.21 \\
GRE & 0.00 & 0.15 & 0.85 & 0.01 & 0.02 & 0.39 & 0.51 & 0.06 \\
GRCF & 0.00 & 0.13 & 0.87 & 0.00 & 0.03 & 0.40 & 0.52 & 0.05 \\
GRS & 0.00 & 0.19 & 0.76 & 0.05 & 0.04 & 0.41 & 0.42 & 0.12 \\
GRB & 0.00 & 0.18 & 0.80 & 0.02 & 0.05 & 0.40 & 0.44 & 0.10 \\
OP & 0.01 & 0.28 & 0.71 & 0.01 & 0.14 & 0.24 & 0.29 & 0.19 \\
INV & 0.00 & 0.13 & 0.83 & 0.03 & 0.05 & 0.40 & 0.45 & 0.11 \\
QUAL & 0.00 & 0.13 & 0.85 & 0.01 & 0.16 & 0.27 & 0.33 & 0.23 \\
PSLIQ & 0.00 & 0.17 & 0.83 & 0.00 & 0.00 & 0.22 & 0.73 & 0.00 \\
TURN & 0.01 & 0.35 & 0.58 & 0.07 & 0.05 & 0.23 & 0.37 & 0.31 \\
DVOL & 0.02 & 0.14 & 0.16 & 0.68 & 0.02 & 0.10 & 0.28 & 0.55 \\
\hline
\end{tabular}

Note: 
Table D.3: Distribution of Mutual Fund and Stock Characteristics: Size-weighted

\begin{tabular}{lcccccccc}
\hline & {$[1-2]$} & $(2-3]$ & $(3-4]$ & $(4-5]$ & {$[1-2]$} & $(2-3]$ & $(3-4]$ & $(4-5]$ \\
\hline ME & 0.01 & 0.10 & 0.09 & 0.81 & 0.00 & 0.02 & 0.10 & 0.89 \\
BM & 0.26 & 0.62 & 0.12 & 0.00 & 0.49 & 0.20 & 0.19 & 0.12 \\
MS & 0.26 & 0.37 & 0.37 & 0.00 & 0.33 & 0.30 & 0.25 & 0.11 \\
MOM & 0.00 & 0.07 & 0.92 & 0.02 & 0.00 & 0.13 & 0.83 & 0.04 \\
MULT & 0.21 & 0.48 & 0.31 & 0.00 & 0.43 & 0.30 & 0.15 & 0.12 \\
GR & 0.00 & 0.42 & 0.45 & 0.12 & 0.11 & 0.32 & 0.36 & 0.21 \\
EP & 0.10 & 0.67 & 0.24 & 0.00 & 0.31 & 0.37 & 0.22 & 0.09 \\
SP & 0.29 & 0.66 & 0.05 & 0.00 & 0.50 & 0.30 & 0.13 & 0.07 \\
CFP & 0.09 & 0.56 & 0.35 & 0.00 & 0.33 & 0.31 & 0.21 & 0.15 \\
DP & 0.08 & 0.40 & 0.39 & 0.13 & 0.26 & 0.18 & 0.27 & 0.27 \\
GRLTE & 0.01 & 0.47 & 0.43 & 0.09 & 0.15 & 0.34 & 0.28 & 0.23 \\
GRE & 0.00 & 0.23 & 0.76 & 0.01 & 0.04 & 0.31 & 0.52 & 0.10 \\
GRCF & 0.00 & 0.22 & 0.77 & 0.00 & 0.00 & 0.32 & 0.60 & 0.07 \\
GRS & 0.00 & 0.28 & 0.70 & 0.03 & 0.01 & 0.38 & 0.42 & 0.17 \\
GRB & 0.00 & 0.28 & 0.71 & 0.01 & 0.02 & 0.38 & 0.45 & 0.13 \\
OP & 0.00 & 0.16 & 0.83 & 0.00 & 0.11 & 0.16 & 0.31 & 0.25 \\
INV & 0.00 & 0.21 & 0.76 & 0.02 & 0.01 & 0.32 & 0.45 & 0.20 \\
QUAL & 0.00 & 0.12 & 0.87 & 0.01 & 0.15 & 0.23 & 0.26 & 0.36 \\
PSLIQ & 0.00 & 0.08 & 0.92 & 0.00 & 0.00 & 0.06 & 0.89 & 0.00 \\
TURN & 0.01 & 0.40 & 0.57 & 0.02 & 0.16 & 0.26 & 0.30 & 0.22 \\
DVOL & 0.00 & 0.08 & 0.10 & 0.81 & 0.00 & 0.01 & 0.08 & 0.86 \\
\hline
\end{tabular}

Note: See Table D.2 but distributions are AUM-weighted for mutual funds and market cap-weighted for stocks. 
Table D.4: 4-Factor Regressions

\begin{tabular}{lrrrrrrr}
\hline & \multicolumn{8}{c}{ Panel A: Betas of SMB, HML, MOM Components } \\
& S & B & H & L & W & L \\
\hline$\alpha$ & 0.01 & 0.01 & 0.01 & 0.01 & 0.01 & 0.01 \\
MKT & 1.02 & 1.02 & 1.04 & 1.04 & 1.05 & 1.05 \\
SMB & $\mathbf{0 . 9 0}$ & $-\mathbf{0 . 1 0}$ & 0.41 & 0.41 & 0.50 & 0.50 \\
HML & 0.26 & 0.26 & $\mathbf{0 . 7 2}$ & $\mathbf{- 0 . 2 8}$ & 0.05 & 0.05 \\
MOM & 0.00 & 0.00 & -0.01 & -0.01 & $\mathbf{0 . 3 5}$ & $\mathbf{- 0 . 6 5}$
\end{tabular}

Note: The tables reports coefficients of the regression

$$
X_{t}=\alpha_{\mathrm{X}}+\beta_{\mathrm{X}, \mathrm{MKT}} \mathrm{MKT}_{t}+\beta_{\mathrm{X}, \mathrm{SMB}} \mathrm{SMB}_{t}+\beta_{\mathrm{X}, \mathrm{HML}} \mathrm{HML}_{t}+\beta_{\mathrm{X}, \mathrm{MOM}} \mathrm{MOM}_{t}+e_{\mathrm{X}, t},
$$

where $X \in\{\mathrm{S}, \mathrm{B}, \mathrm{H}, \mathrm{L}, \mathrm{W}, \mathrm{L}\}$. The sample is from 1980Q1 to $2018 \mathrm{Q} 4$. 